

4.0. Ebert

A gift from L.E.Delanxes

1959 



THE GLONAL

SELEGTION THEORY OF AGQUIRED IMMUNITY 



\section{THE GLONAL}

\section{SELEGTION THEORY OF ACQUIRED IMMUNITY}

BY

SIR MAGFARLANE BURNET

O.M., F.R.S.

THE

ABRAHAM FLEXNER LEGTURES OF VANDERBILT UNIVERSITY

1958

CAMBRIDGE

AT THE UNIVERSITY PRESS

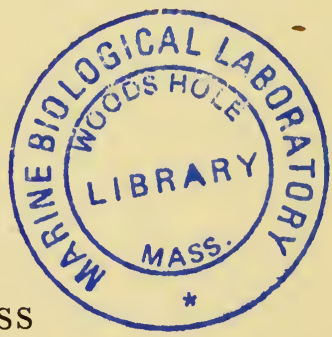

I959

PUBLISHED IN U.S.A. BY

VANDERBILT UNIVERSITY PRESS

NASHVILLE, TENNESSEE 
PUBLISHED BY

THE SYNDIGS OF THE CAMBRIDGE UNIVERSITY PRESS

Bentley House, 200 Euston Road, London, N.W.I

(C)

SIR MAGFARLANE BURNET

1959

Printed in Great Britain at the University Press, Cambridge

(Brooke Crutchley, University Printer) 


\section{GONTENTS}

Preface

page ix

I INTRODUCTION

I

II GLONAL PHENOMENA IN BAGTERIAL AND VIRAL POPULATIONS

I Adaptive enzyme formation and other adaptive changes

2 Mutation

3 Population genetics of bacteria and viruses

(a) Periodic selection in bacterial cultures Io

(b) Pseudo-mutation (Novick and Weiner's experiment)

(c) $O-D$ change in influenza virus $A$

(d) The process of viral infection

(e) Changes in myxomatosis virulence in the field

III THE FACTS OF IMMUNITY

I The nature of 'antibody'

2 Differences between primary and secondary response

3 Lack of immunological reactivity to body constituents

4 The qualitative types of immune response

5 Congenital agammaglobulinaemia

6 Lymphocytes and plasma cells as antibody producers

7 Summary 
THE GLONAL SELECTION THEORY OF

ANTIBODY PRODUGTION

I The side-chain theory of Ehrlich

2 Haurowitz-Pauling (direct template) theory

3 Burnet-Fenner indirect template theory $5^{\mathrm{I}}$

4 Jerne's natural selection theory

5 Clonal selection theory

(a) Developmental considerations

6 Comparison of theories

7 Cellular reactivity required by a clonal selection theory

8 Summary

V IMPLICATIONS OF THE GLONAL

SELECTION HYPOTHESIS

I The secondary response and cognate phenomena

2 Anamnestic responses

3 Action of adjuvants

4 Local immunity

VI IMMUNOLOGICAL TOLERANGE AND RELATED PHENOMENA

I Homograft immunity and tolerance

2 Tolerance to antigens not associated with implantation of genetically foreign cells

3 Natural antibodies

$4 T$ agglutinin as a model of a natural antibody 
5 The influence of ionizing radiation on immunological responses

6 The special qualities of bacterial antigens and endotoxins

IOI

VII MESENGHYMAL CELL FUNCTION IN IMMUNITY

I Lymphocyte and plasma cells

2 Interrelations of mesenchymal cells

IIO

3 Eosinophil function

VIII THE PATHOLOGY OF THE IMMUNE RESPONSE

I 2 I

I Some general considerations

122

2 Hashimoto's disease

124

3 Acquired haemolytic anaemias

I 26

(a) Sedormid purpura

4 The collagen diseases

I3I

(a) The L.E. cell test

I 36

(b) Gajdusek's auto-immune complement fixation test

5 Somatic mutation as a basis

6 Congenital agammaglobulinaemia

I 4 I

7 The nature of the homeostatic mechanism

8 Summary

IX MODIFICATION OF THE COURSE OF INFECTIOUS DISEASE AS A RESULT OF ANOMALIES OF THE IMMUNE RESPONSE

I Jennerian vaccination

2 Measles

3 Streptococcal infections

4 Sarcoidosis 
$X$ PROLIFERATIVE DISEASES OF THE RETICULAR TISSUE AND MESENCHYMAL GELLS

page 165

I Somatic mutation I 65

2 General considerations I 68

3 Experimental leukaemia I 70

4 Human leukaemia I 75

(a) Chronic myeloid leukaemia I 75

(b) Chronic lymphatic leukaemia I 77

5 Hodgkin's disease I 80

6 Multiple myeloma I 80

XI CLONAL SELECTION AND NEOPLASTIC DISEASE

I The turnover of cells in various parts of the body

2 The age incidence of cancer

3 The control of cell relations

4 Mutagenic and carcinogenic agents

5 Conclusion

200 


\section{PREFACE}

I am greatly indebted to the Trustees of the Abraham Flexner Lectureships of Vanderbilt University Medical School for providing the opportunity for the delivery and publication of these lectures. Their substance represents an attempt at a different type of approach to the theoretical problems of immunity that have fascinated me for many years. To many workers the approach will seem out of key with modern trends to press biochemical concepts to the limit in the interpretation of biological phenomena. To others it may be attractive to set aside speculation on matters that are currently inaccessible, in favour of relatively simple morphological and genetic concepts which to a large extent at least are susceptible to experimental test.

The discussion of immunity has been set between a brief account of clonal phenomena amongst bacteria and viruses on the one hand, and of malignant disease on the other. In this way it was hoped to clarify the unfamiliar use of clonal ideas in discussing mesenchymal cells by a comparison with fields in which such ideas are widely or universally accepted. In the process it became evident that there were many conditions in human pathology which are essentially deviations of the immune processes in the direction of malignant change. It may be hoped that the clonal approach will find its most fruitful application in bringing a better understanding of the pathology of these conditions.

F. M. BURNET

NASHVILLE

May $195^{8}$ 



\section{I}

\section{INTRODUGTION}

There are many aspects of life which, when viewed retrospectively, fall into a pattern, although in their developing they seemed but a random play of accident and circumstance. I think this holds for the professional life of many scientists. In any long career of research we tend to move gradually, or on occasion precipitately, from one topic of interest to another. The moves seem to be made for a variety of reasons, the most cogent, that it is the line along which our current work has developed; but more often than not that development was itself influenced by pressures from work done in a dozen different laboratories or by the advent of a new instrument or technique. In one way or another a scientific career unfolds until almost unexpectedly one finds oneself a senior worker with thirty-five years of experience in the laboratory and one is bidden to seek a central theme on which to illustrate significant aspects of one's personal research interests.

Looking back under these circumstances it is nearly always possible to find that central theme. In my own case I think it is perhaps easier than for most scientists. It is almost an automatism that when $I$ have been struggling to find a title for some lecture or article on a general topic the first that came to mind was nearly always 'A biological approach to -', or 'The natural history of (infectious disease, cancer, war, woman or what not)'.

I have always been fascinated by the simple concepts of biology-reproduction, mutation, sexual redistribution of characters and selective survival-and how the interactions of species and ecological communities can be brought into a comprehensible pattern in the light of those concepts. Particularly for the problems of infectious disease in the 
field, this ecological approach is both indispensable and fascinating.

More recently, however, I have gradually become impressed with the way a related but somewhat simpler concept has seemed to pervade much of what I have been thinking about. This is the ecological and evolutionary implications of the clone-as contrasted with the sexually reproducing population. This interest began, I think, in I942, when Bull and I first described what happens when an influenza $A$ virus is transferred to the cavities of the chick embryo. There is a strange and striking shift of characters in the influenza virus during that process-and from that time onward I have been deeply interested in the genetics of animal viruses. Though most of my work in recent years has been concerned with recombination between strains, something that is almost a primitive fusion and redistribution of genetic material, I still regard the clonal aspects as the more basic and it is with these that I shall mostly be concerned.

Along with an interest in virology, I have always found a fascination in the nature of the immune process.

It is irrelevant how my views on the nature of antibody production have changed over the years. What is relevant is the growing opinion that in a real sense the development of specific antibody-producing capacity is something characteristic, not so much of a cell as of a clone of cells.

Such a point of view sets one thinking more generally of the mesenchymal cells of the body, that enormous population of fibroblasts and lymphocytes, histiocytes and granulocytes, cells of variable, often short life, expendable cells produced in large amount or discarded according to the requirements of the body. We can be certain that their form and function may change according to the impact of the internal environment, even if the histologists still seem to be at variance as to which type of cell can give rise to or be converted into which. Surely, here we find also a situation where clones of cells flourish and wane in very much the same fashion as bacterial 
clones do in a culture. And there is the challenge to see whether this concept may not be fruitful for an understanding of the multitude of physiological and pathological changes within the mesenchymal cell populations.

And this in its turn leads naturally to the classic problem of human pathology, the nature of cancer. There are many ways of looking at cancer and at the present time 'somatic mutation' is an unpopular phrase. But I think that whether we are interested in cancer viruses, carcinogens, or ionizing radiation, we come in the last analysis to clones of cells differentiated by their reproductive behaviour from the normal cells of the body. A year ago I attempted to present a simple description of the cancer process along these lines and, though I doubt if it convinced anyone, some readers found it stimulating. In this series of lectures I hope to lead from a discussion of immunological topics and some aspects of the pathology of the mesenchymal cell system, to a recapitulation of this clonal approach to malignant disease.

All the topics I am going to consider can be expressed in a simple generalized form. We have a population of cells or micro-organisms which reproduce wholly or predominantly by asexual methods. In a varying environment, changes in the character of the population take place. In every instance we are concerned to understand $(a)$ whence the change in character of the individual components arises and $(b)$ the nature of the process by which the constitution of the population is modified to conform to the requirements of the changing environment.

This is in essence the oldest of biological problems-the classic struggle between the Lamarckians and the Darwinians on the nature of adaptation in evolution. It is a theme that has been played upon in an infinity of variations over the last Ioo years, and I can only hope that in the present treatment there are scattered elements of novelty, either in regard to example or approach, which will make up for the inevitable inclusion of much that is trite and familiar. 


\section{GLONAL PHENOMENA IN BACTERIAL}

\section{AND VIRAL POPULATIONS}

In the classic days of bacteriology before I 940 changes were always liable to be found in bacterial cultures. For the most part these changes obtruded only when the bacteriologist found, on returning to a topic that had been dropped for some months, that his standard culture was not behaving in the fashion he had expected. With the development almost simultaneously of potent antibiotics and an interest in bacterial genetics, these changes have themselves become important objects of study. The consensus of modern opinion is that most changes are a result of the selective overgrowth of mutants arising independently of the action of the selective agent, and this is the point of view which, with some qualifications, will be adopted.

It is highly desirable, however, to begin with a brief mention of those conditions in which there is adequate evidence that change is not mutational in origin, and of those where a positive effect of the selective agent has been claimed with some cogency. This is particularly important when our main objective is to provide a background for the discussion of clonal phenomena in cell populations within the body.

\section{Adaptive enzyme formation and other adaptive changes}

Workers on adaptive enzyme formation have been able to show directly that the effect of a potent inducer in changing, for example, an Escherichia coli culture not producing $\beta$-galactosidase into one which does, is a modification, dependent on pre-existing genetic qualities, but involving a physiological rather than a genetic change. This holds too for the more permanent change induced by penicillin on a suitable strain 
of Bacillus cereus, where the inducer seems to be bound to the bacterial structure but not incorporated in the genome.

Nevertheless, it must be stressed that the capacity to produce an adaptive enzyme of a given quality is directly dependent on genetic character. In view of the frequent comparison that has been made between the processes of antibody production and of adaptive enzyme formation, it is important to stress that only genetically competent strains will produce $\beta$-galactosidase when stimulated by an appropriate inducer. It is not a matter of just presenting any $\alpha$ - or $\beta$-hexoside to any Gram-negative bacillus and expecting it to produce the enzyme needed to split the compound. Another feature of this reaction which I shall refer to later and which may be relevant to the nature of antibody formation is the recent demonstration by Monod's school of a two-stage process by which the inducer first initiates an increased permeability of the cell wall for itself, and then stimulates the pre-existent genetically controlled synthetic mechanisms to produce and liberate the specific enzyme.

There are many other types of adaptive change about which there is no agreement. Examples are the 'training' of a bacterium to use a new source of carbon or to grow in just sublethal concentrations of bactericidal agents. Most workers prefer to regard such changes as due to minor mutations and differential selection of the mutants. Hinshelwood and his school (Hinshelwood, I946; Dean and Hinshelwood, I953), however, have collected much evidence and argued firmly for the view that there are variations due to physiological alterations, for example, in the composition of the enzyme population within the bacterium, which are not genetic and which can be recognized by the readiness with which they are lost on transfer to a non-selective medium. They find, for instance, that when a strain of bacteria is isolated from the resistant growth appearing on a plate with a low concentration of antibiotic and grown in medium without antibiotic, the descendant bacteria will usually fail 
to grow on similar plates with the same content of antibiotic. There are also theoretical objections to the mutation hypothesis which appear less serious. Dean and Hinshelwood, for instance, consider that 'Adaptive responses to so many $\mathrm{C}$ and $\mathrm{N}$ sources and to so many concentrations of so many drugs occur that a very broad and almost continuous spectrum of mutant types would have to be postulated in all normal cultures'.

Probably the most satisfactory way of covering the facts is to adopt the compromise supported by Ravin (I953). He suggests that the essence of the matter is that there is a genotypic limitation of adaptability. If we have three alternative genotypes $A, B, C$, of a bacterial strain each can be expected to have a certain limited capacity for non-mutational adaptation, which will differ according to the genotype. If they are represented as superscripts $x, y$, etc., we might have the series of mutational changes:

$$
A^{x y z} \rightarrow B^{w x y} \rightarrow C^{x y} .
$$

In this case an ability to adapt to condition $W$ would demand mutation to $B$.

With perhaps some slight reservations, it seems by far the most effective way of handling the reported data to accept an immense range of potential mutability in bacteria and to confine physiological adaptation to those conditions in which the occurrence of mutation can be satisfactorily excluded.

\section{Mutation}

When mutations are specifically looked for in bacteria they are found to be ubiquitous and multiform. In general, mutation will occur at rates of the order of one per million dividing bacteria, and to isolate a mutant present in such an excess of the original form requires that some environment be provided in which the mutant will survive or multiply while the parent form is inhibited or eliminated. There are two standard ways of providing this. 
In the first method we are concerned with mutants which differ from the parent in being resistant to some agent which inhibits or prevents growth of the original type. Here the approach to the isolation of mutants can be quite direct. The most elegant demonstration is of bacteriophage-resistant mutants which can be recognized from the colonies they produce in the areas over which a plate culture has been lysed. There are a variety of types of such phage-resistant mutants, not all of which are stable, but there are many which are completely resistant to the phage 'producing' them, non-lysogenic, and failing to adsorb the phage in question.

In a rather similar situation are the antibiotic-resistant strains obtainable by growing the original strain in the presence of antibiotic at concentrations just below that giving complete sterilization. Some of the difficulties of interpreting such results have already been mentioned. These need not cause hesitation in accepting the mutational origin of all stable resistant variants (Demerec, 1948a, $b$ ).

A third example of basically similar character is seen when a biochemically deficient strain is studied for reversion (by mutation) to wild type. A histidine-requiring strain of Escherichia coli, if grown in a medium containing only a trace of histidine, will give rise to histidine-independent mutants which will grow readily when plated on histidine-free nutrient agar. Another demonstration of the same phenomenon is obtainable by plating the deficient strain on plates with minimal quantities of the critical metabolite. Colonies will develop but will cease growing as the metabolite becomes exhausted. In a proportion of the colonies papillae will appear which can be shown to represent growth of prototrophs which have arisen by mutation in the population of the developing colony.

In the first group of methods the mutants to be isolated were capable of growth on a selective medium that inhibited the parent. There is, however, an important group of nutritionally deficient mutants (auxotrophs) which fail to grow on 
media supporting growth of the parent. By a rather paradoxical manipulation this quality can be used to provide a favourable environment for the mutant. Penicillin is known to destroy sensitive bacteria only when they are growing, apparently because its harmful effect is to dissociate construction of the bacterial wall from enlargement of the contents of the cell. Lederberg and Davis in I 948 independently showed that by treating a bacterial culture with penicillin in an environment in which the parent strain could grow but the type of mutant sought could not, conditions were provided which would allow the survival and subsequent selective isolation of a nutritionally deficient mutant. The usual procedure in seeking a mutant requiring addition of substance $X$ for its growth is to expose a culture to whatever mutagenic agent is being used and then allow the culture to multiply for a few generations in optimal medium in which the deficient mutant can grow. The culture is now washed with minimal medium on which only prototrophic parent can grow and time allowed for the diffusion of any residual $X$ in the mutant cells. The culture is now treated with an appropriate concentration of penicillin in minimal medium until the parent type is rendered non-viable, and then washed to remove the antibiotic. Colonies developing after plating on optimal medium will be auxotrophs, that is, nutritionally deficient types of one sort or another, and their specific requirements can be determined by standard tests.

An auxiliary technique of great usefulness is Lederberg's replica method (Lederberg and Lederberg, 1952) by which a very large number of colonies can be tested simultaneously on plates of any desired combination of nutrients. Essentially it is a disc covered with velvet which is first pressed on to the primary plate to charge the filaments of the pile and then transferred, with proper care as to orientation, to as many test plates as desired. The method makes it possible to prove that some mutants at least are pre-existent and are not 'produced' by the phage or antibiotic used to test for their 
existence. This is usually a tedious process but the isolation, for instance, of a streptomycin-resistant colony without ever exposing the organisms to the antibiotic is a most convincing demonstration of the reality of spontaneous mutation.

\section{Population genetics of bacteria and viruses}

In discussing the population genetics of bacteria there is an unlimited range of material to be drawn upon, but this is not my primary field and I am only concerned to draw from it examples of phenomena that are relevant to the problems of virus or body cell.

One of the important features of any evolving population in which the individuals reproduce asexually is the absence of any means of storing mutational experience that is not immediately helpful to survival. In any large population of higher organisms, the individuals of which can mate freely throughout the population, the genetic pool contains a large reservoir of variation which can be drawn on, as it were, to cope with long-range environmental changes, and which acts as a buffer against too rapid genetic change. Recombination in bacteria is now well known to occur but there is much to suggest that it may be a laboratory artefact shown clearly only in rough $E$. coli mutants of special character. It has never been shown to play a significant part in the evolution and survival of bacteria in natural environments. On the other hand, transduction by temperate bacteriophage could be a process of evolutionary significance, and one can hardly quarrel with Lederberg and Zinder's view that a large proportion of the complexities of the Kauffman-White classification of the Salmonellas are manifestations of transduction within the group. For most bacteria most of the time, however, reproduction is by simple fission, and change by random and rather frequent mutation. The only stabilizing feature is the environment, and if this remains constant the distribution of types within the population is also likely to remain stable. Anyone who has tried to bring reproducible results 
out of work on micro-organismal mutation knows very well, however, that, except for certain rather stereotyped mutations like the phase change in Salmonellas, it is impossible to forecast in detail the population changes which will follow a given modification of the medium on which it is grown.

Variability is an essential feature of all the phenomena in this field, and having regard to the overall function of these lectures it is probably best to discuss it in relation to the socalled periodic selection, and to follow in general the work of Ryan and his collaborators.

\section{(a) Periodic selection in bacterial cultures}

In the days before the use of freeze-dried cultures, when bacterial cultures were maintained by regular subculture and storage at room or refrigeration temperature, there was one standard rule: to transfer on the same medium and to re-isolate the culture from a single typical colony at relatively short intervals. This procedure is sound population genetics. If mutation is occurring with the infrequent production of types with some survival advantage over the original, then any culture that was initially pure will retain the original as the dominant type in the population as long as any significant proportion of the culture remains alive. Mass transfer to another culture tube of the same medium will, however, give a much increased opportunity for the mutant with survival advantage to overgrow the original and, if this procedure is continued, it will inevitably replace the original as the dominant or sole form. Plating for single colonies between stock transfers can be looked at from two angles. The simplest situation is where our primary concern is to maintain some quality in a stock culture which can be manifested in the appearance of the colony, smoothness as against roughness, colour in a chromogenic bacterium, capacity to ferment a given sugar on a suitable indicator medium. As long as the original form is present to the extent of a few per cent, a typical colony can be selected, checked for purity, if neces- 
sary by a second isolation from a single colony, and then used for the preparation of a new stock culture. It is a rather different situation when the requirement is not to maintain one quality but to preserve all the genetic qualities, including some, such as virulence, which would require very elaborate tests to check at each transfer. Here the logical approach would be to assume that mutation is a rare occurrence and that when the culture population has reached its peak there will be only a small fraction of mutants. The random choice of a single colony for transfer will ensure that the genetic character is maintained for all but qualities which are highly subject to mutation. Such continuously repeated re-isolation for transfer of stock cultures has of course been completely replaced by storage of freeze-dried cultures.

Re-initiation of a multiplying culture from a single representative of an old one may seem a very artificial procedure, but it has important analogies with the process of natural infection. Further on (p. 25) I shall mention Fenner's evidence that natural infection of the rabbit with myxomatosis is often, or usually, with a single infective particle.

Even with mass transfer of culture, circumstances may result in an elimination of variants in a fashion almost analogous to what takes place in single colony isolation. In Atwood, Schneider and Ryan (195 I $a, b$ ) the behaviour of a histidine-requiring strain of $E$. coli $h^{-}$and the wild-type revertant $h^{+}$has been studied by transferring $0.5 \mathrm{ml}$. of old culture to $50 \mathrm{ml}$. of new complete culture medium at daily intervals. In this medium there is no selective advantage of either type and appropriate experiments indicate a mutation rate of $h^{-}$to $h^{+}$of $2 \cdot 7 \times 10^{-8}$ and of $h^{+}$to $h^{-}$of $1 \cdot 2 \times 10^{-6}$. In time, therefore, one would expect a corresponding equilibrium ratio to be reached at $44^{h-}$ to $\mathrm{I} h^{+}$. In fact, however, the equilibrium situation is around $1 \cdot 3 h^{+}$to $10^{6} h^{-}$. Analysis indicates that the discrepancy in favour of $h^{-}$is due to the process of periodic selection. The only thing that matters for survival in this or any other situation is an ability to produce 
more descendants than other clones in the environment provided. The mutations $h^{-} \rightarrow h^{+}$and $h^{+} \rightarrow h^{-}$are not associated with any change in growth rate in optimal medium, but it is found in practice that mutation to improved growth rate is also of frequent occurrence. This probably depends on the fact that no two batches of medium are quite identical, so that there is always scope for a genetic change that will have special survival value in a new transfer. If we start with an $h^{-}$culture, $h^{+}$variants will gradually accumulate, but other mutations are also taking place, and we can think of $h_{\mathbf{0}}^{-}$ mutating to $h_{1}^{-}$which has a growth advantage and under the circumstances will soon overgrow and replace $h_{0}^{-}$and all the mutants of unchanged growth rate that were derived from it. The culture will come to be dominated by $h_{1}^{-}$and its mutants almost as definitely as if an artificial selection of a single colony of $h^{-}$had been used for transfer. This process will be repeated giving 'periodic selection' at a rate that is sufficient to maintain the $h^{-}$dominance over $h^{+}$at about the $\mathrm{I} \cdot 3-\mathrm{I} \cdot 5$ to Io ${ }^{6}$ level.

Similarly, when a culture is initiated with a high proportion of $h^{+}$this shows stability for a period and then a rather sudden reversion to the standard ratio between the $h^{-}$and $h^{+}$types.

From the general point of view, the two important features emerging from these experiments are:

(i) the unique importance of capacity to produce more descendants than rival clones-everything else is secondary;

(ii) that even if the details of the process cannot be analysed, if the population is large enough and time allowed an approximate equilibrium can be attained.

\section{(b) Pseudo-mutation (Novick and Weiner's Experiment)}

The second example I want to take from work on the population genetics of bacteria is from a recent study by Novick and Weiner (1957) in the chemostat based on the 
earlier work of Monod and Cohn (1952) on the induction of the adaptive enzyme $\beta$-galactosidase by an inducer, thiomethyl $\beta$-D-galactoside, TMG, which is not a substrate for the enzyme. There are two reasons for bringing these observations into this account of clonal behaviour. The first is to draw attention to the modifications that have taken place in the interpretation of adaptive enzyme formation in recent years. The simple belief that the bacterial cell confronted with a new substrate forthwith produced a new enzyme to deal with it has vanished, just as, I believe, the simple picture of antibody as a protein created or modified on the spot to deal with a new antigen will also be discarded. The second reason is the demonstration in this work of Novick and Weiner of a process which has superficially all the marks of a mutation but which can be shown to be a nongenetic physiological change.

TMG and other inducers of $\beta$-galactosidase have two actions on $E$. coli. Both appear to involve enzyme activation. The first is to induce a specific permeability of the cell wall, ascribed to the activation of a 'permease'. This allows the concentration of TMG inside the cell to a level which may be roo times what it is in the medium. It is this intracellular concentration which determines the activation of the cell to produce and liberate $\beta$-galactosidase.

At low concentrations of inducer the primary induction of permease is slow, but, wherever this is accomplished, the bacterium involved takes in a relatively large amount of inducer which can now maintain the production of permease and induce $\beta$-galactosidase production both in itself and in its descendants. Bacteria which have not yet been rendered permeable are not induced. Such a population is composed of two sorts of bacterium: fully induced and not induced. This can be shown by choosing a 'maintenance concentration' of TMG $\left(5 \times 10^{-6} \mathrm{M}\right)$ which for pre-induced bacteria will allow full synthesis of adaptive enzyme but has only a negligibly small power to induce normal bacteria. If limit- 
infective dilution transfers from a culture in a slightly higher concentration of TMG are made into the maintenance medium, tubes showing growth will be sharply divisible into those containing much $\beta$-galactosidase and those with negligible amounts. Since a bacterial mutation is normally defined as one which can be shown to differ from the parent form in some observable characteristic when both are grown under the same circumstances in the same medium, and the character is transmitted to the offspring, this could be labelled a mutation. Admittedly the conditions required are complex and highly artificial. In addition to those mentioned, the phenomenon would be much less striking if it were not for the fact that induced organisms grow more slowly than non-induced, so that with minimal concentrations very slow induction is insufficient to keep pace with the faster multiplication rate of the non-induced bacteria. Nevertheless it provides an important warning that what we tend to regard as unanalysable biological processes like replication and mutation may, in some or all instances, be analysable into a series of processes more in line with normal ideas of biochemistry. Or in Novick and Weiner's words: 'Some differences which arise in a clone of organisms may be the result of changes in cellular systems other than the primary genetic endowment of the cell'. This warning is especially necessary where the cells concerned are not as accessible to detailed physiological analysis as are bacteria. At the same time the biologist must insist that, until possibilities of biochemical analysis can be exploited, genetic methods of approach and interpretation are still legitimate.

SUMMARY. The following points are probably those which are most likely to be relevant to any discussion of clonal selection in other fields.

(i) Adaptive changes not due to mutation are of frequent occurrence; those normally studied represent quantitative development of latent but genetically determined properties. 
(ii) In thinking about mutational and physiological changes in micro-organisms or body cells, it must be remembered that replication gives two individuals in which only slight change from the phenotypic character of the parent can occur. Irrespective of how it comes into being, a new character will only emerge when the old character is, as it were, diluted out over several generations.'

(iii) In bacterial cultures only mutants with an immediate selective advantage will have a chance to establish themselves in the population provided the environment remains constant. In discussing the general ecological situation of bacteria in nature, however, Stanier (I953) pointed out that the discontinuous nature of appropriate micro-environments in both space and time put a premium for survival on three salient characteristics of bacteria: (a) large populations and short generation time; $(b)$ relatively high mutability; and (c) great powers of dormancy. These will ensure that when the appropriate micro-environment appears it will be speedily colonized by a well-adapted micro-flora.

Perhaps it will be of interest to restate those three salient characteristics of Stanier's, but no longer with reference to bacteria. The salient characteristics of the mesenchymal cell system in man are large populations and short generation time, relatively high mutability and/or adaptability, and great powers of dormancy. These are all matters which are closely relevant to any discussion of mesenchymal cell function in relation to immunity.

\section{(c) O-D change in influenza virus A}

There was a curiously long delay before the clonal or, to speak more conventionally, the pure-culture approach was applied to studies of viruses. This was to a large extent a byproduct of the general experience that material from a given case of virus disease in man or a domestic animal was most unlikely to contain more than one type of virus which was recognizably pathogenic for the experimental animal to which 
the infection was being transferred. It was a commonplace that the material might contain contaminant or perhaps synergistic bacteria, but there were standard methods by which these could be eliminated.

Once an experimental infection had been produced it was transferred to the next host in some technically convenient dose, the usual objective being the Pasteurian one of 'adapting' the virus to the experimental host until it had a high and constant virulence. There is still a tendency to write as if adaptation of a virus were a simple function of the number of passages it had undergone in the new host; not so long ago this attitude was universal. Today it is reasonable to ask that such an approach should be replaced by a recognition that every significant situation involving the functional activities of a virus needs to be looked at from the point of view of population genetics.

The behaviour of strains of influenza $A$ virus on first isolation offers a particularly good example which has been extensively studied in Melbourne. During an extensive influenza epidemic, involving service and civilian personnel, in May 1942, we used the two newly developed techniques of amniotic inoculation of the chick embryo and of haemagglutination for the isolation of virus from human throat washings (Burnet and Bull, 1943). It was soon found that amniotic fluids containing the primary isolate agglutinated guinea-pig or human cells to much higher dilution than fowl cells. A typical fluid might have what we called an $F / G$ ratio of $10 / 160$, with the fowl cell titre as numerator and the guinea-pig cell titre as denominator. At the same time it was observed that isolation usually failed when allantoic inoculation was used. Yet after one or two passages in the amniotic cavity all strains grew freely in the allantoic cavity, giving a fluid which would generally agglutinate fowl erythrocytes to a slightly higher titre than guinea-pig cells. We called this change of influenza $A$ virus when it was transferred from the natural human host to the allantoic cavity of the chick 
embryo the $O-D$ change, the letters standing for the noncommittal original and derivative phases (Burnet and Bull, I 943).

The $O$-phase virus agglutinated guinea-pig but not chicken cells and grew freely in the amniotic but not in the allantoic cavity; $D$-phase virus agglutinated both types equally and grew well in either cavity of the embryo.

$A$ priori there are three possible ways of accounting for the $O-D$ change. The first is that the population of virus particles produced in the human patient, which is inoculated into the amniotic cavity, contains a small proportion of $D$ particles in a great excess of $O$. The second is that when $O$ particles are inoculated into the amnion a small proportion of mutants to the $D$ or intermediate forms appear as the population increases. The third is that the $O-D$ change is an 'adaptive' one affecting all units of the virus population, and essentially representing a change due to continued multiplication within cells of the new host.

The first of these can be automatically eliminated by the demonstration that embryos inoculated with limit-infective dilutions of the original human material give the same type of results as are obtained with larger initial inocula. The presentday approach is, in general, to discard completely the first type of explanation as a relic of an earlier era, unless there is independent evidence of the presence of a second type of virus in the original inoculum. The problem of the nature of the $O-D$ change is really only a variant of the old controversy as to whether an 'adaptive' change in bacterial population is wholly a result of mutation in some individual units or whether a significant proportion of the change is to be ascribed to heritable adaptive change affecting all individual units as a result of their exposure to the new environment.

In I 943 , Bull and I presented the evidence in favour of the Darwinian point of view, namely, that the change from $O$ to $D$ was mutational in origin and was, in fact, precisely analogous to the development in a bacterial strain of resistance to 
streptomycin or to lysis by a particular bacteriophage. Further work was subsequently published in collaboration with Stone (1945). The experimental basis for the interpretation was our ability to maintain virus in the $O$ quality for thirty passages in the amniotic cavity in the sense that it still showed the typical $F / G$ ratio and failed to produce haemagglutinin in the allantoic cavity. This was done-not without much labour-by limit-dilution passage in the amniotic cavity with transfer of selected fluids of low $F / G$ ratio. In general, a full titration in the amniotic cavity and in the allantoic gave results of the type shown in Table I. This is taken from a later investigation of another strain of influenza $A$.

Table I. Titration of an influenza A fluid obtained from an inoculation of an $\mathrm{O}$-type fluid at limiting-infective dilution

\begin{tabular}{|c|c|c|c|c|}
\hline \multirow[b]{2}{*}{$\begin{array}{l}\text { Inoculum } \\
\text { dilution }\end{array}$} & \multicolumn{2}{|c|}{ Amniotic } & \multicolumn{2}{|c|}{ Allantoic } \\
\hline & $\begin{array}{l}\text { Proportion } \\
\text { infected }\end{array}$ & Phase & $\begin{array}{c}\text { Proportion } \\
\text { infected }\end{array}$ & Phase \\
\hline $10^{7}$ & $1 / 5$ & 0 & - & - \\
\hline $10^{6}$ & $4 / 4$ & 000 & $o / 6$ & - \\
\hline $10^{5}$ & $8 / 8$ & 000 & o/6 & - \\
\hline $10^{4}$ & $5 / 6$ & 000 & I $/ 6$ & $D$ \\
\hline $10^{3}$ & & & $4 / 6$ & \\
\hline $\begin{array}{l}10^{2} \\
10^{1}\end{array}$ & $8 / 8$ & $O O O D$ & $\begin{array}{l}5 / 5 \\
6 / 6\end{array}$ & $D D$ \\
\hline $\mathrm{ID}_{50}$ & $10^{6 \cdot 6}$ & & $1 \mathrm{O}^{3 \cdot 2}$ & \\
\hline
\end{tabular}

Evidence of infection was the occurrence of haemagglutination in amniotic or allantoic fluid according to the route of invaluation. Phase $O$ or $D$ determined on the results of haemagglutinin titrations with both fowl and guinea-pig cells.

If we took one of the $O$-type fluids obtained at limit or near-limit dilution and titrated this by the same method, we obtained a similar pattern of results, and, as has already been stated, $O$-phase virus could be maintained indefinitely by this method.

The essence of the experiments was the demonstration that by using a method based on just the same principles as are 
used in pure culture work with bacteria, a strain of influenza virus could be maintained genetically constant despite the fact that a highly favoured mutant was constantly being produced. This type of experiment is, we believe, the only one which can establish that a viral change in character is mutational and not adaptive.

In the light of all our experience, however, we believe that the $O-D$ change is a genetic one in which a mutation or series of mutations is manifested by a modification of the components of the virus surface which react with, and act enzymically on, the sialic-acid-containing receptors of mammalian and avian cells respectively.

Two other examples can be cited of this phenomenon by which a strain of virus can be maintained in its original state, although it is being propagated in a tissue on which various possible mutants would grow much more effectively.

There is a well-known strain of influenza virus which was 'trained' by Stuart Harris to grow in the brain cells of the mouse-a thing no normal influenza virus can do. After more than 100 passages from one mouse brain to the next, the quality of the virus differed in many respects from what we find in viruses cultivated in, and adapted to growth in, the allantoic cavity. In our experiments this virus was transferred to chick embryos, and two sets of transfers set in progress.

In the first, limit-dilution methods were used. In the second, a relatively large amount of virus was used in each transfer. The results were as we should expect. After fifteen passages at limit dilution, the mouse-brain virus appeared to have the same qualities it started with. The mass transfer series, however, had changed in two important characters which brought it much closer to the nature of normal influenza virus strains (Burnet, I95I).

The second example depends on the fact that when many influenza strains are first isolated and persuaded to grow in the cavities of the chick embryo, they are in what we call the 
filamentous form. After long passage they take on what we regard as the normal spherical form. Recently we studied this process directly and found that the same rules held. If a filamentous strain is passaged by the limit-dilution method,

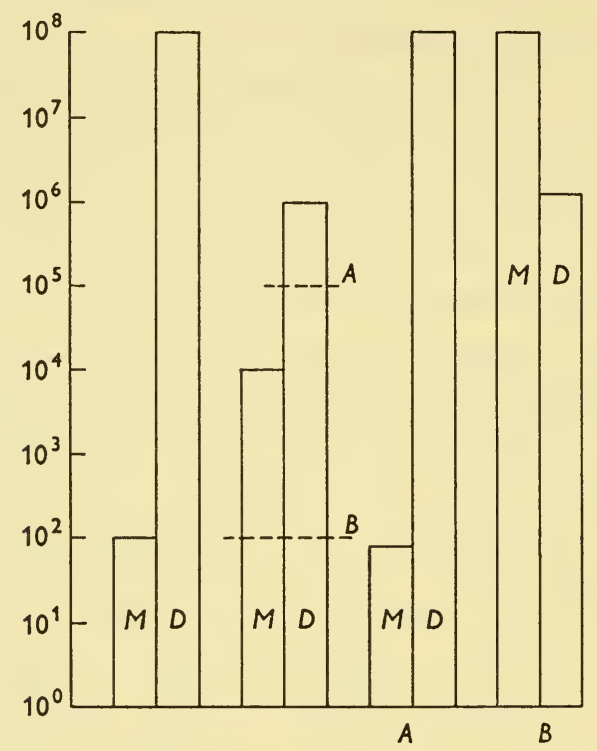

Fig. 1. A diagram to illustrate the function of limit-dilution titration. Each set of bars represents the composition of a population containing a dominant form $D$ and a mutant from this, $M$. The first and second pairs represent two possible results of inoculating only $D$ into the medium or susceptible tissue. If the second population is diluted $10^{-5}$ the amount transferred in passage would be equivalent to the area above $A$, that is, ten infective doses of $D$, none of $M$. The resulting population will be shown in the next set $A$. If a dilution of I to 100 only is used for passage $(B)$ both $D$ and $M$ will be transferred, and if $M$ has a significant proliferative advantage it will become the new dominant form as in the final set $B$.

it stays filamentous. Repeated passage en masse gradually allows the replacement of the long forms by spheres. We are inclined to think that the production of filaments is an indication that the virus is not yet properly adapted to its new host. When the right mutations occur toward better adaptation, 
they are progressively less likely to take on the filamentous form (Burnet and Lind, I957).

Our experience can be summarized as follows. Limitdilution passage will maintain a virus in its original form, despite passage under conditions where potential mutants could outgrow it, only if two conditions are fulfilled. (a) The dominant form of virus in the initial population is homozygous at least in regard to all factors which would influence survival in the new environment. (b) Mutation does not occur with sufficient frequency to overgrow the original clone before harvesting, or alternatively, when this does occur its manifestation is clear enough to allow the elimination from the passage series of the preparation in question.

\section{(d) The process of viral infection}

Both in the laboratory and in the field the process by which a viral infection is initiated is liable to be a complex one, very subject to interruption by essentially accidental circumstances. The standard approach to this question is to examine the end of the titration curve to see whether the proportion of infections produced by dilutions fairly closely spaced about the $\mathrm{ID}_{50}$ level correspond to a Poissonian distribution. The general finding is that, in fact, results do correspond fairly closely, even if we know by experiment that each infective dose in some instance corresponds to many hundreds or thousands of infective doses for some more susceptible host (Parker, 1938). In these circumstances, we have always the alternative to consider, $(a)$ whether the population of virus particles contains one in each thousand which, because of some intrinsic physiological or genetic difference from the other 999, can alone initiate infection, or $(b)$ whether most or all of the 1000 particles can initiate infection but the chance that any one will do so is approximately I to Iooo. Perhaps the clearest indication that the second alternative has at least something to do with the situation is contained in Cairns' (1957) work on the asynchrony of influenza-virus infection. 
In this study he used the strain BEL.D, which he had found to grow more actively and uniformly in the allantoic cavity than any other of those available. A large series of eggs was infected with an inoculum containing less than one infective dose. Samples were taken from each egg at twohourly intervals and stored until it was known by a positive haemagglutinin test whether an infection had been induced. All samples from such positive eggs were then titrated. The results showed that there was a wide variation in the lag period before new virus appeared. Once any new virus was liberated the subsequent course of increase was very uniform but the lag in initiation ranged from 2 to 28 hours. Appropriate experiments indicated to Cairns that the variation could only be attributed to random difficulties in virus and cell making an effective (that is, infection-producing) interaction. Since some particles took as long as 28 hours to provoke first liberation of virus and since the half-life of infectivity at $37^{\circ}$ is of the order of 8 hours, it becomes highly probable that many particles fail to initiate infection simply because they are thermally inactivated before an effective interaction is made. This is probably the simplest-though not necessarily a complete-explanation of the tenfold discrepancy found by Donald and Isaacs (1954) between the number of morphological particles counted by electron microscopy and the infectivity of the same preparation of influenza virus. Under such circumstances, there will obviously be scope for selective survival of any virus particles which, by mutation or otherwise, have developed inheritable qualities which allow them, on the average, to make earlier effective contact with the susceptible cell. The other example, which I shall have to discuss more briefly than it deserves, is concerned with the changes in the virulence of myxomatosis virus after its introduction amongst the wild rabbit populations of Australia.

This is one of the most interesting ecological experiments that has ever been undertaken and it is fortunate that 
excellent facilities were made available by the authorities concerned for a detailed analysis of the situation by Fenner and his collaborators (I957 $a, b)$. All the information I shall present is drawn from their work.

\section{(e) Changes in myxomatosis virulence in the field}

The standard laboratory strain used to initiate the Australian epizootic and all subsequent virus released (with one experimental exception) was obtained from the Rockefeller Institute about I930 and had undergone a long series of passages by contact between rabbits before it was effectively liberated in October I950. It differs somewhat from the virus enzootic in South America by producing less florid lesions, much flatter than those seen when South American strains are inoculated in domestic rabbits. Its lethality is, however, just as high and can be graded as $99.5 \%$ or higher.

Within two years the infection had effectively covered the whole area of Australia which had been occupied by rabbits, that is, all but the tropical and very arid regions. Nowhere were rabbits completely exterminated, and, as far as is known, every considerable region has shown recrudescences of myxomatosis in every subsequent summer. The virus can therefore persist in some way from one summer epizootic to the next.

What chiefly concerns us is the change in the virulence of the virus. Since the days of Theobald Smith, we have given lip service to the view that a pathogen $100 \%$ fatal to the host would be most unlikely to survive in Nature. Rabies, however, exists to show that there may be exceptions and no one had ever actually followed the changing virulence of a virus spreading naturally. The outstanding aspect of Australian experience was the emergence and persistence as the dominant form of clones of myxomatosis virus of significantly lower virulence. In practice, changes in virulence can be much more conveniently estimated by the survival times of small groups of rabbits each given a minimal intra- 
dermal infection than by infecting sufficiently large numbers to allow a statement about the mortality. However, it has become customary to refer to the standard laboratory strain with an average time from infection to death of I I days as a $99.5 \%$ strain and the dominant Australian field strain with a survival time of about 23 days as a $90 \%$ killer. It should be stressed that these are the findings obtained on laboratorybred rabbits never exposed to myxomatosis.

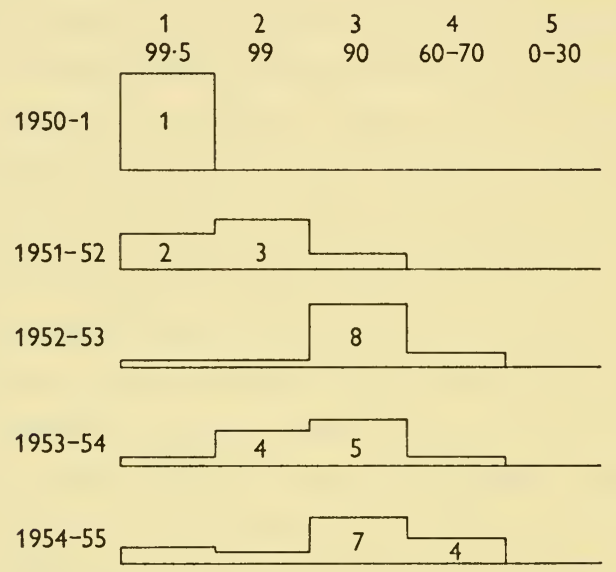

Fig. 2. Changing virulence of myxomatosis virus isolated from successive Australian epizootics (Fenner). The proportion of strains in each category of virulence, as judged by a combination of percentage mortality and length of survival after injection, is shown for each year.

The accompanying figure gives an indication of the differing virulence of strains of myxomatosis virus isolated in the field in various parts of Australia over the last 5 years. The dominance of $90 \%$ strains over the last 3 years is clear. It is of particular interest that neither the repeated reliberation of $99.5 \%$ virus nor the appearance of occasional strains of much less virulent virus has been able to displace the $90 \%$ virus from its dominance. This change to the dominant field virus appears to have occurred independently in several parts of Australia, though the swift initial spread of the virus makes 
it impossible to be certain that a single successful mutation might not also have rapidly spread over the continent. Irrespective of whether it was of single or multiple origin, the appearance of a less virulent strain, which can replace the more virulent, raises some interesting problems that are highly relevant to our general theme of clonal selection.

To understand the situation, we must first consider the process by which myxomatosis is spread in Australia. Acute epizootics nearly always occur in summer and are always associated with a local prevalence of a mosquito which will feed freely on rabbits. The dominant vector is an Anopheles (annulipes) which has developed the habit of resting in rabbit burrows during daytime. Fenner, Day and Woodroofe (1952) have made a detailed study of the process of transmission by mosquitoes. No biological cycle is involved: the virus is not taken in with the blood and there is no multiplication in the tissues of the vector. The process seems to be purely mechanical. The mosquito feeds mainly round the face and ears of the rabbit, and in an animal with myxomatosis lesions the insect will probe through heavily infected tissue to reach blood. The mouth parts will be lightly contaminated with virus which will adhere when the stylet is withdrawn. Once a mosquito has fed through an infected area of skin it is liable to infect any subsequent rabbit on which it feeds. In Fenner's experience, however, the proportion of infective bites is relatively low, and though 'takes' can be obtained as long as 25 days after the infecting feed, they become less and less frequent. The obvious implication is that in at least the later stages almost all infections are initiated by a single virus particle.

This provides the clue to the possibility of replacing a virulent strain by a less virulent one. We may suppose that in a standard $99.5 \%$ strain of myxomatosis virus, mutation occurs to types of significantly lower virulence at a rate around $\mathrm{IO}^{-5}$. If transfer to new individual hosts is always by a small number of particles, and usually by one only, then we can reasonably assume that about once in $10^{5}$ transfers a rabbit 
will be infected with a single infective dose of the mutant form free of the more virulent original type. If one such animal can now serve as a source of infection for a dozen rabbits which are not simultaneously exposed to infection by the virulent type, the new strain will be in a position to compete effectively for survival with the original.

The features making for survival of virus in the field are as follows: (a) high content of virus in the skin lesions through which the mosquito feeds; $(b)$ prolonged availability of virus in such lesions: that is, if a rabbit survives ro days after skin lesions become infective, it is liable to infect twice as many mosquitoes as would be the case if it died in 5 days. It is reasonable to believe that for $(a)$ it is necessary to have a potent virus and for $(b)$ one that allows the rabbit to survive a relatively long period but not long enough for lesions to become non-infective by the development of immunity. The best compromise under Australian conditions seems to be at the $90 \%$ level of lethality. Incidentally, this is a very attractive solution for the farmer and pastoralist for it would ensure that the rabbit population is kept down to ro or $20 \%$ of its former level and that myxomatosis remains constantly enzootic so that each spring flush of young rabbits can be decimated in the summer epizootic.

In 1953 it appeared that in Europe no diminution in the virulence of myxomatosis virus had occurred and the possibility was raised that this strain, much closer to the wild South American virus than the standard Australian 99.5\% strain, might maintain itself at full virulence in Australia. Two introductions were therefore made in areas where events could be closely followed. The results were almost as clear cut as an experiment with bacteria in a test tube.

Virus was obtained from France and two large batches of artificially injected rabbits were liberated late in November and early in December. Mosquitoes had just become prevalent and one case of natural myxomatosis had occurred just as the experiment was begun. The results of three months' 
study of the area are shown slightly simplified in Figure 3. The lesions produced by the French strain are distinctly different from those of the Australian field strain and a combined use of direct observations of the lesions in sick and dead rabbits found in the area, with sub-inoculation in doubtful cases, allowed a clear decision as to which strain was responsible for each infection. It is clear that, although an epizootic was initiated with the French strain, it faded rapidly as soon as the epizootic due to the natural strain got under way.

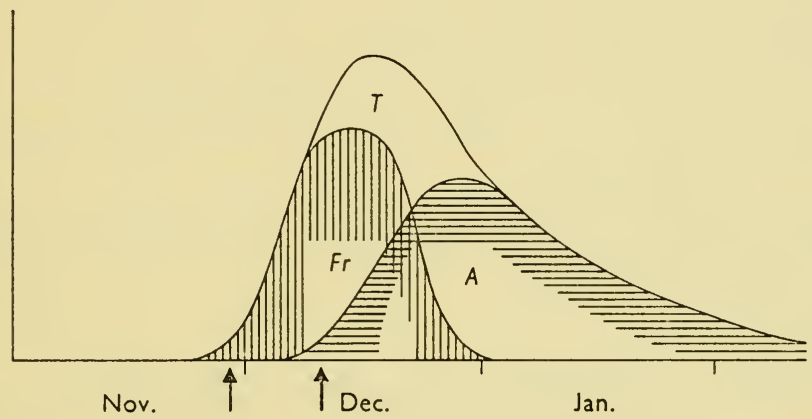

Fig. 3. Selective advantage of Australian field strain $A$ of myxomatosis virus over the more lethal $F r$ strain. Simplified diagram showing daily findings of dead rabbits (ordinate) over period following liberation of the virulent $F r$ strain. Total deaths and those due to $A$ and $F r$ strains separately are shown.

These considerations of the processes of change in populations of bacteria and viruses were designed to act as an introduction to the discussion of clonal selection amongst the cells of the vertebrate organism, more specifically amongst human mesenchymal cells. Throughout, a single theme has been dominant-the potency of mutation and selective survival to change the character of a population of cells to bring it into more appropriate relationship to its environment. The remainder of these lectures are concerned to show that this is as relevant to cell populations within the mammalian body as to populations of viruses or bacteria. 


\section{GLONAL PHENOMENA}

\section{REFERENCES}

Atwood, K. C., Schneider, L. K. \& Ryan, F. J. (i95ia). Cold Spr. Harb. Symp. quant. Biol. 16, 345 .

Atwood, K. C., Schneider, L. K. \& Ryan, F. J. (I95I b). Proc. nat. Acad. Sci., Wash., 37, 146.

Burnet, F. M. (1951). 7. gen. Microbiol. 5, 54.

Burnet, F. M. \& Bull, D. R. (1943). Aust. F. exp. Biol. med. Sci. 21, 55.

Burnet, F. M. \& Lind, P. E. (1957). Arch. ges. Virusforsch. 7, 4 I 3.

Burnet, F. M. \& Stone, J. D. (1945). Aust. J. exp. Biol. med. Sci. 23, 151.

CaIrns, H. J. F. (1957). Virology, 3, I.

Davis, B. (1948). F. Amer. chem. Soc. 70, 4267.

Dean, A. C. R. \& Hinshelwood, C. (1953). Adaptation in Microorganisms (Cambridge), p. 21.

Demerec, M. (1948a). F. Bact. 56, 63 .

Demerec, M. (1948 b). Proc. nat. Acad. Sci., Wash., 31, 16.

Donald, H. \& Isaacs, A. (1954). J. gen. Microbiol. 10, 457.

Fenner, F. J., Day, M. F. \& Woodroofe, G. M. (1952). Aust. F. exp. Biol. med. Sci. 30, 139 .

Fenner, F. J. \& Marshall, I. D. (1957a). 7. Hyg., Camb., 55, I 49.

Fenner, F. J., Poole, W. E., Marshall, I. D. \& Dyce, A. L. (1957b). 7. Hyg., Camb., 55, 192.

Hinshelwood, C. N. (1946). The Chemical Kinetics of the Bacterial Cell (Oxford).

Lederberg, J. \& Lederberg, E. M. (1952). J. Bact. 63, 399.

Lederberg, J. \& Zinder, N. D. (1948). F. Amer. chem. Soc. 70, 4267.

Monod, J. \& Cohn, M. (1952). Advanc. Enzymol. 13, 67.

Novick, A. \& Weiner, M. (1957). Proc. nat. Acad. Sci., Wash., 43, 550.

PARKer, R. F. (1938). 7. exp. Med. 67, 725.

Ravin, A. W. (1953). Adaptation in Micro-organisms (Cambridge), p. 42.

Stanier, R. Y. (1953). Adaptation in Micro-organisms (Cambridge), p. 4. 


\section{III}

\section{THE FACTS OF IMMUNITY}

A theoretical approach to any field of science is something of a luxury. The practical affairs of the world always seem to run along smoothly, or at least normally, without recourse to the theoretical generalizations that are currently worrying the minds of scientists. In that sense they are unnecessary, but we do not have to look far to find something very practical going on around us which is completely dependent on an understanding of what twenty, fifty, or one hundred years ago was a tentative and controversial generalization.

Any discussion of a many-angled field like that of immunology will reflect the major interest of the person responsible for it. In my own case the approach has tended to oscillate between an interest in the specific patterns of macromolecules and a special concern for the epidemiological implications of immunity. It has always been biased toward the biological, rather than the chemical side. The facts of immunity that I want to summarize are those which seem most relevant to any attempt to look at the immune responses as a part of the general biological picture.

They can be listed as follows:

(i) The physical nature of the populations of reactive globulin molecules in a typical antiserum.

(ii) The differences, quantitative and qualitative, between primary and secondary response.

(iii) The lack of immunological reactivity to body components and the related phenomena of tolerance.

(iv) The qualitative types of immune response.

(v) Congenital agammaglobulinaemia.

(vi) The part played by mesenchymal cells, particularly those of the lymphoid series, in immune reactions. 
Each of these topics could well be the subject of a lecture in itself. Any briefer treatment will necessarily have to be a rather dogmatic one, but I believe that it is possible in each case to sort out the essentials needed to present a general picture of the situation.

\section{The nature of 'antibody'}

The first question to be considered is the physical nature of an 'antibody'. A rabbit is inoculated with killed dysentery bacilli on several occasions. A week or two later its serum is found to agglutinate suspensions of the same Shigella to high titre and we say it contains a specific agglutinin or antibody. This system has been widely used in academic immunology and can be taken as representative of the production of 'classical circulating antibody'.

It can readily be shown by appropriate physical fractionation that the functional activity of the serum is in the gamma globulin fraction and with refined methods often in a relatively sharp sub-fraction of the gamma globulins. This, however, does not define the antibody as a uniform population of gamma globulin molecules. As every serologist knows, absorption of the serum with a series of more or less closely related bacterial suspensions will leave behind antibody solutions of quite distinct functional character. Using conventional symbols, if the bacterial antigen has antigenic determinants $A B C D E F$ distributed over its surface, then the reactive gamma globulin molecules in the serum cannot be represented abcdef, abcdef, etc., but perhaps as $a, b, c, d, e, f$, with some possibility that doubly reactive globulin molecules such as $a c, d f$, may also be present.

Antigenic determinants are probably rather small organic configurations equivalent to not more than 2-4 amino-acid or monosaccharide residues (Kabat, I956). Each globulin molecule carries one, two or three reactive sites capable of binding to a particular determinant. What evidence there is points to all the sites on one molecule having the same 
specificity. The possibility of doubly or trebly specific globulin molecules cannot however be wholly dismissed.

In general, the problem of antibody production is to determine how a series of globulin molecules are related to the antigenic determinants with which they react. It will be characteristic of my personal approach that the physical relationship will be dismissed as a pair of complementary configurations and taken for granted. The relation that will interest us is how a large population of appropriately patterned globulin molecules is called into existence by the entry of antigen into the body.

Antigen molecule

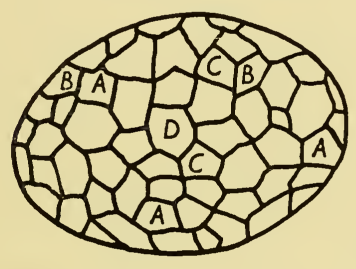

Antibody population

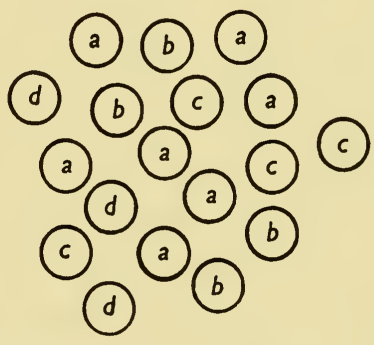

Fig. 4. Schematic representation of an antigen molecule and the antibody population in a corresponding antiserum. Note that of the large number of potential antigenic determinants only those not represented in the components of the reacting animal are active.

\section{Differences between primary and secondary response}

If we take any 'good' antigen, either soluble or particulate, for which we have a convenient in vitro method of titrating the corresponding antibody and inoculate a series of animals, it will usually be a simple matter to show the characteristic difference between primary and secondary response. A particularly clear example is that obtained with staphylococcal toxoid in early work (Burnet, I940), where the primary response is slow and of low titre, the secondary one rapid and rising almost logarithmically to a higher titre. 
At the time, we ascribed the clarity of the difference as seen with staphylococcal toxoid to the fact that we were using a soluble antigen given intravenously, so that the stimulus to antibody-producing cells would be simultaneous and the antigen would in all probability then be removed from the system within a few hours. Both primary and secondary stimuli could therefore be pictured as acting on the cells concerned only over a brief period. On the other hand, when any antigen, particulate or soluble, is placed in the tissues as a depot, antigenic material will leak into the body fluids over a period which may be of considerable duration. If the possibility of secondary type reaction appears within this period, antigen from the primary injection may be responsible for both types of effect with a corresponding difficulty in the interpretation of results.

As an example of response to a small particulate antigen, it is convenient to present some unpublished results of my own from mice immunized with a highly antigenic bacteriophage. Using tenfold dilutions the primary response is shown in the first half of the graph and the secondary response to a uniform small dose in the lower half.

This provides a fairly clear picture, the most striking feature of which concerns the mice given $10^{8}$ particles as a primary inoculum. Three of these gave no detectable antibody and one other an insignificant trace. When re-inoculated with a dose provoking no antibody in controls, three of the four gave high to very high antibody titres. Only one high secondary response was obtained from mice given the $1 \mathrm{O}^{7}$ primary inoculum.

These results point strongly to the conclusion that has frequently been reached in the past, namely, that a first contact with antigen sets some sort of a tooling-up process in train, while secondary contact is needed to evoke actual antibody liberation into the circulation. With the largest inoculum, sufficient antigen can be assumed to persist long enough to act as a secondary stimulus on primarily modified 
cells. The possibility of some of this secondary antigen being liberated, say from macrophages in which it had been partly disintegrated, must be borne in mind. When, however, we have a situation where both first and second inoculum is inadequate to produce antibody as a primary stimulus, yet a high titre response is given to the second, the separation of the tooling-up from the antibody-producing process is almost the only way to account for the observations.

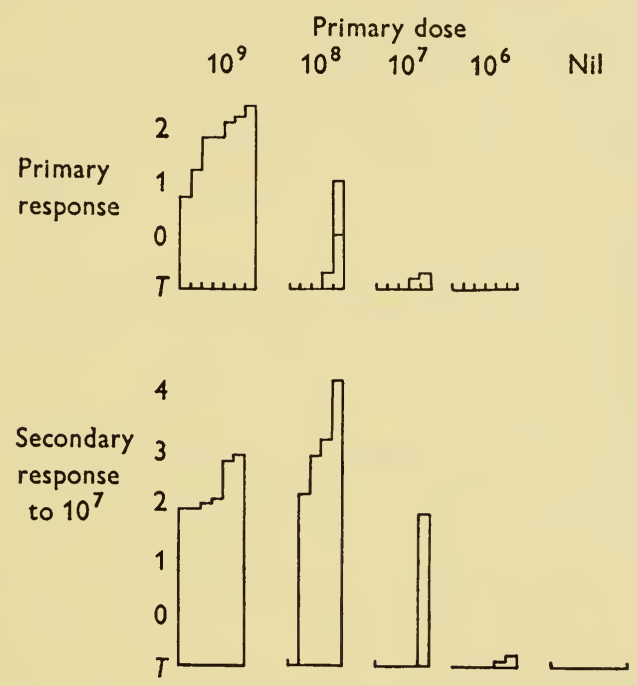

Fig. 5. A comparison of primary and secondary responses in mice to immunization with a bacteriophage $\left(\mathrm{C}_{1} 6\right)$. Ordinates show the activity of serum expressed as $K$. The primary dose in number of infective particles inoculated is shown above. After the primary response had been titrated all mice were given a uniform dose of $10^{7}$ phage particles.

\section{The lack of immunological reactivity to body constituents}

It is axiomatic that no immunological reaction takes place against the normal constituents of the body; no other situation is conceivable in health, and the variety of serious diseases which arise when this rule is transgressed merely underlines its importance. As is the case in many biological fields, a situation which functions smoothly and incon- 
spicuously can often be studied most effectively by analysing what happens when things go wrong. In fact most of the important leads in this field have come from clinical medicine and haematology. It was the complications of blood transfusion and later the unravelling of the results of interchange between maternal and foetal bloods that provided a clear understanding of the importance of 'self' substance. Plastic surgery has shown that if physiological requirements are fulfilled, parts of the body can be transplanted to other parts without disturbance but that most attempts to transplant tissues from any other individual (except an identical twin) are completely unsuccessful. Combining clinical experience with experimental studies in animals, the position can be summarized by saying:

(i) All the body components which either directly or as a result of the break-up of expendable cells can be present in blood or lymph are non-antigenic to the individual himself.

(ii) Cells of different genetic type which have the capacity to implant during embryonic life may also become non-antigenic and survive indefinitely. There are wellknown examples from twin studies in cattle and humans, and in recent years Medawar's work on immunological tolerance has drawn wide general attention to this potentiality (Billingham, Brent and Medawar, I956).

(iii) There are body components which can be shown to be antigenic for the individual providing them. In mammals there are thyroglobulin (Roitt et al. I956) and components of the lens and of spermatozoa. This antigenicity is usually related to the two factors $(a)$ that the components in question are normally inaccessible to blood and lymph and/or $(b)$ they were not present as such in the body when tolerance to self components was established during embryonic life.

(iv) Blood, tissue cells or tissue extracts from animals not genetically identical with the host will provoke some 
type of immune response. The intensity of this may, however, vary within very wide limits.

Under special circumstances, foreign tissues can be implanted in adult animals and persist. The significant examples are $(a)$ corneal transplantation which appears to depend in part on low intrinsic antigenicity of corneal tissue (Bacsich and Wyburn, 1956) and in part on the absence of blood vessels in both host and graft tissues (Billingham and Boswell, 1953); $(b)$ endocrine transplants to the anterior chamber in an animal from which the corresponding endocrine organ has been excised (Woodruff and Woodruff, I950); $(c)$ some malignant tumours.

(v) Tolerance is most readily shown when implanted alien cells can persist from embryonic to adult life. By appropriate injections in utero or in ovo, partial tolerance to non-cellular antigens can be produced in some instances, particularly if the injections are maintained at short regular intervals during the early weeks of the free life of the animal (Dixon and Maurer, I955). With some antigens, no success whatever is obtained in experiments aimed at achieving immunological tolerance.

(vi) There are many conditions in which abnormal destruction of body components, particularly red cells or platelets, can be shown to be due to the activity of antibody-like agents produced by the body. There is no evidence of abnormal antigenicity in the 'target' cells in these cases and opinion is, on the whole, on the side of regarding the 'auto-antibody' as a product of a disordered set of antibody-producing cells.

An overall summary might be that during embryonic life a process of mutual interaction between body constituents leads to the situation by which in subsequent post-natal life no antibody globulins capable of reacting with accessible body components are produced. Immune reactions, in- 
cluding antibody production, occur $(a)$ if antigens carrying foreign determinants enter the body, $(b)$ if body components normally inaccessible become 'accessible' for any reason, or (c) if antibody-producing cells deviate from the limitations implanted during embryonic life.

It may be desirable to elaborate this interpretation slightly in the light of what was said earlier about antigenic determinants. Figure 5 is a highly schematic representation of an antigenic protein molecule. Antigenicity must of course always be relative to the host-the animal being used for antibody production-and the surface of every protein antigen will carry hundreds of potential antigenic determinants which are inert because they are the same as determinants already present in host components. The antigenic quality of the molecule depends on the presence of a small number of antigenic determinants $A, B$, etc. which differ from any present in host components. A diagram of this type will perhaps serve to indicate the magnitude of the 'information' problem involved in differentiating self from not-self.

\section{The qualitative types of immune response}

The subject-matter of immunology has often been unconsciously confined to the high-titre antibodies produced by the immunization of horse or rabbit with diphtheria toxin or some other of the classical antigens. Such antisera react with the antigen by aggregation in the test tube and by 'neutralization' of the biological function of the antigen when this can be tested. Most of the practical applications of serology make use of such antisera and all the classical academic work in immunology is based on their properties. 'Classical circulating antibody' is, however, far from being the only product of specific response by the body to antigenic material and it is, possibly, not even the most important.

Perhaps the simplest way to indicate the differences that may exist in qualitative type of immune response is to compare different types of response to the same antigen, 
diphtheria toxoid, in the same species, man. In normal persons purified diphtheria toxoid given subcutaneously provokes the appearance of antitoxin in the blood and with two or more doses a high enough titre may be obtained to allow demonstration of flocculation with antigen. Concomitantly the individual becomes Schick-negative and is immune to symptomatic infection by Corynebacterium diphtheriae.

In some individuals, however, a different result is obtained. Kuhns and Pappenheimer (1952) describe a child who suffered an acute asthmatic reaction after a 'booster' inoculation of diphtheria toxoid. Investigation showed that a minute dose of purified toxoid injected intradermally provoked an immediate wheal and flare reaction of the type seen with pollen extract in a hay-fever subject. The serum contained 50 units of antitoxin by rabbit skin titration but failed to flocculate with toxin. This led to the examination of a large number of subjects and several more examples of this non-flocculating antitoxin were found. Antitoxic serum of this type can be used to transfer skin hypersensitivity to the skin of a normal individual (Prausnitz-Kustner reaction). It fixes complement only in the presence of a high concentration of serum. It does not precipitate with toxin or toxoid, but co-precipitates when antigen and normal precipitating antitoxic serum are added.

There are other examples where a single antigen can, depending on circumstances, give either classical antibody production or a delayed type of hypersensitivity analogous to the tuberculin reaction. Dienes (1929) and Raffel and Forney (1948) showed that, by providing appropriate cellular environments, antigens like ovalbumin could be made to induce tuberculin type hypersensitivity to intradermal injection of the antigen. There is much to suggest that in addition to these examples there are common features in skin sensitization to simple chemicals like picryl chloride and in homograft immunity. In all cases passive transfer with 
serum from the reactive animal fails, but by the use of cells, apparently lymphocytes, passive transfer of skin reactivity usually succeeds.

The three types of immune response can be conveniently called:

(I) Classical antibody production,

(2) Hay-fever type response,

(3) Tuberculin type response.

It might be equally legitimate to add as a fourth type of immune response the development of specific immune tolerance when by Medawar type manipulations a specifically limited failure to give the expected normal immune response of types (I), (2) or (3) is induced. This is essentially a negative type of finding but it does demand, on some theories at least, a positive process by which non-reactivity is induced.

(I) Under classical antibody we include all serum components which react specifically with homologous (and in some cases related) antigens by the production of visible aggregation on mixing solutions under appropriate conditions. Within this definition there is still scope for inclusion of quite different types of antibody; for example, it includes both low-molecular-weight $( \pm \mathrm{I} 60,000)$ and high-molecularweight globulins $( \pm 900,000)$. In addition, there is much to suggest that under certain circumstances antibody molecules may be produced which show a wide range in avidity or demonstrability but which do not appear to be qualitatively different. It is common, for example, to find in pathological conditions cold agglutinins for certain types of erythrocyte in which agglutination disappears on warming but with intensification of the disease process warm agglutinins, presumably of higher avidity, appear. At a still lower level are the incomplete antibodies which do not cause aggregation but can be recognized by a positive Coombs test. Here the situation is coming close to that of hay-fever type antibody.

It is a moot point whether or not 'natural antibodies' should be included in the class of classical circulating anti- 
body. They form a motley group, most of which have been recognized by the ability of certain apparently normal sera to agglutinate foreign red cells or some bacterial strains. It also includes the human isoagglutinins and the interesting $T$ agglutinins of most mammalian sera which agglutinate red cells altered by the enzyme RDE. In general, the behaviour of natural antibody is indistinguishable from that of a classical antibody of relatively low titre and low avidity.

Properdin presents a special problem. This is a high molecular weight globulin, making up only about $0.02 \%$ of the serum proteins, which reacts with a wide range of bacteria and viruses in a fashion very similar to that of specific antibody. In fact Talmage has recently asked very pertinently whether there is any reason why properdin should not be called an antibody.

(2) The standard responses of hay-fever subjects to the pollen extracts involved closely resemble Kuhns and Pappenheimer's (1952) observations with diphtheria toxoid in allergic subjects. The antibody in serum is associated with a globulin fraction which has been variously identified as of $\beta$ or $\gamma_{\mathrm{I}}$ in type, with recent work suggesting that the latter is correct. Loveless's work (1940) indicates that pollen extracts administered parenterally to hay-fever patients produce classical type antibody which has a blocking effect in preventing, to a large extent, the access of the antigen to the loci responsible for symptoms. This principle, that one type of antibody may modify the activity of an immunological response to the same antigen, is one which may have important bearing on some of the problems associated with pathological disturbances of the immune mechanism.

The principal characters of the hay-fever type response are absence of standard aggregation type reactions and very weak complement fixation; increased tendency for antibody to be taken up by tissue cells-for example, as exploited in the Prausnitz-Kustner phenomenon; and in human beings its failure to pass the placenta. Although most work on this 
type of antibody has, for obvious reasons, been done with human sera, it is probable that a similar type of antibody can be produced in rabbits. Sherman, Menzel and Seebohm (I950) immunized rabbits with ovalbumin precipitated with alum, and found that their serum was capable of passively sensitizing human skin. By fractional precipitation with antigen they obtained a serum fraction incapable of precipitating with antigen but retaining the power to sensitize human skin. Electrophoretic studies of sera from human patients indicate that the activity is associated with one of the faster moving gamma globulin fractions (Humphrey and Porter, 1957). Some workers have considered the fraction as essentially a $\beta$-globulin (Loveless and Cann, I 955). Perhaps the most important point from Humphrey's work is that the antibody was concentrated in a sharp peak which led him to suggest that it may be the product of some specific group of cells.

(3) Types (I) and (2) response are characteristically associated with the production of specific circulating antibody. Type (3) differs sharply in that there is no evidence that any circulating antibody is produced. The classical example is tuberculin hypersensitivity, but it is highly probable that similar reactions are concerned with skin sensitization to simple chemicals and with homograft immunity. Further aspects of this type of immune response will be discussed in the next section on congenital agammaglobulinaemia. A claim by Cole and Favour (r955) to have obtained a serum fraction from tuberculous guinea-pigs capable of transferring tuberculous hypersensitivity to normal animals has not been confirmed. It has, however, been abundantly confirmed that 'leucocytes', presumably lymphocytes, can transfer sensitization and the antibody is to be regarded as a 'cell-borne' one. Jeter, Lawrence and Seebohm (1957) have described a globulin of $\alpha_{2}$ mobility that can be extracted from competent cells and have evidence that a subcellular component, possibly this alpha globulin, is capable of transferring hypersensitivity. This raises the 
important question of whether sensitive cells are representatives of immunologically modified clones or have, in part at least, been altered by some non-genetic process. Much interest has therefore been devoted to the nature of the cells associated with the response.

It is easy to show that cells from the spleen of a tuberculous guinea-pig grown in tissue culture are sensitive to a severely damaging effect when tested with dilute tuberculin, normal cells being unaffected. This reaction is confined to mesenchymal cells, not being shown by corneal cells or a variety of other epithelial cells obtained from tuberculous animals (May and Weiser, I956). The genesis of this type of reactivity seems to be associated with a special type of cellular response best initiated by the simultaneous presence of waxy materials of the type found in the tubercle bacillus. Raffel and Forney (I948), for instance, showed that typical 'contact dermatitis' sensitization could be produced in guinea-pigs by intraperitoneal injection of picryl chloride plus purified wax from tubercle bacilli. In the absence of the wax, sensitization can only be produced by direct contact of the chemical with the skin.

Homograft immunity is not associated with circulating antibody. The most elegant demonstration of this is by Algire's method of applying a foreign graft that is separated from the immune host by a membrane which allows passage of protein molecules but not of cells. Under these circumstances, the graft remains undamaged.

All three types of reactivity can be transferred to a normal animal by suspensions of mesenchymal cells in which lymphocytes seem to be the most significant element. In studies with picryl chloride, Battisto and Chase (I955) found that they could render guinea-pigs insusceptible to sensitization by the normal procedure if the allergenic chemical was fed to the animals for a preceding period. This failure to react, however, did not prevent the passive transfer of hypersensitivity to the non-reactive animal by cells from one that had produced typical active hypersensitivity. Also 
of interest is the finding that the same process of feeding prevented the production of circulating antibody against a picryl chloride-protein complex given intraperitoneally.

\section{Congenital agammaglobulinaemia}

As an incidental result of the effectiveness of antibiotics, an increasing number of children are being recognized and kept alive who have no circulating gamma globulin and who are unable to manufacture circulating antibody. Such children provide what are essentially natural experiments of the greatest importance for the understanding of the immune process.

The essential features of the disease from the immunological angle may be summarized as follows:

(i) It is a sex-linked genetic anomaly seen only in males.

(ii) There is an absence of demonstrable gamma globulin and circulating antibody; the isoagglutinins to be expected from the blood group of the individual are also absent.

(iii) There is no response to the ordinary immunizing inoculations either by the appearance of circulating antibody or in the case of diphtheria antigens by the change from Schick-positive to Schick-negative.

(iv) There is an absence of plasma cells in bone marrow and lymph nodes even after antigenic stimulation.

(v) Agammaglobulinaemic patients may be actively sensitized to tuberculin by BGG vaccination and to 2-4dinitrofluorobenzene by skin sensitization. Sensitivity to the latter is transferable by blood cells to normal individuals.

The important clinical features that have been recorded are as follows:

(vi) There is a great susceptibility to pyogenic bacterial infections, especially pneumonia, but these can generally be cured by administration of antibiotics and normal human gamma globulin. 
(vii) The common virus diseases, including measles, chickenpox, mumps, poliomyelitis and Jennerian vaccination, run a normal course and are followed by evidence of clinical immunity. In one case three attacks of mumps were reported (Bruton, 1952) but one feels that the possibility that two (or three) of these were subacute bacterial parotitis should be seriously considered.

(viii) In one case a successful skin graft from an unrelated donor was reported, but subsequent experience indicates that most such grafts were rejected in normal fashion.

(ix) Children maintained with normal gamma globulin injections and antibiotics are showing a high proportion with arthritis of rheumatoid type.

(x) One patient is on record who developed an idiopathic haemolytic anaemia without autoantibodies. The condition was cured by splenectomy (Rohn, Behnke and Bond, 1954).

These findings lead to the simple conclusion that what is lacking in these patients is the ability to develop plasma cells capable of producing Type I (classical) antibody. They show normally functioning immune responses of Type 3. I have found nothing in the literature relevant to Type 2 responses. This has the important, and to most people unexpected, implication that immunity to the common virus diseases may be mediated by processes not requiring the release of antibody into the circulation. It is natural, therefore, to believe that antiviral immunity in such persons is developed by a response of Type 3 character. Whether this is also the case in normal persons must await further study. Perhaps some evidence for this can be seen in the fact that the immune type response to Jennerian vaccination is essentially a delayed hypersensitivity response and can also be given by non-infective vaccine lymph.

Another aspect of agammaglobulinaemia which may be stressed is that the normal isoagglutinins are absent and are 
not stimulated when the child is inoculated with foreign red cells of the type which should stimulate their formation in the individual studied. This is at least another hint that normal agglutinins and immune antibodies have much in common.

\section{Lymphocytes and plasma cells as antibody producers}

At the present time there is no serious opinion against the view that the acute production of antibody in, for example, the secondary response to some standard antigen like diphtheria toxoid is a function of plasma cells, especially what Fagraeus (I948) calls immature plasma cells. The study by Coons, Leduc and Connolly (1955) of antibodyproducing cells using the fluorescent antibody 'sandwich' technique provided a clinching final support for a variety of less direct earlier approaches.

This, however, is only part of the story. For an adequate account of the cellular basis of immune responses we need to know:

(i) What is the origin of plasma cells? In two senses, (a) from what cell types are they descended and (b) what stimulus in the internal environment calls forth their appearance?

(ii) What are the origins and degrees of interconvertibility of macrophages, lymphoid cells and plasma cells?

(iii) What is the cellular basis of Types 2 and 3 responses?

(iv) Can antibody be liberated from lymphocytes and, if so, under what conditions?

(v) Have the spleen and thymus immunological functions different in quality from other mesenchymal tissues?

It seems necessary to say at once that no complete answer to these questions is available, and the rest of this section will be confined to listing some of the evidence that small lymphocytes are concerned in the immune response, and to offering some opinions from the literature in regard to the 
potentialities of lymphocytes giving rise to cells of other functional type. Since the work of McMaster and Hudack (I935) there has been no doubt that antibody was produced in lymph nodes and spleen, but the general view has been that the actual producers are plasma cells. It is extremely difficult to obtain a gross preparation of lymphocytes that can be 'certified' free of plasma cells and there must always be some doubt as to the composition of the cells used in various forms of tissue survival experiments in vitro. Perhaps the most convincing evidence is that of Wesslen (1952) who used thoracic duct lymph from rabbits immunized some time previously with Salmonella paratyphi $B$. This contained extremely few cells other than small lymphocytes. Extraction of the cells with distilled water provided no detectable antibody, but if they were incubated overnight in Tyrode solution small amounts of antibody were liberated into the medium. This suggests perhaps no more than a potentiality that when conditions are appropriate lymphocytes in an immune animal can liberate antibody.

Many experiments have been described in which cellular transfer of immunological reactivity has been accomplished. Lymph-node cells, or those from subacute peritoneal exudates, are those commonly used, and in all such preparations there are numerous lymphocytes. In fact, it is probably true to say that in recent years most authors have taken it for granted that lymphocytes were the cells concerned in the process. Dixon, Weigle and Roberts (I957) have recently clarified the position somewhat by showing transfer of antibody-producing capacity, either by lymph-node cells with 80 to $90 \%$ lymphocytes or by peritoneal exudates 80 to $90 \%$ monocytic in character. In each case the dose used was close to the marginal, so that it could be said that in neither case could the minority type have been wholly responsible for the effect.

This seems to point strongly to a unitarian interpretation which has, in fact, been strongly defended for some years 
by Taliaferro (1949). He holds that we should consider not any particular type of cell but what he calls the mesenchymal reserves which comprise reticular cells, macrophages and the lymphoid series. He believes that lymphocytes can develop into macrophages or plasma cells.

My own working picture of the situation is frankly based on a desire to obtain the simplest interpretation of the cellular basis of antibody production which is not clearly at variance with the available facts. This is that cells of any clone of mesenchymal cells may, under appropriate conditions of the internal environment, take the form of stem cell, macrophage, lymphocyte or plasma cell and that the observed form is essentially a reflection of the function it is performing at the time of fixation. In all probability the fibroblast should be included as a product of these mesenchymal cells, but the possibility of its back-conversion to one of the specifically functioning types is not established.

\section{Summary}

This outline of the facts of immunity is selective and incomplete. Its purpose is simply to present the aspects which seem to be specially significant for any biological interpretation of immunity. From our own particular point of view the crucial points are probably:

(i) In some way there is a recognition of self components from 'not self'; from the facts of immunological tolerance the recognition mechanism is laid down toward the end of embryonic life. Any such mechanism must differentiate between self and not self in one or both of two ways:

Either (a) All significant antigenic patterns of the body are positively recognized by the antibody-producing mechanism. Foreign patterns, because they are not recognized, provoke an immune response;

Or (b) All the possible types of foreign and antigenic determinant can be positively recognized as foreign and hence calling for an immune response. 
It seems inescapable that either alternative or any combination of the two will require an extensive 'library' of information to be stored, either individually or collectively, in the cells of the antibody-producing system.

(ii) It is certain that once antibody production has been effectively established, there is a long-lasting retention of information, in man lasting very many years, which must be mediated by some form of genetic transmission from cell to descendant cell. The prolonged ability to respond to a 'booster' of tetanus toxoid and Davenport's phenomenon of the re-evocation of the serological pattern of the first influenza $A$ antibody produced may be quoted.

(iii) In agammaglobulinaemic persons many characteristic immune responses can be carried out in the absence of plasma cells and circulating gamma globulin antibodies. In the case of all these residual activities there is some evidence to link them to lymphocyte functions.

(iv) Some normal antibodies such as the human red cell isoagglutinins behave in essentially similar fashion to classical antibody.

(v) There are at least three sharply differentiated types of immune response.

These are the points on which I believe most stress should be laid in discussing the nature of the immune responses.

\section{REFERENGES}

Algire, G. H., Weaver, J. M. \& Prahn, R. T. (1954). F. nat. Cancer Inst. 15, 493 .

Bacsich, P. \& Wyburn, G. M. (r956). Nature, Lond., 178, 1228.

Battisto, J. R. \& Chase, M. W. (1955). Fed. Proc. 14, 456.

Billingham, R. E. \& Boswell, T. (1953). Proc. Roy. Soc. B, r4i, 382.

Billingham, R. E., Brent, L. E. \& Medawar, P. B. (1956). Phil. Trans.

239, 357 .

Bruton, O. C. (1952). Pediatrics, 9, 722.

Burnet, F. M. (1940). Production of Antibodies (ist ed. Melbourne).

Cole, L. R. \& Favour, C. B. (1955). 7. exp. Med. 1or, 391.

Coons, A. H., Leduc, E. H. \& Connolly, J. M. (1955). J. exp. Med.

ro2, 49 . 


\section{THE FACTS OF IMMUNITY}

Dienes, L. (I929). J. Immunol. I7, 53 I.

Dixon, F. J. \& Maurer, P. H. (1955). 7. exp. Med. ror, 245.

Dixon, F. J., Weigle, W. O. \& Roberts, J. C. (i957). F. Immunol. $\mathbf{7 8}, 56$.

FAgraeus, A. (1948). Antibody production in relation to the development of plasma cells (Stockholm).

Humphrey, J. H. \& Porter, R. R. (I957). Lancet, r, I 96.

Jeter, W. S., Lawrence, K. A. \& Seebohm, P. M. (1957). J. Bact. 74, 680 .

Kават, E. A. (1956). J. Immunol. 77, 377.

Kuhns, W. J. \& Pappenheimer, A. M., Jr. (1952). J. $\operatorname{exp.~Med.~95,~} 363$.

Loveless, M. H. (1940). 7. Immunol. 38, 25.

Loveless, M. H. \& CANN, J. R. (I955). 7. Immunol. 74, 329.

MAY, J. K. \& Weiser, R. G. (I956). 7. Immunol. 77, 34.

McMaster, P. D. \& Hudack, S. S. (1935). J. exp. Med. 6r, 783.

Raffel, S. \& Forney, J. E. (I 948). 7. exp. Med. 88, 485.

Rohn, R. J., Behnke, R. H. \& Bond, W. H. (I954). J. Lab. clin. Med. 44, 9 I 8.

Roitt, I. M., Doniach, D., Campbell, P. N. \& Hudson, R. V. (I956). Lancet, 2, 820.

Sherman, W. B., Menzel, A. \& Seebohm, P. M. (i950). F. exp. Med. 92, 191.

Taliaferro, W. H. (1949). Annu. Rev. Microbiol. 3, I59.

Wesslen, T. (1952). Acta derm.-venereol., Stockh., 32, 195, 245.

Woodruff, M. F. A. \& Woodruff, H. G. (1950). Phil. Trans. B, 234, 559. 


\section{IV}

THE GLONAL SELEGTION THEORY OF ANTIBODY PRODUGTION

In the last chapter I gave a short account of what I regarded as the important experimental and observational facts of the immune responses. In this, I want to discuss the possible ways in which a general theoretical account of the findings can be constructed. It would be difficult, presumptuous, and inappropriate to this series of lectures to attempt to deduce directly from the facts the most likely theory of antibody production. Instead, I shall consider only points of view that have already been expressed, beginning with Ehrlich's side-chain theory.

\section{The side-chain theory of Ehrlich}

This is, of course, based on an old-fashioned picture of cell metabolism, but its essence can be expressed in terms that would be intelligible today. Ehrlich assumed that all foreign antigens, and especially the bacterial toxins with which he was primarily concerned, damaged body cells by combining with pre-existent chemical patterns (side chains) normally concerned with some metabolic function. The union was specific and irreversible and the damage to the cell could only be overcome by casting off the blocked side chain and replacing it with a new one. Such regeneration was regarded as conforming to the general law of over-compensation that had been formulated by Weigert, and would therefore tend to produce an excess of side chains which were liberated into the body fluids.

The side-chain theory implies the existence of cellular patterns complementary to all possible antigenic determinants. With Landsteiner's studies of serological specificity 
it became clear that an enormous variety of cell receptors would need to be provided, so many that Ehrlich's theory was discarded. Landsteiner in 1936 concluded that antibodies are produced by some modification of the process of protein synthesis by which the proteins (antibodies) are adapted as closely as possible to the immunizing antigen.

\section{Haurowitz-Pauling (direct template) theory}

With the development of a better understanding of protein chemistry, Landsteiner's work became the basis for the first of the current theories of antibody production, for which Alexander, Mudd and Haurowitz are usually given joint credit. Its most fully developed form is due to Pauling (I940) and it is probable that most immunologists still find it the most convenient framework for thought on practical matters. Following Talmage (I957), the theory can be called the 'direct template' theory. It holds that antibody molecules have their specificity determined by being synthesized against a template of the antigen molecules themselves. In Haurowitz's (1952) view the specificity is conferred not at the synthesis of the polypeptide chain but at a later stage when the folding of the chain is taking place. In this way a complementary configuration is developed at one or more, probably two, sites on the coiled-up globulin, which 'fits' accurately with the antigen or its particular determinant against which it was moulded.

It is doubtful whether anyone has attempted to cover all the main fields of immunology in relation to this view. Clearly accessory hypotheses not very closely dependent on the primary one are needed to deal with normal antibodies, immunological tolerance, homograft immunity, etc. Its chief virtue has been the stimulus it has provided for the experimental study of specificity of chemical structure, and of the persistence of foreign organic material in various tissues. The important implications of this theory in which it differs from others are: 
(i) antibody can be produced only while antigen or its determinants remain as such in the tissues:

(ii) antibody can be produced against any type of organic pattern provided it is presented on an appropriate carrier macromolecule, most commonly protein in character.

\section{Burnet-Fenner indirect template theory}

In 1949, Burnet and Fenner published a comprehensive discussion of the available information in terms of what has been referred to as an 'indirect template' theory. This was elaborated but not basically altered by Burnet in 1956 .

The theory was an attempt to include in a general formulation those features for which the direct template theory has no point of contact. We held, for instance, that the two most important features of immune reactions were $(a)$ that body components are immunologically inert and that an equivalent tolerance to foreign antigens can be demonstrated if they are introduced at an appropriate stage in embryonic life and (b) that antibody production can continue long after the effective antigen has disappeared from the body.

The indirect template theory still adopted the view that antibody production was an active response of cells to the entry of foreign organic material, and for this theory the existence of natural antibody was an accidental and irrelevant circumstance. The new features were essentially three in number:

(i) To account for the non-antigenicity of body components these were assumed to carry 'self-markers'; at some point in the antibody-producing sequence a 'recognition unit' was postulated to act as a means of detecting material carrying self-markers and deflecting it from the possibility of immune response;

(ii) To account for the persistence of antibody-producing capacity it was postulated that a 'genocopy' of the antigenic determinant was incorporated in the genome 
of the stem cell concerned, so allowing the indefinite production of descendant antibody-producing cells;

(iii) This incorporation of pattern determinants into the genetic structure of antibody-producing cells provided some basis for the changes in antibody character that may result from secondary antigenic stimuli or simple lapse of time.

This theory had its main success in predicting that immunological tolerance following prenatal injection of appropriate antigens should be experimentally demonstrable. On the other hand, the concept of self-markers and recognition units was seen to be a clumsy one that could only be a rough paraphrase of the actual mechanism.

\section{Jerne's natural selection theory}

In 1955 Jerne published a new and strikingly different conception of antibody production in which, for the first time since Ehrlich, natural antibodies were seriously considered in relation to 'true' antibodies. Jerne discarded altogether the view that antibody production was a direct result of the entry of an antigen into body cells. He held that the gamma globulin molecules of the plasma represent a population comprising carriers of all the reactive sites needed to unite with any potential antigenic determinant except those already existing in accessible components of the body. The function of the antigen which enters the body from without is to act as 'a selective carrier of spontaneously circulating antibody to a system of cells which can reproduce this antibody'. It is assumed that once antibody is taken into cells of the antibody-producing system, replicas of this natural antibody will be produced. With the liberation of this crop of new antibody a second injection of antigen will find many more antibody-producing cells and give a stronger 'secondary' stimulus to antibody production. Like the direct template theory, the natural selection theory leaves a considerable range of questions unanswered. It is not clear, for instance, 
whether the multiplicity of antibody reactivities in gamma globulin molecules is a random character due to a simple indeterminacy of pattern in the molecules produced or whether there are clones of cells which produce pattern $a$, others pattern $b$, and so on for the thousands of patterns required. This second possibility would naturally also demand a corresponding range of coding for pattern in the nucleic acids of the cells forming the clones in question. Jerne appears to favour the first alternative and to assume that when a (partially denatured) globulin molecule which happens to have pattern $x$ is brought to any one of the antibody-producing cells this cell is stimulated to produce globulin of definitive pattern corresponding precisely to the random pattern of the 'natural' antibody molecule. This appears to be out of line with any of the current ideas on protein synthesis and is one of the main points which led to the development of a 'clonal selection' theory.

\section{The clonal selection theory}

The great contribution of Jerne's theory was that it drew attention to the theoretical possibility that the recognition of self from not-self could be achieved in another fashion than by the recognition of 'self-markers'. As Talmage (1957) points out, Ehrlich's side-chain theory was in many ways the logical equivalent of Jerne's concept. The side-chain theory was quietly shelved as evidence accumulated of the vast variety of antibodies that could be produced, some against non-biological determinants such as arsanilic acid. Itseemed, and to most immunologists still seems, inconceivable that all types of antibody could be pre-existent in the normal complement of gamma globulin molecules. Nevertheless, if Jerne is correct that a comprehensive range of molecules corresponding to all organic patterns other than those of body components is present in the gamma globulin population, this would be an effective and much more elegant way of accounting for the differentiation of self from not-self. 
The outstanding difficulty in accepting Jerne's theory is the claim that when a given type of natural antibody molecule is brought to a cell by antigen, the cell then proceeds to make more natural antibody molecules of the same type. The facts that, in general, union with specific antigen results in partial denaturation of antibody globulin, that there is no nucleic acid in antibody and that homologous antibody is very rapidly broken down when it is taken into a cell (Humphreys and Macfarlane, 1954), all speak against the concept. Talmage (1957) pointed out that it would be more satisfactory if the replicating elements essential to any such theory were cellular in character ab initio rather than extracellular protein which can replicate only when taken into an appropriate cell. He did not elaborate this view but clearly regards it as the best current basis for immunological theory. Our own view is that any tenable form of Jerne's theory must involve the existence of multiple clones of globulin-producing cells, each responsible for one genetically determined type of antibody globulin. This immediately poses the question of how the antibody-antigen complex can reach the cells, which are genetically determined to produce the corresponding type of antibody molecule. Clearly it would simplify matters a great deal if the antigen were in a position to react with natural antibody or a pattern equivalent thereto on the surface of the cell which produced it.

This is the crux of the clonal selection hypothesis. It assumes that in the animal there exist clones of mesenchymal cells, each carrying immunologically reactive sites corresponding in appropriate complementary fashion to one (or possibly a small number of) potential antigenic determinants. This provides a population of cells which, when an appropriate stage of development has been reached, are capable of producing the population of globulin molecules which collectively provide the normal antibodies. When an antigen is introduced it will make contact with a cell of the corresponding clone, presumably a lymphocyte, and by so doing 
stimulate it to produce in one way or another more globulin molecules of the cell's characteristic type. The obvious way of achieving this is to postulate that stimulation initiates proliferation as soon as the cell in question is taken into an appropriate tissue niche, splcen, lymph node or subacute inflammatory accumulation.

The reasons for temporarily or permanently discarding the 'indirect template' hypothesis in favour of this clonal selection approach were cumulative and largely indirect.

(i) In discussing the biology of malignant disease the importance of clonal phenomena in the expendable cells of the body became increasingly evident (Burnet, I 957 b).

(ii) Interest in the auto-immune complement fixation test developed in my laboratory by Gajdusek (r957) led to the tentative conclusion that the 'antibody' concerned was an adventitious mixture of globulin molecules produced by clones of cells which had undergone some type of somatic mutation.

(iii) Workers in the field of adaptive enzyme production in bacteria are now unanimous that the pattern of the adaptive enzyme is genetically determined and not a 'transcript' of pattern introduced by substrate or inducer molecule. This destroyed the significance of any analogy between adaptive enzyme production and the indirect template hypothesis of antibody production.

(iv) Changing views on the life-history of the lymphocyte have made it admissible to postulate that a lymphocyte appropriately stimulated could give rise to a clone of descendant cells. In particular, work from Florey's laboratory (Gowens, I957) shows that lymphocytes can undergo more than one cycle between tissue and circulation. Simonsen (1957), working with avian material, showed that adult fowl blood contained circulating cells which could settle and proliferate in 
embryo spleen and produce antibody against the new host.

(v) Several immunologists, including Jerne himself, have suggested that the self-marker theory is semi-mystical in character and generally unattractive.

For these reasons a sketch of what appeared to be necessary modifications in Jerne's theory was prepared (Burnet, I957a) and found to have some interesting potentialities, particularly in relation to the pathology of immune reactions in man. As in every such theoretical elaboration, a number of ad hoc assumptions had to be made, but it is felt that all of these are in line with the basic concept. This may be stated from a more generalized viewpoint as follows:

The antibody-producing cells of the body make up a mobile population of mesenchymal cells constantly undergoing physiological and mutational change. It is composed of large numbers of clones from which subclones are constantly arising as a result of somatic mutation.

Individual clones prosper or dwindle in accord with their experience of contact with the corresponding antigenic determinants. The result of such contact will depend on a variety of physiological considerations of which the most important is probably the age of the individual concerned. The fate of these clones can legitimately be regarded as a study in the population genetics of mesenchymal cells in the internal environment of the whole organism.

\section{(a) Developmental considerations}

The development of the starting population of mesenchymal cells present at birth or hatching is part of the general problem of differentiation and requires a number of additional ad hoc assumptions which, however, are of the same general quality as are needed for the provisional interpretation of any phase of embryonic differentiation.

Perhaps the clearest way to present the processes that must be postulated during embryonic development is to consider 

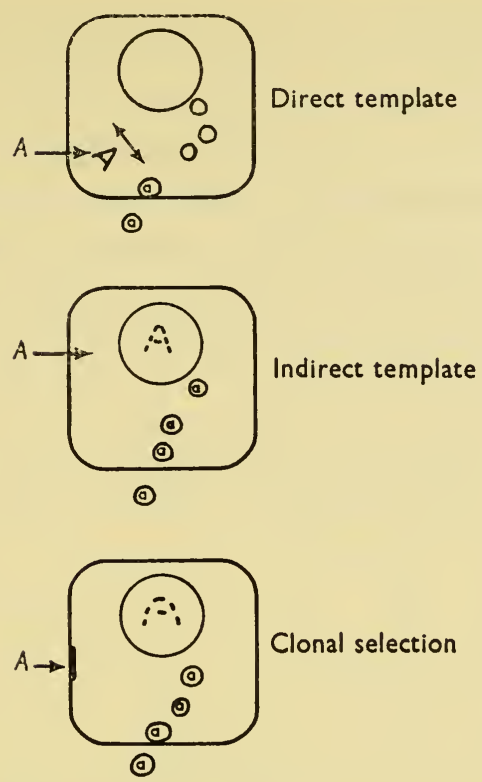

Fig. 6. A diagram to suggest the essential differences between the three theories.

In the first (direct template theory) the antigen itself enters the cell and stamps a complementary pattern on each globulin molecule after it has been produced.

In the indirect template theory the antigen, as it were, incorporates an image of itself in the genetic mechanism of the cell. This is suggested by putting a broken $A$ in the nucleus-but the possibility of a cytoplasmic mechanism of inheritance might appeal more to others.

In the clonal selection theory, the image of the antigenic determinant is present, shadowy perhaps, in the genetic mechanism before first contact with antigen, which can stimulate, but not effectively enter, the cell. The image and the globulin pattern can be sharpened up or modified by mutation and selection.

the most conspicuous of the normal antibodies, the isoagglutinins anti- $A$, anti- $B$ and anti- $H(O)$.

There are still conflicting opinions in regard to the significance of the isoagglutinins but, having regard to the phenomena of immunological tolerance, that suggested by Burnet and Fenner (I949) is still the most probable. They 
suggested that there were normal globulin-producing cells which 'by accident' were potentially capable of producing molecules with the configurations needed to act as isoagglutinins of the two types (and we should now add anti- $H$ as well). If, however, the genetic constitution of the embryo resulted in the production of $A$ substance on red cell surface or elsewhere, the potential producers of anti- $A$ were rendered tolerant; that is, $A$ was recognized as self and only anti- $B$ developed. The other groups would be similarly interpreted. Two haematological anomalies provide rather strong support for this view. The human chimaera described by Dunsford et al. (I953) was genetically $O$ with $A$ cells from her twin brother derived presumably by prenatal implantation of haematopoietic cells. She showed no anti- $A$ isoagglutinin and the $A$ cells were negative to Coombs' test. It seems that the capacity to produce anti- $A$ which was genetically present must have been inhibited or annulled during embryonic life. The converse situation is to be found in persons with therare 'Bombay' blood group anomaly (Bhende et al. 1952). In this phenotype the cells are not agglutinated by any isoagglutinin, presumably as a result of genetic anomaly. The serum contains anti- $A$, anti- $B$ and anti- $H$.

This can be taken as a prototype of the kind of interpretation to be adopted in developing the present modification of Jerne's theory. How clones to cover all possible antigenic determinants can arise must be left for later discussion. We assume simply that this does take place at some stage in embryonic life and that mesenchymal cells, presumably lymphocytes, begin to circulate with the characteristic pattern on their surface but do not liberate antibody-type globulin. In the Burnet-Fenner theory, any potentialities of antibody production against body components were eliminated by the development of tolerance. In the present theory they are more readily disposed of by assuming thatat this particular stage of embryonic life-contact with the corresponding antigen pattern results in the death of the cell. 
If the potential antigen persists long enough in high enough concentration, all clones which can produce this natural antibody will be eliminated. This provides a simple explanation for the red cell isoagglutinins and could obviously be extended to cover all examples of prenatal tolerance. Selfnot-self recognition means simply that all those clones which would recognize (that is, produce antibody against) a self component have been eliminated in embryonic life. All the rest are retained.

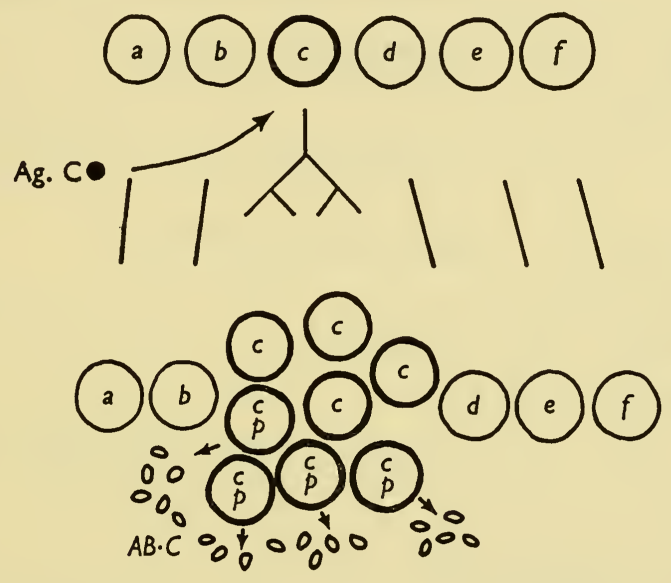

Fig. 7. To illustrate the clonal selection theory of immunity. Contact of the corresponding antigenic determinant $\mathrm{Ag}$. C with cells of clone $c$ stimulates proliferation to antibody-producing plasma cells $c p$ and nonantibody producing types $c$.

To obtain such a result a fairly complex developmental sequence must be postulated. The first point to be considered is how a complete sequence of globulin patterns capable of reacting with all possible determinants could be established. There is a possible clue to be found in the fact that all substances capable of acting as antigens are susceptible to enzymic breakdown. Enzymes are proteins and it is probably a reasonable deduction that proteins have the potentiality of carrying steric patterns complementary to every chemical 
configuration that has been produced by living organisms. It may be suggested as a corollary to this that if at a certain stage of embryonic development certain synthetic elements in mesenchymal cells were 'randomized', the possibility might well emerge of producing all the 10,000 or more patterns required.

\section{Table 2. A representation of the process of} immunological maturation
Embryonic
Phase of differentiation or randomization
Birth or hatching $\rightarrow$
Stabilization of patterns
Development of tolerance by elimination of reacting clones
$\leftarrow$ Critical point of Medawar
Maturation
Post-natal
Liberation of natural antibodies and poten- tiality of antibody production
Development

Suppose that at the appropriate stage of development a limited genetic determinant carrying the coding responsible for globulin pattern releases control in such a fashion that purely random arrangements are allowed which will be different at each replication. Then at a later stage control is re-established and the various random sequences are stabilized as the guides to the genetic control of globulin synthesis by the cell line concerned. This is still during embryonic life when gamma globulins are not liberated into the blood and are produced only to the extent necessary to bring their specific patterns to the surface of the cell. It is at this stage that contact with any determinant associated with 
a body component or any foreign determinant artificially introduced results in the elimination of cells carrying such sites, and if all such clones are eliminated full tolerance is established.

The next phase is the gradual change in the response to contact with antigenic determinant. From the lethal effect seen in the early stage it changes, perhaps with an intermediate phase of damage and partial recovery, to stimulation of protein synthesis and, in the appropriate tissue environments, active proliferation to produce plasmacytoid cells and lymphocytes with active antibody-liberating capacity.

This sequence, shown schematically in Table 2, provides the outline of what can be called the clonal modification of Jerne's hypothesis or the clonal selection theory.

\section{Comparison of theories}

In comparing the four modern theories that I have outlined, the first requirement is a decision over the fundamental difference between the direct template theory and the other three. If antigenic determinants are needed to take a direct part in all antibody production, then there is no scope for discussion of the problem along genetic lines and no way of providing an interpretation of such phenomena as the nonantigenicity of self-components, immunological tolerance, cell-borne antibody or modification of antibody character with time and differing degrees of stimulation. As a general hypothesis to cover immunological behaviour, this theory is manifestly inadmissible. The only question that really arises is whether, on a background of one of the other three hypotheses, a new mechanism has been superimposed by which production of urgently needed protective substance may be accelerated. This might take the form of an enforcement of somatic mutation in the required direction in those cells whose natural pattern fitted best for this function. This would be a rather unhappy hybrid.

For reasons that have already been given, we believe that 
Jerne's theory in its original form is inadmissible until it has been provided with a cellular basis. It then becomes identical with the clonal selection hypothesis (theory 5). The common feature of the two 'biological' approaches, the indirect template hypothesis (3) and the clonal selection hypothesis (5), is that once antibody-producing capacity is implanted in a clone, cells of that clone respond by activation and proliferation when they have new contact with the appropriate antigen. This provides an evolutionary situation within which clones will wax and wane in size and activity in ways analogous to a mixture of bacterial clones in a common but changing environment.

A direct comparison between the indirect template theory and the clonal selection theory is more difficult than at first sight would seem likely. Once a potential antibodyproducing cell has been modified by the antigen so that it can give rise to antibody-producing descendants, we have a clonal situation even with the indirect template theory. The only essential difference between theories (3) and (5) is simply the origin of the primary specific patterns. In the clonal selection theory (5) they are pre-existent as a result of processes of embryonic development. The indirect template theory (3) gives each macrophage an inbuilt and somatically inheritable recognition mechanism which allows it to recognize and inactivate body components, perhaps by breaking them down into inert small molecular fragments. Unrecognized (foreign) macromolecules pass to the nucleus and induce genetic modification. The modified character is then passed to a cell of the lymphoid series, either by some mechanism resembling transduction or by actual conversion of the modified cell to a lymphoid stem cell.

Perhaps the best way to summarize the position is to say that there are two sets of observable phenomena which are crucial to the understanding of antibody production.

(i) The non-antigenicity of body components and the phenomena of prenatally induced tolerance. 
(ii) The persistence of immunological 'memory' over many years-for example, Davenport's phenomenon (Davenport and Hennessey, I956).

In addition, there is (iii), an accepted principle derived largely from modern work on adaptive enzyme formation in bacteria that the 'code' determining the pattern of all functional proteins is genetically provided.

The last of these is perhaps not to be regarded as a categorical requirement until a great deal more is known about genetic aspects of differentiation, but it would seem most unwise to disregard the principle unless absolutely forced to do so.

If we adopt it, we can in the first place accept some of the differences between individuals in the type or amount of antibody produced as being related to inborn genetic differences. Qualitative differences amongst gamma globulin molecules produced by the same individual may be ascribed (a) to the process of embryonic differentiation, $(b)$ to somatic mutation at any time during life. The equally or more important differences in the relative numbers of different types of gamma globulin molecule can be ascribed to $(a)$ selective proliferation of cells of certain clones as a result of specific stimulation, $(b)$ activation to produce and liberate globulin of cells of appropriate clones, $(c)$ transfer of genetic character from cells of one clone to those of another by some process of transduction in the broad sense.

Any hypothesis to incorporate such a point of view must take the form of a clonal selection theory. That can hardly be a matter for controversy. The principal difference of opinion will be whether it is or may become necessary to accept more active participation of foreign antigens in determining the emergence of antibody-producing clonesin other words, to graft something of the indirect template theory on to the clonal selection hypothesis. The possibility cannot be eliminated and if new experiments make it necessary to adopt such a point of view, the remoulding of genetic 
mechanism might be visualized in the fashion discussed by Burnet (1956) and by Schweet and Owen (1957). At the present time, however, there seems no reason to engraft such a grossly Lamarckian qualification on what might be described as a strictly Darwinian process at the cellular level.

\section{Cellular reactivity required by a clonal selection theory}

The mechanism by which contact with antigen can influence a cell of the corresponding clone must probably be sought from analogies with the various results that have been described by which antigen-antibody reaction will damage cells. The classic examples are immune haemolysis and the anaphylactic response. Haemolysis requires complement and in the classical demonstration of anaphylaxis by the SchultzDale procedure no addition of complement is necessary, though Becker (1957) feels that the presence of adsorbed complement on the reacting cells cannot be excluded. None of the reactions is yet adequately understood but it appears to be a valid generalization that reaction of antibody with antigen either incorporated in or attached to the cell surface initiates a process leading to some breakdown in the integrity of the cell surface with leakage of cell contents. In general the character of the response will depend on the type of cell; red cells can show virtually only haemolysis, mast cells liberate heparin, serotonin and histamine, while it seems likely that other mesenchymal cells may suffer damage of various degree up to necrosis. It seems likely that parenchymal cells are not affected directly by antigen-antibody reaction but only by the pharmacologically active agents liberated by the more generalized mesenchymal cells.

It is known that immunological reactivity can vary widely according to such factors as the age of the subject, the degree of exposure to antigen and the level of circulating steroid hormones. There is therefore no reason against the postulate that the type of reactivity changes characteristically with maturation of the body in the immunological sense. All that 
is being assumed is that each immunologically conditioned cell carries at some accessible sites reactive groupings equivalent to those by which an antibody globulin molecule attaches to the specifically corresponding antigenic determinant. When a reactive site makes specific adsorptive contact with an antigenic determinant, this union is assumed to act as a trigger initiating intracellular processes whose character and result will depend on the various factors already mentioned.

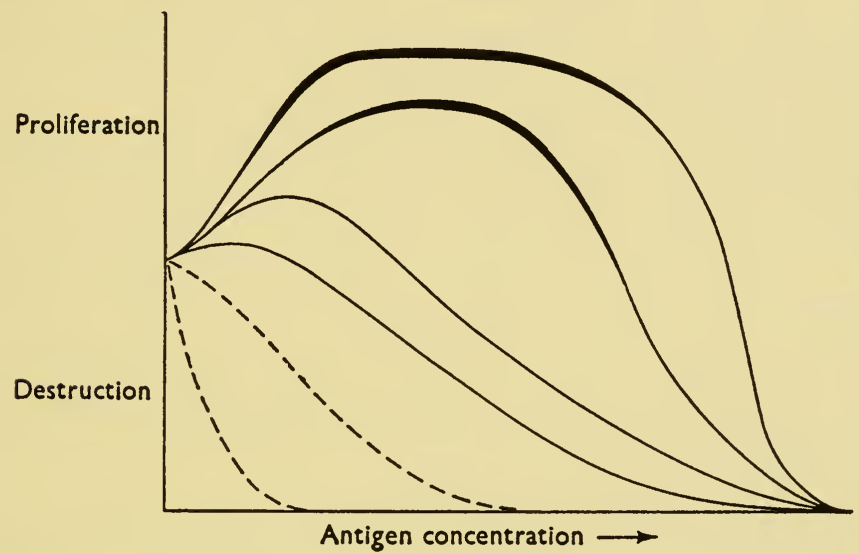

Fig. 8. The changing reactivity postulated for immunologically conditioned cells at various stages of maturity. (See text.)

Figure 8 has been devised to indicate the types of reactivity which need to be postulated to cover the various phenomena of immunological tolerance and of antibody production. The ordinates correspond to the main types of reactivity that are significant from the point of view of cell numbers. The zero point corresponds to no reaction, above this proliferation, and-where the lines are thickened-the development of plasma cells and antibody production, are indicated. Below the zero point we have inhibition of proliferation extending down to complete dormancy or destruction. The abscissae represent effective concentration of antigenic determinants. This will almost certainly be a complex function in which 
'goodness of fit' between reactive site and antigenic determinant plus the accessibility of the receptors to antigenic determinants under the existing conditions will play a part as well as usual measures of concentration of antigen.

The family of curves, beginning with the most steeply sloping broken line, is intended to represent immunological reactivity of immunologically conditioned cells at variousstages of the process of maturation. It is assumed without proof that curves shown in broken lines would depict eventual destruction of a stimulated cell, while continuous lines represent persistence of the cell line.

This diagram is of special interest in relation to work on the induction of non-reactivity by administration of a single dose of a pure antigen to rabbits at birth (Smith, 1958). Under these circumstances so long as an appropriate number of antigenic determinants are in contact with a cell, the cell is rendered dormant in two senses: $(a)$ it is incapable of developing into a plasma cell and producing antibody and (b) it remains at the same stage of immaturity as it was at the time of first contact with antigen.

In any workable form of the clonal selection theory it will be necessary to consider reaction with related patterns. All that is demanded of the primary differentiation or randomization of pattern is that a sufficient number of clones are produced to provide sites with a close enough fit to all possible antigenic determinants to allow some reaction. As long as it is possible by directed protein synthesis to secure a better fit, it is legitimate to look to minor somatic mutation to allow its emergence.

If, in fact, the concept of randomization of pattern in embryonic life is accepted, or even a complex genetically determined output of multiple globulin patterns arising by differentiation, then it would be in accord with biological probabilities to find an occurrence of relatively frequent (somatic) mutation in the range of loci concerned in this particular function of specifying pattern of gamma globulin. 
The combination of frequent minor mutation and a highly effective selective process would rapidly improve the accuracy of the complementary relationship to new antigenic determinants. The final distribution of patterned globulin molecules in the adult animal would on this view come to be almost wholly determined by the immunological history of the individual. Such a view would provide opportunity for many functional variations depending $(a)$ on the completeness or otherwise of the initial complement of prototype clones, something which might well be determined by the genetic make-up of the individual; $(b)$ on changing capacity to mutate with advancing age. It may be relevant that Sabin et al. (1947) found that elderly Japanese men produced an antibody against Japanese encephalitis $B$ vaccine only if they had evidence of past infection by the virus.

\section{Summary}

The clonal selection theory of antibody production is based on the concept that the antibody-producing cells of the body form part of a mobile population of mesenchymal cells constantly undergoing physiological and mutational change.

When mutational change occurs a new clone is initiated. It is postulated that mesenchymal cells carry surface sites analogous to the specific patterns on the antibody globulins they produce. Stimulation by contact of these sites with the corresponding antigenic determinant may provoke more than one type of response, but the crucial one is the proliferative response which allows a selective advantage to the clone concerned.

The theory differs from the standard interpretation of antibody production in replacing the concept that in one way or another the antigen actively enforces production of a new pattern of specific globulin, by the view that somatic mutation and selection within the mesenchymal cell population can have the same overall effect. 


\section{REFERENCES}

Becker, E. L. (1957). 7. cell. comp. Physiol. 50, Suppl. I, 303.

Bhende, Y. M., Deshpande, C. K., Bhatia, H. M., Sanger, Ruth, Race, R. R., Morgan, W. T. J. \& Watkins, Winifred M. (I952). Lancet, $\mathbf{I}, 903$.

Burnet, F. M. (1956). Enzyme, Antigen and Virus (Cambridge).

Burnet, F. M. (1957a). Austral. 7. Sci. 20, 67.

BurNet, F. M. (1957b). Brit. med. 7. 1, 779, 841.

Burnet, F. M. \& Fenner, F. (I949). Production of Antibodies (2nd ed. Macmillan, Melbourne).

Davenport, F. M. \& Hennessey, A. V. (1956). F. exp. Med. 104, 95.

Dunsford, I., Bowley, C. C., Hutchinson, A. M., Thompson, J. S., SANGER, R. \& RAce, R. R. (1953). Brit med. 7. 2, 81.

Gajdusek, D. C. (1958). Arch. int. Med. 1or, 9.

Gowens, J. L. (1957). Brit. J. exp. Path. 38, 67.

Haurowitz, F. (1952). Biol. Rev. 27, 247.

Humphreys, J. H. \& Macfarlane, A. S. (1954). Biochem. 7. 57, I 86, I 95.

Jerne, N. K. (1955). Proc. nat. Acad. Sci., Wash., 4I, 849.

LANDSTEINer, K. (1936). Specificity of Serological Reactions (Baltimore).

Pauling, L. (1940). 7. Amer. chem. Soc. 62, 2643.

Sabin, A. B., Ginder, D. R., Matumoto, M. \& Schlesinger, R. W. (1947). Proc. Soc. exp. Path. 65, 135.

Schweet, R. S. \& Owen, R. D. (1957). F. cell. comp. Physiol. 50, Suppl. I, 199 .

Simonsen, M. (1957). Acta path. microbiol. scand. I1, 480.

Sмith, R. T. (1958). Fed. Proc. 17, 535.

Talmage, D. W. (1957). Annu. Rev. Med. 8, 239. 


\section{V \\ IMPLIGATIONS OF THE GLONAL \\ SELECTION HYPOTHESIS}

The preceding chapter contains a general account of the clonal selection hypothesis. In the next three chapters an attempt is made to examine in some detail a rather wide range of immunological topics in terms of the hypothesis.

The primary objective was, of course, to find situations from which it could be deduced that one or other of the current hypotheses was clearly inadmissible. So far this has proved impossible of accomplishment.

All experimental work on antibody production has necessarily been compelled to employ large natural populations of cells of diverse origins irrespective of whether experiments are carried out in vivo or in vitro. Under these circumstances it seems unlikely that any experimental decision will be possible as between the indirect template hypothesis and the clonal selection hypothesis. It is easily seen that once the capacity to produce antibody has been developed in a cell the implications of the two theories are virtually identical. The difference concerns only the way in which a primary immunization is effected. Is the new pattern produced by a direct impact of antigenic determinant pattern on the protein synthetic mechanism-or does the antigenic pattern act purely as a selective agent on material provided by spontaneous mutational processes? Only by the use of a pure clone technique of tissue culture which allowed mesenchymal cells to retain full functional activity would we be likely to find an answer.

The clonal selection hypothesis would be completely validated if it could be shown that single cells from a nonimmune animal gave rise to clones, each cell of which under proper physiological conditions contained, or could liberate, 
antibody-type globulin of a single pattern or at most of a uniform small range of patterns.

It could be disproved by showing that cells of a pure clone could, by appropriate manipulations, be induced to produce any one of a variety of antibodies.

Until such methods of handling pure clones in vitro are available, choice between the current hypotheses can only be on the basis of their convenience in co-ordinating phenomena and their heuristic value in stimulating new experimental approaches. It will therefore be essentially from these two points of view that the topics in this chapter will be treated.

\section{The secondary response and cognate phenomena}

One of the first objections which might be raised against the clonal selection hypothesis is its failure to give due weight to the difference between primary and secondary responses. On the simplest form of the hypothesis, all responses could be said to be secondary in type, the only difference being a quantitative one. The primary stimulus finds only a few examples of the appropriate clones; by the time of the secondary stimulus many more individuals of the selected clones are accessible. In fact, however, there appears to be an additional qualitative factor. Coons' studies on the intracellular demonstration of antibody by the 'sandwich' technique of fluorescent staining (Coons, Leduc and Connolly, I 955) led him to differentiate very sharply between primary and secondary response. In his view, the secondary 'stimulus acts as a trigger mechanism which detonates a remarkable biological event engaging many cells in the area' in contrast to 'the paucity of cells engaged in antibody synthesis during the primary response'. Coons holds that antibody response is a function of the plasma cell family, a cell type which does not exist except for this function and which conceivably may be called into existence only by a secondary antigenic stimulus. In the previous chapter we have described the behaviour of staphylococcal toxoid as an antigen and cited 
the opinion that the primary response might not be a production of antibody at all but a 'tooling-up' to allow response to a secondary stimulus. A similar conclusion might be drawn from the results of immunizing mice with bacteriophages used to construct Figure 4 .

If we attempt a more specific interpretation, it would take the form that the commonest result of primary contact of an antigenic determinant with a cell carrying potentially reactive sites is to stimulate it to proliferative activity with the production of a greatly increased number of cells of the clone, but lymphocytic rather than of plasma cell type. The switch to proliferation in plasma cell form takes place when these activated lymphoid cells make a new contact with the same antigen. Where antigen is being liberated from a depot in the tissues over a period of days or weeks, the observed response will be essentially secondary in type even if only a single inoculum has been given.

Further elaboration of this theme is better left till the anamnestic reactions are being considered, but it may be useful at this stage to draw attention to the interesting similarity of this interpretation to that now current in regard to the production of some adaptive enzymes by bacteria.

In the case of $\beta$-galactosidase of Escherichia coli, its induction by an appropriate inducer is a complex matter best elucidated by the use of an inducer such as TMG (thiomethylgalactoside) which is not a substrate of the enzyme induced. The first phase of induction is the activation by the inducer of a surface change in the bacterium, presumably a result of the action of an induced enzyme (permease). Once this action has taken place the inducer is in a position to evoke or uncover the production of $\beta$-galactosidase. The important point relevant to the difference between primary and secondary response to antigen is that once permease has brought a bacterium to the inducible state, a culture genetically unchanged can be made to continue indefinite production of $\beta$-galactosidase in a medium containing a low 
concentration of inducer which would be ineffective in producing the primary (permease) effect and therefore induce no $\beta$-galactosidase production by the unmodified strain (Novick and Weiner, I957).

There is nothing to suggest that any detailed resemblance to the adaptive enzyme situation is involved, but one can readily imagine that once a genetically 'competent' mesenchymal cell is stimulated specifically by antigen, a transmissible (? cytoplasmic) condition might be induced which would allow more direct activation of the descendants to proliferate and produce antibody.

\section{Anamnestic responses}

There is a good deal of confusion in the literature in regard to whether any stimulus other than specific antigen can provoke a rise in antibody titre in an animal previously immunized with that antigen. There is much to be said for the view expressed by Fischel, Lemay and Kabat (I 949) that if a single antigen, in their case crystalline ovalbumin, is used, no antibody rise is produced by steroid hormones or other non-specific stimuli.

They did not, however, carry out the more interesting experiment of seeing to what extent related antigens, for example, fowl serum albumin, duck ovalbumin and bovine serum albumin, could provoke a secondary rise and whether that rise was due to antibody reacting preferentially with the first or with the second antigen. This was subsequently done by Dixon and Maurer (1954) and their results will be discussed later.

This topic is one of the greatest importance for any clonal approach to antibody production. In the application of any such theory, it will be necessary to know:

(i) the size and complexity of the average antigenic determinant, which will be defined as the portion of the antigen complementary to a given reactive site on an antibody molecule, 
(ii) whether more than one type of specific site can exist on a single antibody molecule,

(iii) how many types of antibody can be produced by a single cell, and if more than one what the mechanism is by which the cell is stimulated to produce them. For example, if a cell can produce two distinct antibodies, $a$ and $b$, will stimulation of the cell by $A$ result in the liberation of $a$ and $b$ or only of $a$ ?

In order to simplify discussion, we shall assume that antigenic determinants are relatively small and that the specificity of a serum depends largely on the constitution of the antibody population, not on the existence of a single type of antibody molecule. An antigen $A B C D$ will provoke an antibody population which may be represented $a b c d$. These in turn may be derived from separate clones of cells for $a$, and for $b, c$ and $d$, or from a clone, each cell of which can produce $a, b, c$ and $d$ antibody molecules.

The evidence on these points comes largely from studies of immunity to virus disease in which the antigens involved are admittedly poorly defined. Such virological studies can, however, give striking and reproducible results and they will be discussed in some detail. Before doing so, however, it is desirable to examine experimental work in which Dixon and Maurer studied the type of response to a number of purified antigens given in different sequence.

In general, they found that unrelated antigens-for example, egg albumin and human serum albumin-showed no mutual influence when used as antigens one after the other. If, however, bovine serum albumin (BSA) and human serum albumin (HSA) were used, the response to the second antigen was strongly modified. With BSA given first, injection of HSA intravenously (a) results in a moderate increase of anti-BSA, some of which is specific in the sense that it cannot be absorbed by HSA, (b) produces anti-HSA, including specific antibody, more rapidly than would be the case with a primary response, and (c) gives a much higher proportion 
of antibody precipitable by both antigens than is found with any monovalent serum. Instead of at most $15 \%$, the proportion of doubly reacting antibody is always higher and often over $50 \%$.

To account for such results, one could represent the two antigens as each having three types of determinant $B S A$ and $H S^{\prime} A^{\prime}$ in the sense that $S$ and $S^{\prime}$ are sufficiently similar that a commonly occurring mutation may change $S$ - to $S^{\prime}$-producing cells and vice versa. $A$ and $A^{\prime}$ have an equivalent relation, $B$ and $H$ are quite distinct.

On any clonal selection hypothesis BSA will produce cells conditioned to produce $b, s$ and $a$, but with a large proliferation of these clones a significant proportion of $a^{\prime}$ and $s^{\prime}$ cells will also appear. This will allow the possibility that either HSA or BSA will be able to evoke a secondary type response. The fact, however, that HSA provokes an increase in specific BSA antibody must indicate that clones of cells exist which, when stimulated by one antigen, can produce another. If we use lower-case letters to represent the antibody types corresponding to each antigenic determinant, it must be assumed that clones of the type $a b, a a^{\prime}, a^{\prime} b, a^{\prime} s, a s^{\prime}, s b, b s a^{\prime}$ are in existence at the time of the second stimulus and that when a cell of clone $a^{\prime} b$ is stimulated by $A^{\prime}$ (of HSA) in addition to $a^{\prime}$ globulin molecules $b$ will also be liberated. As long as we keep within the framework of a clonal selection hypothesis, no other type of explanation seems to be available.

A similar conclusion that a single cell can produce two types of antibody molecule, both being liberated by stimulation with either antigenic determinant, can be drawn from the virological work.

The first group of observations can be conveniently brought together under the name of Davenport's phenomenon or, if preferred, under Davenport's own description of it as the 'doctrine of original immunologic sin'. When someone has an attack of influenza $A$ or is given an immuniz- 
ing injection of an influenza $A$ vaccine, his serological response depends mainly on what 'family' of influenza $A$ viruses he first encountered. People in their fifties at the present time give a response to the antigen we call 'Swine' which we believe was characteristic of the virus responsible for the I9I8-19 pandemic. Young men in their twenties respond with antibody against $P R 8$ type current in the thirties and children to type $F M_{\text {I }}$ which emerged in 1946. Today's babies will presumably be stamped with the mark of Asian $A$ influenza for the rest of their lives. There are many minor discrepancies in individual reactions but the general pattern is fully established.

Suppose we consider a person who has been exposed to three successive 'families' of influenza $A$ virus; we can give these viruses the antigenic formulae $A B C D, A B E F, A E G H$. As a result of the first infection, antibody sites $a, b, c$ and $d$ are available in one form or another. The response to the entry of antigen $A E G H$ is to call forth again $a b c$ and $d$, with perhaps small amounts of $e g$ and $h$. This could be represented conventionally by assuming that cells carrying $a$ also carry $b c$ and $d$, so that stimulation by $A$ results in the replication of cells which will provide antibody more equivalent to $A B C D$ than to the actual infecting antigen $A E G H$. This is the simplest formal explanation but other variants of the same theme could be devised.

A related finding from Jensen et al. (1956) has a similar form but introduces a further complication. If an animal is successively immunized with strains $A B C D$ (1), $A B E F$ (2) and $A E G H$ (3) and the antibody titres examined, the result will be as shown in Figure 9. Now if the final serum is absorbed with each of the three strains, the important result is that strain ( $\mathrm{I}$ ) alone is capable of absorbing out all the antibodies against (I), (2) and (3).

If we examine this result in terms of the clonal selection theory, we must assume that the clones concerned were sorted out by $A B C D$ and can be represented as $a, a b, a c d, a b$, 
$a b c$, etc. When appropriately stimulated these will give globulins $a b c$ and $d$. Extension of the argument to the serum after triple immunization, however, meets serious difficulties. Since $A B C D$ absorbs the antibody completely, all antibody molecules must have $a b c$ or $d$ quality. Yet the facts are that new reactivities have been added to the globulin population by the immunizations with (2) and (3). It is clear that no explanation with globulin molecules indicated as simple units will suffice.

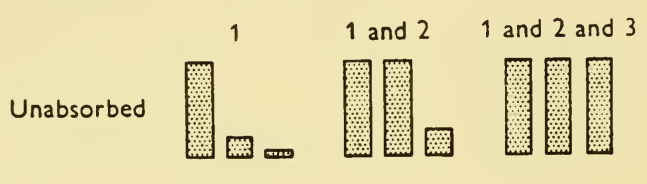

Absorbed 1

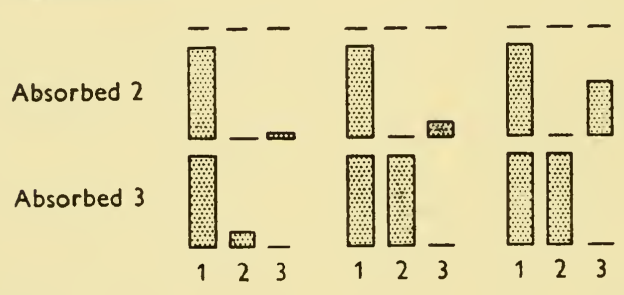

Fig. 9. Successive immunization of ferrets by three influenza strains (1), (2), (3) (after Jensen). Bars indicate anti-haemagglutinin titres against influenza virus strains (1), (2) and (3), using sera unabsorbed and absorbed as shown.

If we switch Jensen's own explanation into terms of the present theoretical approach, it is that the same clones responsible for antibody to (I) are concerned in responding to (2) and (3). If $a b c$ and $d$ are sites corresponding to virus (I) $(A B C D)$ then the change to fit virus (2) must involve the modification of some of sites $c$ and $d$ to modified forms $c^{\prime}$ and $d^{\prime}$. These are sites which can now fit determinants $E$ and $F$ respectively of the new strain as well as $C$ and $D$ of the old. Similarly, to react with the third strain, $A E G H$, we have to assume such a further modification of the antibody popula- 
tion that a proportion of sites $b^{\prime} c^{\prime}$ and $d^{2}$ develop. If we now tabulate:

Serum (I) $a b c d$

(2) $a b c c^{\prime} d d^{\prime}$

(3) $a b b^{\prime} c c^{\prime} d d^{\prime} d^{2}$
Serum (3) absorbed with

$A B C D$

$A B E F \quad c d d^{2}$

$A E G H \quad b c d d^{\prime}$

we obtain a formal representation of the results in Jensen's experiment as well as an indication of the nature of Davenport's phenomenon, namely, that the original components $a b c$ and $d$ still dominate the mixture.

The only visible mechanism is some form of somatic mutation. Any cell of clones corresponding to $a, b, c, d$ or complexes thereof in which a mutation to broader reactivity (allowing reaction with (2) or (3)) has occurred will be preferentially stimulated to proliferation. Equally it is only in clones of the types that have responded to $A B C D$ in the past that the minor mutations needed to fit a new $A$ type virus are likely to have occurred. These experiments of Jensen's appear to provide substantial support for the view that, provided the fit between antigenic determinant and cell receptor is good enough to start a process of selective proliferation, this will result in a sufficient scatter of mutations to allow the emergence of a better fitting type of cell receptor (and antibody) with considerable speed.

A related phenomenon not as yet so intensively studied concerns the broadening of antibody response that is seen after infection with a second serotype of the ARBOR viruses of Casals' group $B$ (Casals, I957). Here it seems that first infection, say with Dengue I virus, gives a relatively specific response, but if this is then followed by an Ilhèus virus infection the subsequent serum is likely to neutralize yellow fever and many of the other type $B$ viruses as well. The interpretation here will be that if several types of reactive site can change by mutation and selective survival to fit two modifications of the determinants concerned, then they are likely to show as well an increased reactivity to other 
related determinants. It may be that this evidence of increased immunological reactivity with a new type of antigen, never actually experienced as an antigenic stimulus, will be of some value in convincing those with a firmly Lamarckian attitude to antibody production of the potentialities of preadaptation by 'chance' mutation.

To complete the type of experimental evidence having some bearing on these questions, we may add the finding that so far it has not been possible to show that a single globulin molecule will react with two distinct and unrelated antigens even when they are inoculated together, nor that a single cell can produce an antibody population that will react in this double fashion.

If we attempt to pull together this rather fragmentary evidence into a coherent interpretation, it may emerge in the form of two general conclusions:

(i) The clones 'produced' as a result of a virus infection are composed of cells which have active sites corresponding to several of the antigenic determinants.

(ii) Active sites can be modified so that the globulin produced is capable of reacting with various modifications of an antigenic determinant pattern.

If (i) is correct, it has a very important implication, namely, that some means of transferring a genetic potentiality from a cell of one clone to a cell of another must exist. Such a capacity has always been recognized as something which might be needed to account for aspects of antibody production, though its use, for example in Burnet and Fenner (1949), was in distinctly different fashion from what is being suggested here. The working hypothesis would be that in the lymph node to which influenza virus particles and various antigenic fragments will be brought, clones with $a b c$ and $d$ prototype sites will be stimulated to proliferate. Cells from all will be in close mutual contact and replicating. Transfer of a specific inheritable capacity from one to another could be envisaged at either nuclear or cytoplasmic level. The only 
reason for preferring the nuclear alternative and postulating something equivalent to transduction rather than the transfer of a self-replicating cytoplasmic entity, is that it is in line with the current climate of opinion on such matters. Differentiation is now regarded as being associated with nuclear changes, and in bacteria, where induced changes and interactions between organisms have been most adequately studied, it is striking that with one doubtful exception all have been shown to be of nuclear type. Transformation, recombination, transduction, lysogenesis, all represent modifications of the central genetic control. The long persistence of immunological memory points in the same direction. And there is the widespread intuition that where a cytoplasmic unit seems to be self-replicating it possesses that privilege only while the conditions for it are maintained appropriately by the nucleus.

It has already been noted that the widespread sensitivity of mesenchymal cells from tuberculous animals to P.P.D. damage must represent the transfer of something from the primary clones of cells. In this case we have the alternative that a globulin with high affinity for the surface of other mesenchymal cells may be liberated, and that we are concerned not with a genetic phenomenon but merely with a reaction between antigen and antibody at the surface of a cell. This seems the more likely but the possibility of a widespread genetic transduction cannot be excluded.

If Medawar's (1957) opinion is correct that the effective antigen in homograft immunity is a DNA nucleoprotein, we must postulate that there is a constant traffic of such nucleoprotein within the body. The breakdown of a tolerated homograft, for instance, when a normal lymph node is implanted in the tolerant host, must mean that an antigen from the alien cells of the graft is constantly being set free. Directed transduction by nucleoprotein liberated from replicating cells might well play an important role in differentiation and the various modifications of mesenchymal cell function that are called for in health and disease. 
The second postulate, that active sites on cell surface or globulin molecule can be modified to a wider reactivity by somatic mutation, provides the chief agent to allow change in antibody character as immunization proceeds. If the primary postulates of the clonal selection theory are accepted, such a result of somatic mutation is as much in order as any other.

\section{The action of adjuvants}

There is no doubt that by incorporating an antigen in a variety of mildly irritating and depot-producing substances more antibody can be produced, and with a number of antigens this is the only practical way of obtaining a reasonably active serum. According to the classic Haurowitz and Mudd theory of antibody production, the general explanation of this phenomenon was that it was a complex action in which the most important factor was probably the prolonged maintenance of a depot of antigen. The local accumulation of a variety of mesenchymal cells could also be expected to facilitate the intracellular processes concerned.

On the clonal selection hypothesis, the first assumption will be that 'sites' corresponding to the determinants of antigens requiring adjuvants are present in very few clones. In line with what has already been said in discussing secondary responses, it is highly probable that minor degrees of somatic mutation are constantly occurring, so that we can retain the possibility that mutation and selective proliferation may eventually build up, from parental cells with only minor reactivity, clones which react well with certain determinants. For such a process to occur the main requirement is simply time and opportunity. If we have a clone with a reactive site not quite appropriate to determinant $D$, but sufficiently close for contact to provoke activation and proliferation occasionally, cells of this clone will multiply more rapidly on the average than other clones. Mutation within the clone will be more likely to occur and any favourable 
mutation will automatically be strongly favoured while antigen at appropriate concentration persists in the body. In this way we can picture a slow appearance of antibody in an animal which, by normal methods, would fail to produce any. The effect of the adjuvant is essentially to ensure that antigenic determinants are being made accessible at a more or less steady rate for a prolonged period. Each minor mutation in the right direction is thereby persistently favoured for survival, and, provided such mutations are biologically possible, an appropriate antibody will eventually be produced.

A point of interest is that in some instances antibody production is slight or absent in the lymph node draining the area in which the antigen plus adjuvant is deposited but is active in distant lymph nodes (Askonas and White, I956). (See chapter vin, section 7.)

It may be desirable at this point to discuss the extent to which modification of clonal patterns by somatic mutation should be included as an essential part of antibody theory. There is no biological objection that can be raised against the occurrence of minor somatic mutations. Research on various aspects of cancer makes it certain that such mutations are constantly occurring in any population of cells which is in a suitable situation for the appearance of the mutant to be recognized. Law's work on the appearance of radio-resistant or drug-resistant lines of malignant cells is the most striking only because the experimental set-up is particularly well designed to demonstrate the type of mutant which is prospering.

Similarly, the type of mutant we are postulating here is also in a position to prosper excessively. If the right mutation occurs the cell in question is, in the presence of the antigenic determinant, given a major advantage in the struggle to produce a larger clone of descendants than its congeners. If our general hypothesis is correct, there is no escape from the picture of the mesenchymal cells of the body as an 
evolving population as subject to mutation and selective survival in all their complications as any large animal population in nature. The initial population may be determined, say, at the beginning of immunological maturity by the stabilization of wholly random patterns from which those reacting with body determinants have been withdrawn. With the first impact of infection, however, the clonal pattern will be altered, first by simple selective survival and subsequently by the combination of somatic mutation and survival. As in every other evolutionary situation, the occurrence of neutral or deleterious mutations is quite unimportant, no matter how frequently it occurs. It is only the mutant which finds its opportunity to proliferate when the appropriate antigen is in the internal environment that is significant in changing the balance of the mesenchymal clones within the body.

In many ways the effect of adjuvants seems likely to provide an important field for comparison of the implications of template and selection theories. It could be said, for instance, that on any template hypothesis, if an animal can produce antibody as a result of the use of adjuvants, it should also be capable of doing so without adjuvants. To account for the facts on this hypothesis it seems that we must wait until a mutant clone of cells appears which differs from the normal in being able to incorporate the template and produce antibody. This is virtually to accept most of the clonal selection hypothesis.

Another line of thought might be that the presence of the adjuvant materials attracts a local accumulation of predominantly monocytic cells. Antigen taken into these cells is converted, according to one elaboration of template theory, into a form which can be taken as template into a cell of the lymphocyte-plasma cell series. It could be argued that the much larger number of monocytes which could have experience of the antigen would increase the chance that some of it was converted into the necessary modified form. It should not be difficult to find experimental situations to differentiate these possibilities. 


\section{Local immunity}

This is a term which has been used in rather indefinite fashion, but for the present purpose it will be applied essentially to the only example which has been well studied in recent years-intestinal immunity against polio viruses. The evidence is clear that by immunization with formalin-killed polio vaccine, circulating antibody is induced and effective immunity provided against the paralytic disease. No resistance is induced to implantation of homologous virus in the bowel. This so far has been induced only by actual intestinal infection with virulent natural virus or by the administration of attenuated variants. To date there is virtually no factual knowledge of the physiological and serological basis of this local immunity. It appears to be type specific and therefore to be mediated by an immunological mechanism. The only fragment of probably relevant data is that the virus can multiply in the lymphoid tissue of Peyer's patches, but it will be taken as axiomatic that this immunity is mediated by mesenchymal cells and/or the globulins they produce.

It is characteristic of all mucous surfaces which are in contact with a contaminated or potentially contaminated environment that in the submucosal tissue there are collections of lymphoid and plasma cells ranging from scattered cells to single lymph follicles and larger accumulations such as the Peyer's patches of the small intestine. The final stage is reached in the specialized accumulations of lymphoid tissue, the tonsils and the appendix. In all these situations there is usually clear evidence that lymphocytes or any product of their functioning can readily pass into the lumen of the viscus or on to the surface exposed to the environment. Over a Peyer's patch, for instance, the intestinal epithelium is heavily infiltrated with lymphocytes, many of which are clearly passing into the intestinal lumen. If antibody is being produced by the plasma cells, which are numerous in the Peyer's patches, it must be leaking into the lumen by the 
same route. Similarly if histology is any guide, lymphocytes and their products must continually be oozing into the cavity of the appendix and the crypts of the tonsil-presumably for a purpose.

There are two other situations where plasma cells are reported to be conspicuous. The first is in relation to the mammary gland. Campbell, Porter and Petersen (1950) observed in the bovine udder at the time of calving numerous plasma cells in the interstitial tissue between the lobules of the gland. At this time the colostrum with its high content of antibody is being produced and there is perhaps special likelihood of infection being present in the gland. Some weeks later biopsy of the lactating udder showed no such accumulation. The second is from an observation of Bowden and French that in children dying after influenza the seromucous glands of the trachea and bronchi show interstitial accumulations of plasma cells (French, 1958).

All these findings seem to point in a specific direction. The suggestion that these varied lymphoid accumulations have some sort of protective function has been current for many years but there has never been an adequate immunological background to provide any detail to the contention.

In terms of the clonal selection theory, any lymphocyte in the submucosal region which is 'tuned' to react with a determinant from an infective agent in the region will tend to be activated and fixed in the tissue. By a natural process of selective proliferation the population of lymphoid cells in the submucosal accumulations will come to carry predominantly reactive sites corresponding to antigenic determinants that have been associated with past micro-organismal invasion of the surface in question, perhaps specially with viral infection. If these sources of antibody are continually providing an outflow to moisten the surface, there is available a simple explanation of local immunity to polio and other intestinal viruses.

The danger of invasion must be common to the whole 
surface, not concentrated on the points where lymphoid follicles occur, so that we must regard the focal rather than diffuse distribution of the lymphoid tissue as having one or both of two reasons. In the first place they must represent a focal distribution of a mechanism which can distribute the immediate protective agents uniformly over the whole mucous area concerned. This must be common to any interpretation and a plausible expansion of the idea is that there is continuous seeping of protective substance on to the mucosal surface, where it spreads between the cell surface and the protective film of mucus. This will probably allow the maintenance of a high concentration of antibody or other protective globulins in the region where it will be most effective. The reasons for the focal nature could be $(a)$ that this does the least harm to the physiological functioning of the viscus concerned or $(b)$ that there are immunological functions which can only be served when a germinal centre develops, that is, are only possible in a lymphoid follicle or larger accumulation.

Since the movement of locally produced antibody is to the lumen, it will not necessarily be reflected in a similar antibody level in the blood. Similarly, unless the pathogen (antigen) comes from the lumen, this mechanism cannot be laid down. Parenteral vaccination would therefore not be expected to produce intestinal immunity to anything like the same degree.

The logical extension of this point of view is to bring into the picture the glands responsible for part of the moistening and lubrication of the surfaces. We have been particularly impressed by the plasma cells in immediate relation to the tracheal glands in influenza-since it would be completely in line with current thought about the nature of immunity to influenza if a large component of the antibody known to be present on the respiratory epithelium were derived from local production as well as, or instead of, from the general circulation. Of even greater interest is the possible role of the 
tonsils and the appendix as two strategically situated major sources for the liberation of what might almost be called antiseptic paint for the protection of the walls of the adjacent cesspools.

\section{REFERENCES}

Askonas, B. A. \& White, R. G. (1956). Brit. F. exp. Path. 37, 6 1. Burnet, F. M. \& Fenner, F. (1949). Production of Antibodies (2nd ed. Macmillan, Melbourne).

Campeell, B., Porter, R. M. \& Petersen, W. E. (1950). Nature, Lond., 166, 9 I 3 .

Casals, J. (1957). Trans. N.Y. Acad. Sci. 19, 219.

Coons, A. H., Leduc, E. H. \& Connolly, J. M. (1955). 7. exp. Med. ro2, 49 .

Davenport, F. M. \& Hennessey, A. V. (1956). F. exp. Med. 104, 95. Dixon, F. J. \& Maurer, P. H. (1954). F. Immunol. 74, 4 I8.

French, E. L. (1958). Personal communication.

Fischel, E. E., Lemay, M. \& Kabat, E. A. (1949). F. Immunol. 6r, 89. Jensen, K. A., Davenport, F. M., Hennessey, A. V. \& Francis, T. (1956). F. exp. Med. ro4, 199.

Medawar, P. B. (1957). Ann. N.Y. Acad. Sci. 68, 255.

Novick, A. \& Weiner, M. (1957). Proc. nat. Acad. Sci., Wash., 43, 550. 


\section{VI}

\section{IMMUNOLOGICAL TOLERANGE AND}

\section{RELATED PHENOMENA}

\section{Homograft immunity and tolerance}

A summary has already been given of the work on the antenatal induction of tolerance in mice by Medawar's group. Taken along with the findings in natural chimaeras resulting from twin pregnancies in cattle, sheep and, rarely, in man, it is now possible to state that foreign cells implanted before a certain critical stage in prenatal development can survive without provoking the normal immune response and will render the animal tolerant to a skin graft from the strain supplying the foreign cells (Billingham, Brent and Medawar, I956a). Recent work, however, is developing a keener interest in the necessity for mutual development of tolerance between host and graft (Brent and Billingham, 1957). Many of the animals rendered tolerant by the inoculation of spleen cells of a foreign strain showed a marked atrophy of lymphoid tissue, loss of weight, low-grade diarrhoea and eventual death. The interpretation is presumably that the implanted splenic cells include many representatives of antibody-producing clones, some of which are stimulated to produce antibody against host components which are not represented in the graft. To obtain the desired experimental result in which the experimental animals remain healthy and tolerant of the graft, a mutual tolerance must be established. The mechanism of graft tolerance of the host has yet to be worked out.

It is already clear that the nature of the strains of mice concerned is vitally important. Billingham (I958), for instance, finds that when $A$ strain mice are intravenously inoculated on the first day of life with cells from strain $C B A$, 
a majority of the mice develop tolerance to skin grafts from $C B A$. On the other hand, if $C_{57}$ mice are used as donors to new-born $A$ mice, an intravenous inoculation of spleen cells is virtually always productive of 'runt disease' and very often the mouse dies rapidly. In order to produce the effect mature lymphoid tissue must be used. A point of very great interest is that thymus cells are fully competent to produce it; in other words thymocytes are functionally as well as morphologically equivalent to lymphocytes.

The indications are strong that the antigens concerned in homograft immunity (that is, those concerned in provoking accelerated rejection of a graft in an immunized animal) are the same as those involved in tolerance phenomena. This makes the recent finding of Billingham et al. $(1956 b)$ that the antigen involved in homograft immunity appears to be a DNA-nucleoprotein, of special interest. If to a white mouse of strain $A$, rendered tolerant to, and carrying a skin graft of, strain $B$ (black), a second graft of lymph node from a normal strain $A$ mouse is made, an immune response against $B$ cells develops and the graft is destroyed. This suggests strongly that, presumably at each mitosis, potentially antigenic nucleoprotein molecules are liberated into body fluids, that an important part of the development of tolerance to body constituents is directed toward these and that the nucleoprotein antigens are capable of producing only cell-borne antibody. There is an insistent suggestion here that the liberated DNA nucleoprotein molecules may play an important role in the mutual control of cellular growth, and that special mesenchymal ceil clones may be differentiated during development to deal with any anomalous liberation of such material.

Since all modern theories of antibody production are designed to allow an interpretation of tolerance, it is unnecessary to elaborate how the clonal selection theory functions in this respect. It is more important to consider the production of X-ray chimaera and the various phenomena of partial tolerance. 
When mice are given a certainly lethal dose of 90o-I ooo $\mathrm{r}$ whole body X-radiation, they can be saved by injection of bone-marrow cells from a normal mouse. Bone marrow from mice of the isologous strain is most effective but cells from other strains are often satisfactory. In such cases the mouse (Ford et al. 1956) can be shown to have adopted the foreign cells permanently and to have developed tolerance to a graft of the donor skin (Main and Prahn, I955). Graft intolerance of the host is very frequently shown in these experiments. When the donor has been immunized and is producing antibody, the new host will show the appearance of and increase of this antibody (Mitchison, cited by Ford et al. 1956). Rat bone marrow may be used to save mice and in satisfactory experiments it can be shown that rat gamma globulin is being produced (van Bekkum and Vos, I 957).

In most instances the rat cells in such mice are eventually replaced by mouse cells.

It will be obvious that while this is happening some form of tolerance must have been developed by the graft cells producing rat antibody for the mouse albumin still circulating and other accessible mouse determinants. This is part of the problem discussed in the next section.

On the clonal selection theory one assumes that in lethally irradiated animals there is an elimination of the vast majority of representatives of all antibody-producing clones and the foreign cells have an opportunity to become implanted and apparently overwhelm the few host survivors that can react with the foreign determinants that have been introduced. It is of much interest that when the irradiated mouse has been previously immunized with tissue of the donor strain, then the foreign bone marrow cannot save the irradiated mouse. This, on the clonal selection theory, would mean that the immunized mouse has a large population of cells of the appropriate clones, many of them perhaps in the less radio-sensitive form that seems to be associated with 
immunological functioning. Sufficient survivors would exist to damage the foreign cells and prevent their effective establishment.

\section{Tolerance to antigens not associated with implantation of genetically foreign cells}

It has not proved easy to demonstrate immunological tolerance to antigens other than those associated with living cells distinct from, but related to, those of the host.

We may first outline the facts which have been established by the use of red cells as antigen. In view of the fact that Woodruff and Simpson (1955) have shown that tolerance to skin graft can be established in rats up to 14 days after birth, this species has been extensively used. Bauer, Peckham and Osler (1956) showed no development of tolerance if a single dose of sheep cells were given either prenatally or immediately after birth and were inclined to doubt the existence of any tolerance phenomena with such antigens. Nossal (1958) in my laboratory has studied this system extensively, and finds that with $\mathrm{C}_{3} \mathrm{H}$ mouse cells as antigen, lasting tolerance can be produced by a series of injections beginning immediately after birth and continuing twice weekly for eight weeks. A three weeks course shows distinct evidence of partial tolerance but much less than with the longer course. There is no evidence to suggest that continuing tolerance depends on the presence of antigen in the body 'mopping up' antibody as it is produced. Passive administration of antiserum to tolerant and normal rats shows a disappearance of antibody at the same rate in each group and results in no subsequent modification of response. Older rats given massive doses of antigen showed no evidence whatever of any inhibition of the immune response. The fact that in one series rats were still fully tolerant eight months after birth, and more than three months after the last injection of antigen, in itself speaks strongly against any suggestion that sufficient residual antigen is present to absorb any antibody 
produced. Studies with bacterial and viral antigens have usually failed to demonstrate tolerance, although Buxton's (1954) positive findings with a Salmonella pullorum vaccine in chick embryos should be mentioned. In fact, this may be due to the large number of antigenic determinants involved in such antigens.

More work has been done with soluble antigens, notably bovine serum albumin (BSA) in the rabbit. If large doses of BSA are given from birth a prolonged suppression of ability to respond to this antigen is obtained (Hanan and Oyama, I954). If a series of large inocula of the same antigen are given to mature rabbits a similar inhibition of antibody-producing capacity can be induced, but after a rest period the capacity is rapidly regained. The problem of the part played by persisting antigen in these reactions has been clarified by recent experiments due to Smith (1958). They showed that tolerance produced by a single dose of roo $\mathrm{mgm}$. of bovine serum albumin given to rabbits on the day of birth could be maintained indefinitely if the rabbits were challenged at approximately three-month intervals. Each inoculation of antigen failed to provoke antibody, and the rate of removal of the foreign protein from the circulation was comparable to what would be found for homologous serum albumin. If, however, challenge is deferred until 200 days after the tolerance-producing injection, the animal develops antibody. The time over which tolerance persists is a function of the dose initially given and all the results are consistent with the view that at birth in the rabbit, potential antibody-producing cells of the appropriate clones are inhibited from activation and from normal maturation as long as antigenic determinants remain attached. Once all antigen has been eliminated by normal metabolic processes the inhibition is removed and the cells develop the normal reactivity of a mature cell.

This interpretation is in accord with all the experimental facts available, but it does not necessarily eliminate the possi- 
bility that with very early or very prolonged exposure to the foreign antigen the reactive clones may be completely destroyed. In general, however, tolerance production is a relatively inefficient process.

In considering these phenomena, the logical point to start the discussion is the question why young animals are such poor producers of antibody. To a large extent this is associated with their inability to produce gamma globulin, and this in its turn may represent an inability of modified lymphocytes to take on the plasma cell (antibody-producing) phase. Dixon and Weigle's (1957) finding that Harris' (1954) experiment fails in new-born rabbit recipients and that this is associated with failure of the transferred lymphocytes to be converted, in part at least, to plasma cells, is highly relevant here. This is just one indication of the part the physiological environment must play in determining what type of response a cell will make to an immunological stimulus.

The problem of tolerance and partial tolerance can only be analysed in terms of the conditions modifying the response of the cells concerned to the corresponding antigenic determinants.

It would be quite unrealistic to believe that any mechanism of antibody production can be expressed as a series of simple deterministic reactions. Experiment and observation suggest (a) that there are several types of response of a cell to specific stimulation by an antigenic determinant and $(b)$ that the extent and type of response will be modified by a number of intrinsic and environmental factors.

A. The types of response which are called for to allow a clonal selection hypothesis to account for the facts may be divided into two groups according to whether the effect concerns only the cell in question, or whether the effect is essentially relevant to the behaviour of the cell's descendants.

(i) Responses limited to the cell itself.

(a) Lethal damage eliminating the possibility of descendants. 
(b) Dormant damage inhibiting active response for a prolonged period.

(c) Rapid liberation of relatively small amounts of preformed antibody as in Stevens' and Peitry's (1957) and Wesslen's (1952) experiments.

(ii) Responses essentially relevant to descendants.

(a) Activation to multiply after lodgment in appropriate tissue to lymphocytes or plasma cells. Under special circumstances proliferation may occur as epithelioid cells, and perhaps as eosinophils.

(b) The switch from primary modification to the secondary type of reactivity.

B. The most important factors in determining which of these types of response is elicited may be

(i) The concentration of antigen or the number of surface receptors on the cell stimulated.

(ii) The goodness of fit between antigenic determinant and surface receptor.

(iii) The past immunological history of the cell and of the clone to which it belongs.

(iv) The physiological age of the individual at the time.

(v) The particular internal environment in which a stimulated cell happens to lodge.

On this background we should ascribe the non-reactivity of young animals largely to their inability to provide an environment in which plasma cells can develop, plus the fact that the existent clones carry only primary type patterns.

The conditions relevant to tolerance can perhaps best be illustrated by such a family of curves as is shown in Figure 8 . This allows a continuously changing pattern of reactivity with the maturation of mesenchymal cells, plus an indication of the influence of antigen concentration. It is probable that the parameter antigen concentration is in part a function of 'goodness of fit' between antigenic determinant and reactive site on the cell. The better the fit the higher the equivalent concentration. As has been suggested on other pages the 
qualitative character of the proliferative response will depend greatly on where the stimulated cell lodges. Depending on the site and the physiological condition of the site, proliferation may give lymphocyte, plasma cell, epithelioid cell or, with greater reservations, eosinophil granulocytes.

It may be useful to consider the situation where tolerance to BSA is induced by a single injection in the new-born rabbit in the light of this diagram. At the time of primary inoculation we are concerned with the line nearest the horizontal, and a dose of antigen large enough to produce inhibition of proliferation is given. The contact with antigenic determinant also prevents any movement of the cell's reactivity from that curve to the next in the family. As soon as antigen has disappeared the cell can resume its interrupted maturation and then will respond normally.

This is a simple and natural explanation of the facts, which include the ability of the tolerant rabbit to produce antibody against any unrelated antigen. Any non-clonal interpretation immediately encounters some grave difficulties. Any suggestion must take the form that all potential antibodyproducing cells have taken up the antigen and are so affected that while the antigen remains they cannot respond. It will probably be assumed that the antigen initiates the first step in producing the necessary template, but then in some way inhibits any further progress without interfering with the organization and functioning of other immunological templates in the same cells. This would demand a series of independent antibody-producing mechanisms in each cell capable of independent stimulation or inhibition, a very difficult situation to imagine.

Immune paralysis as exemplified by mice inoculated with moderate or large doses of pneumococcal polysaccharide seems to be based on a very effective adsorption of all antibody produced by polysaccharide held in the macrophages. The deposition of antibody on this material (Dixon, Maurer 
and Weigle, 1955) will itself result in a great decrease in antigenic stimulus so that probably very little antibody is actually being liberated. The essence of the matter is that the antigen takes the form of a tightly bound insoluble and enzymatically insensitive complex.

\section{Natural antibodies}

In the clonal selection hypothesis, natural antibodies are not of such primary importance as they were in Jerne's theory. There is no requirement that all the clones should be represented by corresponding globulin molecules in the plasma, although this possibility is equally not excluded. In fact, it is highly characteristic of most 'natural antibodies' that they do not appear until some days or weeks after birth. If there is a process of 'clone elimination' during embryonic life to prevent the maturation of clones adapted to react with body determinants, plasma globulin can play no part in it.

Of the natural antibodies produced in man, the anti- $A$ and anti- $B$ isoagglutinins are the best known and the $T$ agglutinin active against RDE-treated red cells is another which has been studied in my laboratory. Reasons have been given already for the assumption that cells capable of producing the isoagglutinins are genetically produced and that isoagglutinins reactive with whatever antigen is present in the body are not developed because of specific elimination of the clones of cells which would eventually produce the isoagglutinins in question. There is no indication as to the site or histological nature of the cells responsible for their production in adult life, but the fact that they are absent in congenital agammaglobulinaemia speaks strongly for their production, like classical antibodies, from certain clones of plasma cells. It is evident that similar types of modification with development must be ascribed to these cells as to those concerned with antibody production proper.

At an early stage in the development of a child of blood group $A$, we must postulate cells potentially, but not actually, 
producers of anti- $A$ which can 'recognize' and react with $A$ by undergoing either destruction or inactivation. Those which are potential producers of anti- $B$, in the absence of $B$, survive, and with or without multiplication give rise to cells capable at the proper time of secreting anti- $B$. At a later stage the introduction of $B$ substance provides a stimulus to the production of a rising titre of anti- $B$.

These points are stressed to show the possibility that clones of a given character may or may not be in a state in which they produce soluble antibody and may differ greatly in the character of their response to the specific antigenic stimulus. It is not necessary that we should be able to demonstrate minute amounts of all possible antibodies in the plasma to make the clonal selection theory tenable.

\section{T agglutinin as a model of a natural antibody}

Our own laboratory has had a minor continuing interest in $\mathcal{T}$ agglutinin and $\mathcal{T}$ antigens on red cells treated with viral neuraminidase or the receptor-destroying enzyme RDE of Vibrio cholerae. Normal human serum does not agglutinate $O$ erythrocytes. If the red cells, however, are treated with RDE or a myxovirus, they become agglutinable to a serum dilution of about roo. This phenomenon is seen almost equally well with chicken or guinea-pig cells, and all adult vertebrate sera seem to contain $T$ agglutinin.

At birth, human cord blood contains no $T$ agglutinin, the first appearing about six months and reaching to about a quarter of the final adult titre at the age of two years. In our experience the only pathological condition showing a sharp rise in $T$ agglutinin is atypical pneumonia. In those sera from cases of this disease which showed cold agglutinins in significant titre, very high titres (average 850 ) of $T$ agglutinin were found (Lind and McArthur, 1947).

Experimentally, $\mathcal{T}$ agglutinin titres can be raised by giving guinea-pigs large enough doses of purified RDE to modify all the circulating erythrocytes. In French and Ada's experi- 
ments, the agglutinin disappeared immediately but was present in four to eight times normal titre on the sixth and eighth day, returning to normal about the twenty-first. Associated with the rise there was an appearance of cold agglutinin for human $O$ cells (French and Ada, I954). Fraser (1955) using rabbit cells treated in vitro found no response when these were injected into normal rabbits, presumably because the dose was much lower than in French and Ada's guinea-pigs. He could, however, confirm Burnet and Anderson!( I 947), in that treated heterologous cells gave a brisk and specific response. The latter showed that with fully treated guinea-pig or human cells, there was a sharp diminution in the production of agglutinin for normal cells and the appearance of a specific 'immune $T$ ' agglutinin. Table 3 from Burnet and Anderson shows a typical protocol to establish this.

\section{Table 3. Behaviour of 'immune $T$ ' agglutinin} (Burnet and Anderson, 1947)

\begin{tabular}{|c|c|c|}
\hline Immunized & $\mathrm{NH}$ & $\mathrm{RDH}$ \\
\hline $\mathrm{NH}$ unabsorbed & 6000 & . \\
\hline abs. NH & $<$ I00 & 160 \\
\hline abs. RDE & I 80 & 4 \\
\hline RDH unabsorbed & I 500 & 2000 \\
\hline abs. NH & $<100$ & 2000 \\
\hline abs. RDH & 200 & $<$ I \\
\hline Unimmunized & 10 & $40-15$ \\
\hline
\end{tabular}

Fraser (I955) was interested in the changes associated with warm and cold agglutinin titres. The normal $\mathcal{T}$ agglutinin of the rabbit contains a considerable proportion of less avid 'cold' agglutinin which cannot be absorbed at $40^{\circ}$ by $\mathrm{RD}$ cells. On immunization with heterologous treated cells, a high $\mathcal{T}$ agglutinin was not associated with any cold agglutinin which, however, reappeared 6 to 12 months later. 
Table 4. Effect of immunization on the titre and character of T agglutinin (Fraser, 1955)

Normal

Immune 12 months later
Unabsorbed

\begin{tabular}{|c|c|}
\hline $4^{\circ}$ & \\
\hline 55 & 5 \\
\hline 100 & 100 \\
\hline
\end{tabular}

Abs. with RD cells at $40^{\circ}$

$\begin{array}{rr}\overbrace{4^{\circ}} & 37^{\circ} \\ 4^{\circ} & 0 \\ 0 & 0 \\ 128 & 0\end{array}$

Titres against RD cells shown.

Fraser interprets this as indicating that the cells responsible for the normal $T$ agglutinin were responsible also for production of the immune agglutinin. A physiological change has, however, taken place in virtue of which the non-avid cold agglutinin is no longer produced. With waning of the stimulus the cells revert to the former type.

This system of normal and immune $T$ agglutinin may well prove to be of great importance in testing the clonal selection hypothesis.

The interpretation on that hypothesis would take the following form. There is no known neuraminidase in the body, at least where it is accessible to the red cell surface, and its action results in the exposure of a set of determinants new to the body. The determinant in question is not the same for each species of red cell but has at least the common quality of being not-self. There may well be one common determinant for all RD cells plus others more species-specific. It is probably significant that the guinea-pig $T$ titres obtained by French and Ada were relatively low and transient compared with those obtained by heterologous cells in the rabbit.

We assume that the normal $T$ agglutinin is a fraction of the gamma globulin population which 'by accident' reacts with the common determinant produced or uncovered by $\mathrm{RDE}$ action. It is produced by one or more clones of mesenchymal cells. In embryonic and neonatal life those clones had no power to produce globulin but could have been 
eliminated by contact with the $T$ determinant. In humans the capacity to produce globulin of the type in question emerges some time after six months of age. Presumably in other animals a similar situation holds.

In cases of atypical pneumonia the increased titre of $T$ agglutinin is associated with cold agglutinins against $O$ human cells. The two antibodies can be shown to be quite distinct by absorption tests. They are presumably produced by two different sets of cells, both of which are stimulated to activity conceivably by a product of the virus responsible or perhaps as a result of actual invasion of the cells by the virus.

SUMMARY: There is no reason to look for other than accidental reasons for the pattern of natural antibodies. Of the wide range of clones in existence at birth some patterns will have recurred more frequently than others and a variety of influences may determine which of these patterns is most frequently set free in the plasma. In addition, there are bound to be globulins with special functions. Properdin may well turn out to be a key substance in the interpretation of antibodies. It was isolated by what are essentially physical methods and its constituent molecules have a wide range of reactivity with various pathogens of at least pseudo-immunological character. It could well represent a significant constituent in the population of gamma globulin molecules which is collectively termed an antibody. It is immaterial whether properdin is a special species of globulin evolved by selection ('designed') to act as an emergency generalpurpose antibody until more specific antibody populations can be built up or whether it is a sort of pre-antibody secreted in common by cells which on specific stimulation would produce each its own patterned gamma globulin.

\section{The influence of ionizing radiation on immunological responses}

As has already been indicated in discussing tolerance to homografts, it is possible to make a normal animal into one resembling in some respects a neonatal one by whole-body 
irradiation with an appropriate dose of X-rays. The most conspicuous effect histologically is a striking disappearance of small lymphocytes - a variety of other mesenchymal types persist. For a short period after irradiation there is virtually no power to give an antibody response. X-radiation can also prevent the development of tuberculin sensitivity in rabbits (Lennox, Dempster and Boag, 1952). These processes are undoubtedly complex. For one thing whole-body irradiation provokes a stress reaction with cortisone, producing a circulatory lymphopenia and atrophy of lymphoid tissue.

In respect to the influence of X-radiation on antibody production as such, most of the work has been done with rabbits and it is convenient to follow Taliaferro and his colleagues in their studies of the response to sheep red cells as antigen given intravenously. The most striking finding is that there seems to be only a very limited phase of the antibody-producing process that is susceptible to inhibition by non-lethal irradiation. If a maximal effect is to be produced, the radiation should be given 24 to 48 hours before the immunizing injection. If given after, or even simultaneously with, the antigen there is very little influence. When the spleen is shielded, there is a variable reduction in the effect of whole-body irradiation. According to Sussdorf and Draper (1956), shielding the appendix provides $100 \%$ protection, although irradiation of the appendix alone has no power to reduce antibody production. In fact, there is slight evidence of an additive effect. With very heavy irradiation of the rabbit spleen, the rest of the animal being shielded, Taliaferro found a highly significant increase in antibody production.

There is some controversy as to the effect of X-rays on the secondary antibody response, but Talmage, Freter and Thomson (1956) conclude that there is no clear difference in the effect on primary and secondary responses.

The standard effects-namely that (a) radiation must be given 24 hours before the antigen to produce a maximal 
effect, $(b)$ that if a major source of lymphocytes, the appendix, is shielded the response is undiminished and $(c)$ that a variety of cell extracts, etc. given with the antigen will allow response-can be fitted well into the picture of the clonal selection theory.

X-ray has a destructive effect upon lymphocytes and 24 hours later there are few normal lymphocytes which can respond to contact with antigenic determinant in normal fashion. Of the lymphocytes not lethally damaged, the loss of responsivity to antibody takes some hours to develop and contact with antigen in the latent period reverses the damage.

Any lymphocytes which have been activated to primitive types, or started on development to plasma cells, are relatively resistant. Hence the failure of X-rays to modify the reaction to antigen given before the radiation.

There is an interesting paradox that while splenectomy diminishes the antibody-producing capacity of the rabbit to a very marked extent, appendicectomy does not modify it. Yet whole-body irradiation with the appendix shielded gives I $00 \%$ protection of antibody production; with the spleen shielded production is reduced by $82 \%$ (Sussdorf and Draper, 1956).

The explanation on the clonal selection hypothesis is simply that the appendix is a greater source of mobile lymphocytes than the spleen but the red pulp of the spleen is the place par excellence where lymphocytes stimulated by antigen can settle to produce clones of antibody-forming plasma cells. It is hard to see how any other theory of antibody production could offer any explanation whatever of the interrelations.

\section{The special qualities of bacterial antigens and endotoxins}

The most soundly based objections to a clonal selection theory of immunity will probably be derived from two sets of facts:

(i) It has proved almost impossible to produce tolerance against bacterial antigens, 
(ii) yet bacteria and bacterial products are highly potent antigens producing detectable antibody in the rabbit usually within four days.

Several workers have suggested that tolerance becomes progressively easier to induce the closer the foreign antigen is to normal body components. Homologous living cells and mammalian serum proteins have been the reagents chiefly used in tolerance experiments.

On the other hand, experimenters concerned with demonstrating early production of antibody have almost always used killed Gram-negative bacteria or soluble agglutinogens (endotoxins) derived from them. Harris et al.'s (1956) work on the production of antibody in an X-rayed recipient rabbit by the transfer of normal lymph-node cells treated in vitro by a soluble Shigella preparation is a typical example. The serum of the recipient contains moderate amounts of antibody presumably produced by donor cells within four days of their injection. Under these conditions there seems to be inadequate time available for the selective proliferation and mutation of a small number of cells from clones with appropriate predetermined patterns.

The difficulty in regard to tolerance is relatively less important and may depend only on the multiplicity of determinants in all bacterial antigens plus their high activity in mature or maturing animals.

The relevant work on the antigenicity of bacterial products has been carried out almost wholly in rabbits and any discussion of the speed with which bacterial agglutinins or antitoxins can be produced after a primary stimulus can legitimately be confined to rabbit reactions. An important clue seems likely to be found in the character of the cellular reactions induced in rabbits by bacterial endotoxins. These are closely related to, if not identical with, the polysaccharidecontaining somatic antigens of the Gram-negative intestinal bacteria.

Under appropriate conditions of injection or manipula- 
tion such endotoxins will (a) provoke a pyrogenic response by liberating from polymorphonuclear leucocytes and possibly other types of mesenchymal cells a cell-product acting directly on the temperature-controlling centres of the hypothalamus, (b) provoke a rapid but transient development of power to eliminate the pyrogen much more rapidly, (c) by intravenous injection precondition a rabbit so as to allow acute production of antibody in tissue culture of its spleen cells (Stevens and McKenna, 1957), (d) adsorb properdin and initiate a subsequent acute rise in the properdin content of the serum, (e) condition cells (? endothelial) to respond to a subsequent stimulus of the same type by a destructive lesion giving the haemorrhagic patches of the Shwartzman phenomenon.

In general we can say that an appropriate endotoxin preparation has very much the same effect in a normal rabbit that antigen has in an immunologically conditioned animal. Stevens and McKenna specifically make this comparison in regard to the capacity to produce antibody against bovine gamma globulin in vitro; the Shwartzman reaction is much like a hyper-acute Arthus reaction, properdin more and more takes on the appearance of a stop-gap non-specific antibody.

There is still an absence of much of the data necessary to substantiate the point of view, but these properties of bacterial endotoxin obviously call for very much the same sort of formulation as we developed for the varying reactivity of mesenchymal cells to antigenic determinants. Suppose we adopt the convention that $X$ is the corresponding antigenic determinant for an immunologically differentiated cell or endotoxin in relation to any mesenchymal cell. Then we can postulate that first minimal effective contact with $X$ activates the cell in the following ways:

(i) It becomes progressively more liable to destruction by renewed contact, within 24 to $4^{8}$ hours, with $X$.

(ii) It liberates properdin over the same period. 
(iii) It is likely to settle in the cortical regions of lymph nodes and initiate a clone of cells which are immunologically more reactive.

(iv) With considerably greater uncertainty it can be suggested that this activated cell undergoes a partial labilization of the section of the genome concerned, and acquires a probably correlated capacity to accept information by transduction from other activated cells in the vicinity.

Second contact with $X$ will, depending principally on its timerelation to the first, produce either destructive or proliferative responses. Under the appropriate conditions the stimulus will result in active protein synthesis and liberation of antibody.

On this basis it can be suggested that exposure of normal mesenchymal cells to what is equivalent to endotoxin plus specific antigenic determinants, as in Harris and Harris' experiments, will have the following effects. Most cells will be activated and those which for any reason carry sites corresponding to the foreign antigenic determinants will be stimulated to take on a secondary type of antibody-producing activity with rapid proliferation when they reach an appropriate site; for example, local lymph nodes and spleen. The possibility is also not excluded that injection of cells and antigen in the irradiated host may reactivate antibodyproducing mechanisms which have been inhibited by the irradiation, so that some of the early antibody production may be due to the recipient's cells.

More detailed study, including if possible search in lymph nodes and spleen for antibody-producing cells, and an estimate of the number of cells required to produce the observed amount of early antibody is clearly needed. It could conceivably show that the number of cells and the time available for their proliferation are inadequate to account for the results on the clonal selection theory in its original form. Only under such conditions would it be necessary to adopt 
a modification suggested to me in early discussions with Dr Joshua Lederberg, namely, that a formal equivalent to a clonal selection theory could be elaborated at a subcellular level. If in an activated cell antibody production is a function of self-replicating units at a lower genetic level than the chromosomes and if these units are subject to limited mutation then a process of selective proliferation of those units corresponding most closely to the antigenic determinant in question must be considered as a possibility. If this were combined with the possibility of movement of such units from one activated cell to another, any of the results so far described could be met, still within the framework of an approach in which the action of antigen as a direct template is excluded. If the acceptance of selective intracellular proliferation of competing subcellular units becomes necessary, it will be a complicating factor, particularly because it will make experimental decision between template and selective theories even more difficult. It will not, however, be in any way incompatible with the clonal selection theory presented here on a cellular basis since in each cell the dominant subcellular entity would determine the immunological competence of the clone.

\section{REFERENGES}

Bauer, J. A., Peckham, P. E. \& Osler, A. G. (1956). Proc. Soc. exp. Biol., N.Y., 92, 714.

van Bekкum, D. W. \& Vos, O. (1957). F. cell. comp. Physiol. 50, Suppl. I, 139.

Billingham, R. E. (1958). Pediatric Research Conference, Dallas, I3-15 March 1958.

Billingham, R. E., Brent, L. \& Medawar, P. B. (i956a). Phil. Trans. 239, 3 I 5 .

Billingham, R. E., Brent, L. E. \& Medawar, P. B. (1956b). Nature., Lond., 178, 5 I 4 .

Billingham, R. E. \& Brent, L. E. (1957). Transplantation Bull. 4, 67. Burnet, F. M. \& Anderson, S. G. (1947). Aust. F. exp. Biol. med. Sci. 25, 2 I3.

Buxton, A. (1954). J. gen. Microbiol. 10, 398. 
Dixon, F. J., Maurer, P. H. \& Weigle, W. O. (i955). F. Immunol. 74, 185 .

Dixon, F. J. \& Weigle, W. O. (1957). F. exp. Med. 105, 75.

Ford, G. E., Hammerton, J. L., Barnes, D. W. H. \& Loutit, J. F. (1956). Nature, Lond., 177, 452.

Fraser, K. B. (1955). F. Path. Bact. 70, 18.

French, E. L. \& AdA, G. L. (1954). Aust. 7. exp. Biol. med. Sci. 32, 165. Hanan, R. \& Oyama, J. (I954). J. Immunol. 73, 49.

Harris, T. N., Harris, S. \& Farber, M. B. (1954). Proc. Soc. exp. Biol., $\mathcal{N} . \Upsilon_{.}, \mathbf{8 6}, 549$.

Harris, S., Harris, T. N., Ogburn, C. A. \& Farber, M. B. (1956). 7. $\exp$. Med. ro4, 645 .

Lennox, B., Dempster, W. J. \& Boag, H. W. (1952). Brit. F. exp. Path. 33, 380.

Lind, P. E. \& McArthur, N. R. (1947). Aust. 7. exp. Biol. med. Sci. 25, 247.

Main, J. M. \& Prahn, R. T. (1955). F. nat. Cancer Inst. 15, 1023.

Nossal, G. J. V. (1958). Aust. F. exp. Biol. med. Sci. 36, 235.

Smith, R. T. (1958). Fed. Proc. 17, 535.

Stevens, K. M. \& MaKenna, J. M. (1957). Nature, Lond., 179, 870.

Stevens, K. M. \& Pietry, H. G. (I957). Personal communication.

Sussdorf, D. H. \& Draper, L. R. (I956). F. infect. Dis. 99, 129.

Taliaferro, W. H. \& Taliaferro, L. G. (ig54). J. infect. Dis. 95, i 34.

Talmage, D. W., Freter, G. G. \& Thompson, A. (1956). F. infect. Dis. 99, 247 .

Wesslen, T. (1952). Acta derm. venereol., Stockh., 32, 195, 265.

Woodruff, M. F. A. \& Simpson, L. O. (1955). Brit. F. exp. Path. 36, 494. 


\section{VII}

\section{MESENGHYMAL CELL FUNCTION}

IN IMMUNITY

\section{Lymphocyte and plasma cells}

There is no serious objection to the view that the main contribution of circulating antibody comes from cells with the histological character of immature plasma cells (Fagraeus, I948) and that mature plasma cells may contain high concentrations of antibody. Probably most would agree that there is no indication that plasma cells have any other function than to produce gamma globulin and many would go further and say that the presence of plasma cells indicates the production of one or other kind of antibody.

The part played by the lymphocyte is, however, less widely accepted. The ubiquity of the small lymphocyte seems to demand that it is a cell of important function and in the clonal selection theory of antibody production it plays a central role as $(a)$ the carrier of the genetic 'information' determining antibody specificity and the potential parent of the plasma cells which are responsible for active production of antibody, and (b) the mediator of the functions of cellborne antibody. The evidence for such a central function in immunity is still inadequate in the view of most commentators. The most recent critical discussion of the cells of the reticular tissue is that of Marshall (1956). He states bluntly that 'the fate and functions of the lymphocytes... are mainly unknown'. The chief difficulties are $(a)$ that all functional studies must be made on complex cell populations which will normally contain a proportion of plasma cells and macrophages that may be responsible for the observed effects and (b) that it has proved very difficult to provide a satisfactory interpretation in terms of genetic sequence and physio- 
logical response of the various types of mesenchymal cell seen in stained sections of lymphoid and inflamed tissues. Support for the central immunological function of the lymphocyte must be sought in a variety of fields and reliance placed on a consistent accumulation of circumstantial evidence without expecting to obtain any single crucial test of its correctness.

Dougherty, White and Chase in the period 1943-6 worked extensively on the theme of the lymphocyte as antibody producer and the influence on it of adrenocorticotrophic hormones. The work is reviewed in Dougherty (1952).

The points from their work which were regarded as significant were:

(i) Cells from lymphoid organs, spleen, lymph nodes, thymus, contain gamma globulin and, in immunized animals, antibody.

(ii) The weight of the lymphoid organs and the number of circulating lymphocytes is reduced by ACTH and there is concomitant evidence of morphological damage in lymph nodes. Their contention was that antibody was liberated by shedding of lymphocyte cytoplasm under hormonal stimulus.

(iii) The results of administering ACTH to mice which had lost antibody titre after a single injection of sheep erythrocytes some weeks previously. Antibody could still be extracted from lymphoid tissue but only appeared in circulation as a result of the ACTH injection.

(iv) A lymphoma arising in a mouse immunized with staphylococcal toxin went on producing antibody when transferred to normal mice.

Subsequent work has failed to substantiate some of these claims and it can be stated definitely that in rabbits receiving a standard antigen such as ovalbumin and, after the antibody level had fallen to a low level, injected with an adequate dose of ACTH to reduce the circulating lymphocytes to a low 
level, no release of antibody into the circulation occurs (Fischel, LeMay and Kabat, I949; de Vries, I950). There is no question that ACTH or cortisone treatment of animals and man results in involution of the thymus, a peripheral lymphopenia, degeneration of lymphocytes in lymphoid tissue and a diminution of their number in thoracic-duct lymph. It seems possible that the positive results claimed for antibody rise in association with damage to lymphoid tissue may have been dependent on some adventitious factor, perhaps equivalent to the endotoxin injection that Stevens and McKenna (1957) found to be necessary to active spleen cells to produce antibody in vitro. It is interesting that Hammond and Novak (I950) could confirm Dougherty and White's results using a complex antigen, sheep red cells, and a crude adrenal-cortical extract. The possibility that potential antibody producer cells must be activated immunologically before they could be expected to liberate antibody under hormonal impact may need to be kept in mind.

The presence of antibody in lymphocytes is not as easy to demonstrate as it is for plasma cells. It is hardly adequate to show that splenic or lymph-node cells contain more than the fluid bathing them, since plasma cells are bound to be present and may be wholly responsible. Investigators who have studied thoracic-duct lymph are dealing with a cell population approaching $99 \%$ of lymphocytes, and with these it has been difficult to demonstrate any preformed antibody, even though the lymph contains a relatively high concentration of antibody. Craddock, Valentine and Lawrence (1949) and Wesslen (1952), the first working with cats, the second with rabbits, agree that extracts of the washed cells obtained under these conditions contain no antibody. Wesslen, however, observed that if the cells were maintained in Tyrode solution they produced a moderate amount of antibody. Coons, Leduc and Connolly ( I 955) found by fluorescent antibody 'sandwich' technique that in lymph node in secondary antigenic response most of the antibody was in plasma cells, 
but many lymphocytes near the centre of the follicles showed a light fluorescence. They considered that these cells might also be producing antibody in smaller amounts.

Ortega and Mellors (1957), using human material and examining, not for specific antibody but for production of gamma globulin, lay much stress on what they call intrinsic cells present in the germinal centres. These produce what appear to be symplastic aggregations, the cytoplasm showing fluorescence characteristic of gamma globulin. These probably correspond to the cells found by Coons in his experimental animals.

An objective survey of the facts could well lead to the conclusion that there was no evidence of immunological activity in the small lymphocytes which make up the dominant majority of lymphoid cell populations. All the positive results could well be ascribed to plasma cells, large lymphocytes and intermediate forms. The position might, however, take an entirely different aspect if small lymphocytes can be converted into other functional forms. At this stage, therefore, it is highly desirable to consider the transformations of the mesenchymal cells.

\section{Interrelations of mesenchymal cells}

There does not yet seem to be an adequate technical method for determining the intermediate stages that must have been interposed between the undifferentiated mesenchymal cell of early embryonic life and any given cell observed, for example, in a lymph node where antibody production is in progress. Any presumptive genealogy is likely to have many weak links but the only practical approach is to adopt with appropriate minor reservations the views most widely held in common by histologists of repute. Taking Maximow and Bloom (1948) as the most widely used text on mammalian histology for a starting point, we can in the first instance omit the granulocyte series although the ubiquitous association of eosinophils with immune responses will call for subsequent 
comment. Specialized mesenchymal cells concerned with bone, cartilage or dense connective tissue can also be neglected. This leaves for consideration cells which can be placed in one or other of five categories or in some intermediate position.

(i) Primitive reticulum cell, haematoblast.

(ii) Lymphocyte.

(iii) Plasma cell.

(iv) Macrophage (tissue) or monocyte (free).

(v) Fibroblast.

(i) The primitive reticular cell, representing an almost undifferentiated type of mesenchyme, is usually regarded as a stem cell from which under intense enough call other types may develop. Much evidence suggests, however, that this type of cell is not primitive in the sense that it is descended wholly from similar undifferentiated ancestral forms running back to the earliest mesenchymal cells. There is a growing body of opinion that under appropriate physiological conditions any type of mesenchymal cell may take on the functions of a stem cell. Yoffey and Courtice (1957), for instance, summarize the evidence that lymphocytes lodging in the bone marrow may be transformed to haematoblasts with potentiality to produce either lymphoid or myeloid cells.

(ii) Lymphocytes are produced in the germinal centres of lymphoid tissue where the cells undergoing mitosis have the histological character of medium or large lymphocytes and sometimes primitive reticular cells. There is increasing evidence that lymphocytes are constantly being returned from the blood and tissue fluids to the lymph nodes and other aggregations of lymphoid tissue. Farr (I95I), using lymphocytes labelled with a non-toxic dye, considered that a proportion of those returned to the body intravenously settled in lymph nodes and gave rise to new lymphocytes.

Gowans (1957) finds that when lymphocytes labelled with ${ }^{32} \mathrm{P}$ are injected intravenously into rats, some rapidly appear in the thoracic-duct lymph. 
Medawar (1957) has recently suggested that the essential function of the lymphocyte is as a carrier of nucleic acids. $\mathrm{He}$ bases this largely on the evidence of Otteson (1954) and Hamilton ( 1956 ) that lymphocytes labelled with ${ }^{32} \mathrm{P}$ give indications that some of the cells (or their nucleic acids) have lives of 100 to 300 days. There is no doubt that a circulation of lymphocytes exists but there is known to be a constant wastage and it is hard to accept so long a life for the intact cell. If in lymph nodes or elsewhere the nucleic acids of effete cells were used as the source of nucleic acids for the new cells of the germinal centres with mobilization of their phosphate, a more satisfactory interpretation would be available. Medawar considers that there is no evidence that functionally genetic nucleic acid is taken into the new cells, though Hamilton toys with this possibility.

From the point of view of the clonal selection hypothesis, it is rather irrelevant whether lymphocytes do or do not take up relatively intact nucleotides from other cells and from outworn lymphocytes. It would be of more interest to examine the situation that arises when a homograft initiates a rejection response, on the assumption that Medawar was correct in regarding the effective antigen for homograft immunity as being DNA protein.

Our interpretation would be $(a)$ that DNA nucleoprotein is liberated wherever multiplication of cells is occurring and that lymphocytes, particularly in germinal centres, may be specially adapted to utilizing this material with minimal breakdown for the construction of new cells as required. (b) Foreign DNA- $P$ acts like any other antigen except that, for reasons not yet apparent, lymphocytes stimulated by contact cannot (or only rarely can) take on the plasmacyte form but produce only more lymphocytes. (c) Specifically 'labelled' lymphocytes in the immediate neighbourhood of a homograft will, as soon as the foreign cells start dividing, find plenty of the specific antigenic determinant and, suffering damage, will liberate pharmacologically active 
agents or in some more direct fashion lead to the destruction of the homograft.

The point of special interest raised by Medawar's speculation is in regard to transduction. If multiplying large and medium lymphocytes are specially able to utilize nearly intact pieces of nucleic acid from other cells, the possibility of some type of transduction must exist. On general grounds it would seem that DNA- $P$, from other cells of the same type multiplying in the immediate neighbourhood, would be the most likely vehicle. This appears to offer an attractive if speculative basis for the transduction that seems to be needed to account for some of the anamnestic phenomena such as those described by Davenport (see chapter v, section 2).

If a more recent suggestion is correct, and the antigen concerned in homograft immunity is of amino-polysaccharide character only adventitiously associated with DNA, most of this discussion will have to be discarded.

Medawar, like many other authors, believes that the small lymphocyte is an end-cell incapable of diversion. At least an equal number, however, would still allow it potentialities for development. Maximow and Bloom (I948) state that under suitable conditions the small lymphocyte may hypertrophy and regain the ability to divide. Lymphatic nodules anywhere start from a small focus-conceivably one cell may serve to initiate it-which when first recognizable consists of multiplying medium lymphocytes.

Marshall's description of the initiation of cellular response to antigenic stimuli indicates that small foci of large basophilic cells appear first in the spleen in the immediate neighbourhood of the arterioles of the pulp and develop mainly to plasma cells. In the Malpighian nodules the first sign is the appearance of mitoses in the centre and the accumulation of similar basophil cells which, however, develop further along the lymphocytic path. In lymph nodes the first small foci of plasmablasts appeared in a perivascular situation near the arterioles of the medullary cords. The 
findings, therefore, would support an hypothesis that activity in spleen and lymph nodes could be initiated by the entry of activated cells from the blood when they settle down and initiate replication.

In the blood the small lymphocyte and the monocyte are very different cells but there is a continuous range of morphological intermediates and most authors seem willing to allow lymphocytes to give rise to monocytes under some conditions. Lymphocytes are not phagocytic but they are actively mobile and are constantly seen to migrate out of the vessels into the tissues. There is doubt as to whether lymphocytes can give rise to macrophages. Marshall (1956), who uses silverstaining methods to define macrophages (his metalophil cells), is sceptical of the possibility and believes that many of the small cells called lymphocytes by Maximow, which are seen escaping into the tissues from the blood, are small metalophil monocytes. When large numbers of cells from lymph nodes of the rabbit are inoculated intravenously into another rabbit, they tend to accumulate in the small blood vessels of the lymph nodes, spleen and periportal tissues of the liver (Farr, I95I). Gowans (1957) has shown that the supply of lymphocytes in the thoracic duct can only be maintained if the cells are returned to the circulation, and current opinion is now almost solid that the lymphocyte has a longer life than is deduced by the numbers passing through the thoracic duct; in other words, lymphocytes can return to the lymphoid tissues several times in their life span.

It should be stressed that there can be no more than circumstantial evidence that a (small) lymphocyte suitably activated can settle in reticular tissue and there give rise by division to a focus of lymphocytes or plasma cells, depending on the site of lodgment or other factors. Equally at the present time there is no direct evidence to prove or disprove the claim that a similar activated cell reaching the bone marrow may develop into a haematoblast from which eosinophil cells develop as progeny. 
(iii) Plasma cells are always associated with lymphocytes and much of the controversy as to which is the important antibody-producing cell seems to have turned on the purely verbal point as to whether something should be called a lymphocyte or an immature plasma cell. All transitions between small lymphocytes and plasma cells can be observed and there is equally evidence for transformation of more primitive cells, reticular cell or large lymphocyte into immature and eventually mature plasma cells. Marshall derives the plasma cell wholly from the primitive reticulum cell via what he calls an activated reticulum cell. $\mathrm{He}$ mentions one type of generalized myelomatosis in which the neoplastic cells include both lymphocytes and plasma cells. If on activation a lymphoid cell can take on the character of a primitive reticulum cell, it follows automatically that, under appropriate conditions, it can give rise to plasma cells. There is a suggestion from the work of Bjornboe, Gormsen and Lundqvist (1947) that in grossly hyper-immunized rabbits collections of mature and probably non-functional plasma cells accumulate in the fatty tissue of the renal pelvis, but there is very little other evidence of what is the fate of, for example, the large numbers of plasma cells which develop in response to a secondary antigenic stimulus.

(iv) Macrophages, the reticulo-endothelial system of Aschoff, include fixed macrophages, wandering tissue macrophages or polyblasts and the blood monocytes. Opinion holds that they can be derived from similar cells, from lymphocytes or from primitive reticular cells. Under appropriate conditions they can become fibroblasts. It has been claimed that polyblasts can become immature antibodyproducing plasma cells. Taliaferro (1949), looking at the situation as an immunologist, brings the cells concerned into a single mesenchymal cell pool, the lymphoid-macrophage system. Particularly in protozoal infections he finds clear evidence (of conversion) of lymphocytes into macrophages.

Marshall, who identifies macrophages as metalophil cells, 
finds no evidence that they can be derived directly from lymphocytes. They can, however, be derived from forms morphologically identical with those from which lymphocytes are derived.

In chronic conditions associated with hypersensitivity, there is usually evidence of a modified macrophage response in the form of an aggregation of metalophil cells (Marshall, I956). In long-continued immunization of rabbits, the Malpighian bodies in the spleen may show a perifollicular accumulation of such cells, and in most chronic hyperplasias of lymph nodes associated with infection there is proliferation of the macrophages lining the sinuses.

The epithelioid cells of the tubercle are metalophil and are probably derived from blood monocytes rather than lymphocytes. Marshall considers the possibility that these metalophil reactions are indicative of immunological hypersensitivity but, while not completely rejecting it, considers that the more likely interpretation is that they are a response to lipid material either provided by an infecting microorganism or by some pathological process in the body.

The essence of the sarcoid lesion (and the Kveims reaction) is the formation of an epithelioid (metalophil) nodule. If this, as we have claimed, is an immunological response, we shall have to include, as members of the immunologically characterized clones, macrophages as well as lymphocytes and plasma cells. Depending on how new experimental approaches develop, it may become possible to decide whether their membership of a responsive clone is by virtue of direct descent or by some process of transfer from cells of the lymphocyte-plasmacyte series.

(v) Fibroblasts can arise from any of the cells of the other types, but it is uncertain whether they retain any potentiality of reversion to primitive types and redifferentiation in another direction. 


\section{Eosinophil function}

At this point it seems desirable to return to the question of the significance of the eosinophil cell in immune reactions. Such cells are known to be conspicuous in lesions associated with many types of immunological sensitization especially where antigens derived from helminthic parasites are concerned. Speirs (1958) has described systematic studies of the eosinophil content of the peritoneal fluid in mice subjected to various types of antigenic stimuli. He found a clear correlation between the number of eosinophils present and the extent of antibody production. The curves given in his paper suggest strongly that the numbers of eosinophils in peritoneal fluid move in parallel with the numbers of antibody-producing plasma cells in the body. The most striking rise in eosinophils is seen when a secondary antigenic stimulus is given as an intraperitoneal injection of an antigen previously experienced by the mouse.

Although in most immune responses eosinophils are in a rather small minority, the regularity of their appearance and rise must mean that they are influenced specifically and presumably have some significant role in immunity. Their immediate function is unknown, but if it is established that they respond specifically to a secondary antigenic stimulus it is very difficult to exclude them from membership of the specifically modified clones with which we are concerned. Although some reservations may be necessary-for example, the possibility that the stimulus to the outpouring of eosinophils is the liberation, from reactive lymphoid cells stimulated by antigen, of some non-specific pharmacologically active substance-Speirs' findings seem to fit better with the assumption that the eosinophil and the plasma cell are two specialized products of activated cells which have lodged in appropriate physiological niches.

Speirs (1958) has suggested that the eosinophil may have a central role in antibody production by constructing tem- 
plates which are subsequently transferred (by phagocytosis) to macrophages. These are then converted to plasma cells. Such a view is neither in keeping with the clonal selection approach nor adequately supported experimentally. It is much more likely that the eosinophil has some immediate function in the immune response.

If it can be shown conclusively that eosinophils are immunologically 'labelled' cells this will provide strong support for the unitarian view that all mesenchymal cells can give rise to the whole range of forms under appropriate conditions. Evidence has already been cited that lymphocytes may give rise to haematoblasts in the bone marrow. Some rather direct evidence in the same direction has recently been obtained by Ford, Ilberry and Loutit (1957). They studied the recolonization of bone marrow spleen and lymph nodes of mice which had been saved from lethal doses of X-radiation by injection of heterologous (rat) cells. Eventually mouse cells completed recolonization and in some individuals it could be shown that up to $44 \%$ of the cells showing mitosis carried common chromosome markers, indicating their derivation from a single damaged stem cell. It is almost inconceivable that such a high proportion of the mitoses in bone marrow should not include both granulocytic and erythrocytic precursors or that a similar proportion in lymph nodes and spleen should not include lymphoblastic cells.

If this is a reasonable summary of current histological opinion, it can be used to provide a cellular basis for the clonal selection theory. This is that cells of any mesenchymal clone can, under appropriate sequences of intrinsic or environmental stimuli, take on any of the forms mentioned which represent merely adaptations to the functional activity called for by circumstances. The small lymphocyte represents the central figure in the situation: it is the dominant product of mesenchymal proliferation and it is highly mobile, passing incessantly in and out of the circulating blood and lymph. Vast numbers are expendable but there is everything to 
suggest that the lymphocyte is specially adapted to move to areas where mesenchymal activity is required and there take on the appropriate functional activity. It is the obvious and, in fact, only possible candidate for the role of the responsive cell type in the clonal selection theory.

The alternative view is that there persists a line of stem cells, primitive reticular cells presumably, which retain all the potentialities of the embryonic mesenchyme, giving rise to granulocyte, erythrocyte, lymphocyte, plasma cell or macrophage, as occasion requires. On this view there will also be a place for the replication of intermediate forms, myelocytes, erythroblasts, etc., but with any urgent call for new cells the stem cells are presumed to be brought into activity.

As Marshall points out, there is no present way of determining whether a primitive-appearing cell has been already conditioned to produce one line of descendants only or still retains potentiality to produce any line when appropriately stimulated. To this we could add that it is equally impossible to be sure that the primitive cell is not a derivative of a line which had included developed lymphocytes or macrophages in its sequence. If the facts of immunology demand such an interpretation, there seems to be nothing in the histological picture which renders it untenable.

There is one special reason for stressing the probability that the primitive reticulum cell is not descended from a line of primitive cells which have never been exposed to functional experience. If this were the case, there would be no place for the store of 'memories' which allow the various types of secondary and anamnestic responses discussed in chapter v. Whatever hypothesis of antibody production is adopted, the mesenchymal cells of the adult need to carry a relatively enormous amount of information based on past immunological experience. This demands either that cells which have been functionally selected as successful give rise to descendants directly or that they transfer to stem cells the relevant genetic information gained as a cause or result of that success. The 
second cannot be wholly excluded and we have been inclined to believe that something equivalent to transduction may occur under special circumstances. It seems fantastic, however, to picture a constant transfer of information to primitive non-functional cells when a much simpler and intrinsically more likely hypothesis is available. The clonal selection hypothesis with, as an integral part, the assumption that circulating cells, presumably lymphocytes, can on appropriate stimulation become proliferating mother cells, seems almost ideally suited to allow a simple interpretation of the body's capacity to store large amounts of immunological information.

\section{REFERENCES}

BJornboe, M., Gormsen, H. \& Lundevist, F. (1947). Acta path. microbiol. scand. 20, 649 .

Coons, A. H., Leduc, E. H. \& Connolly, J. M. (1955). 7. exp. Med. I02, 49.

Graddock, G. G., Valentine, W. N. \& Lawrence, J. S. (i949). 7. Lab. clin. Med. 34, I58.

Dougherty, T. F. (r952). Physiol. Rev. 32, 379.

Fagraeus, A. (1948). Acta med. scand. Suppl. 204.

FARR, R. S. (I95I). Anat. Rec. 109, 5 I5.

Fischel, E. E., LeMay, M. \& Kabat, E. A. (I 949). F. Immunol. 6r, 89. Ford, G. E., Ilberry, P. L. T. \& Loutit, J. F. (i 957). J. cell. comp. Physiol. 50, Suppl. r, rog.

Gowans, J. L. (1957). Brit. F. exp. Path. 38,67.

Hamilton, L. D. (1956). Nature, Lond., 178, 597.

Hammond, C. W. \& NovaK, M. (1950). Proc. Soc. exp. Biol., N. Y., 74, I 55.

Marshall, A. H. E. (1956). Cytology and Pathology of Reticular Tissue (Oliver and Boyd, Edinburgh).

Maximow, A. \& Bloom, W. (1948). Textbook of Histology (5th ed. Philadelphia).

Medawar, P. B. (1957). Ann. N.Y. Acad. Sci. 68, 255.

Ortega, L. G. \& Mellors, R. C. (1957). F. exp. Med. 106, 627.

Ottesen, J. (1954). Acta physiol. scand. 32, 75.

Speirs, R. S. (1956). F. Immunol. 77, 437.

Speirs, R. S. (1958). Ann. N.Y. Acad. Sci. 73, 283.

Stevens, K. M. \& MaKenna, J. M. (1957). Nature, Lond., 179, 870.

Taliaferro, W. H. (1949). Annu. Rev. Microbiol. 3, I59.

DE VRIES, J. A. (I950). 7. Immunol. 65, I.

Wesslen, T. (1952). Acta derm. venereol., Stockh., 32, 195, 265.

Yoffey, J. M. \& Courtice, F. C. (1957). Lymphatics, Lymph and Lymphoid Tissue (2nd ed. London). 


\section{VIII \\ THE PATHOLOGY OF THE \\ IMMUNE RESPONSE}

There is a large and important group of disease states whose essential pathogenesis seems to be related to malfunction of the mechanism of immunity. These can be divided into five main groups.

(i) The allergic diseases in which there is clear evidence that the responsible antigen is some substance extrinsic to the body, whether it is a chemical, a migrating helminth, grass pollen or house dust. This group has its own special problems and will not be discussed further in this chapter.

(ii) The so-called collagen diseases characterized histologically by fibrinoid degeneration of connective tissues in various parts of the body and including rheumatic fever, rheumatoid arthritis, disseminated lupus erythematosus, polymyositis and dermatomyositis, scleroderma and lupoid hepatitis.

(iii) Primary and secondary haemolytic anaemia of autoimmune type, that is, showing a positive direct Coombs test with which can be included auto-immune thrombocytopenic conditions.

(iv) Hashimoto's disease-sub-acute thyroiditis or lymphadenoid goitre, which is the only fully established autoimmune disease in the strict sense of the term. Other conditions such as sympathetic ophthalmia may eventually also be included here.

(v) Congenital agammaglobulinaemia is in a different category, but it is, of course, of the greatest interest to any basic consideration of immunological theory. Of special interest in the present context is the fact that changes resembling those of rheumatoid arthritis are common in 
children with this disease who have been maintained for some years by appropriate therapy.

It is a truism that the best test of a physiological concept is its application to pathological conditions. An attempt must therefore be made to discuss these conditions in terms of a clonal selection hypothesis. I believe that this theory is capable of effective application in the pathological field and that the form of the clonal selection approach makes the task much simpler than would be the case with any of the alternatives. This of course does not prove that the clonal selection hypothesis is true, any more than the convenience of the Pauling-Haurowitz theory for immunological chemists proves its universal validity.

\section{Some general considerations}

If the clonal selection hypothesis is correct, antibodyproducing clones must, from their nature, be subject to a high level of random somatic mutation in regard to the pattern of gamma globulin produced. Some of the mutant patterns are bound to be what by analogy with spectroscopy might be called 'forbidden' patterns, that is, capable of reaction with self-components. We feel certain therefore that the normal healthy individual must possess some means by which minor somatic mutations giving rise to forbidden pattern, either in cell surface or free globulin, are rendered ineffective. There are a number of ways in which such a homeostatic mechanism could be envisaged but no experimental evidence whatever on the point. There are, however, some clinical observations which in addition to strengthening our belief that there is such a protective mechanism, offer some indirect suggestions about its nature. These will be referred to in relation to the disease conditions with which they are associated.

If we omit the allergic diseases associated with exposure to extrinsic agents, all the conditions to be considered are interpretable as being based on immunological interaction of cell-borne or soluble antibody with components of the body 
tissues. We may, for convenience, use the term auto-antibody to cover reactive globulin, either soluble or incorporated in a mesenchymal cell surface, which has a specific power to interact with an antigenic determinant carried by some body component. As in all such situations, there are two possible types of explanation not necessarily mutually exclusive. Either there is an abnormality on the side of the antigenic determinants or there is malfunctioning of the antibody-producing cells. If we look at these two alternatives more closely we can see that both may function in different ways and in fact there have been five basic interpretations that have been put forward to cover one or other type of auto-immune disease.

(i) There are some body components which during the period of development are either not present or are inaccessible to mesenchymal cells and in later life are not in potential contact with any of the mesenchymal cells. If as a result of pathological changes such a component becomes accessible it can act as a stimulus to antibody production. This appears to be the nature of Hashimoto's disease.

(ii) Gear and others have suggested that a body component may develop antigenic determinants as a result of chemical modifications following micro-organismal infection or chemical action. If an antibody is developed against this modified component, it is assumed that it will also be active against the corresponding normal component.

(iii) The other possibilities all involve the antibody-producing cells primarily and can be grouped under three headings.

A. Mesenchymal cells may be modified by persisting infection with a low-grade virus, the change disappearing with recovery. This is introduced to cover the findings in infectious mononucleosis and atypical pneumonia. Other examples may well be found.

B. On the clonal selection hypothesis, random somatic mutation in mesenchymal cells must continually allow 
the appearance of forbidden patterns. If, for local or general reasons, the normal elimination of such clones fails to take place, immune disease may result.

C. Like all other body cells, mesenchymal cells may undergo mutation to a form approaching or reaching malignancy.

The main groups of diseases involving a distortion of the immune response-immunopathies or dysautasic diseasesmay now be considered. It will be convenient to consider them in a different order from that given on p. $12 \mathrm{I}$.

\section{Hashimoto's disease}

In this disease, also called lymphadenoid goitre, there is a diffuse swelling of the thyroid with histological evidence of sub-acute inflammation, the tissue being infiltrated with lymphocytes and plasma cells. There are frequently symptoms of hypothyroidism.

The serum in most typical cases shows an increase in gamma globulin content and antibody reacting by complement fixation and precipitation with thyroid extract or thyroglobulin. It is immaterial whether the antigen is prepared from normal or thyrotoxic glands (Roitt, Doniach and Campbell, 1956).

An almost completely analogous condition has been produced experimentally in rabbits by Witebsky and Rose (1956) by immunizing the animals with thyroid extract and Freund adjuvant. In a number of instances the condition was induced in hemithyroidectomized rabbits by immunization with their own tissues.

This is the only condition in human pathology that has been clearly shown to be an auto-immune condition in the sense of being a result of the production of antibody by normal body cells against a definable antigen. In this case the antigen is human thyroglobulin which we must assume does not normally find opportunity to make contact with 
mesenchymal cells. The exact pathogenesis is unknown; it may be a sequel of thyroiditis due to mumps virus or some other infective agent but in any case thyroglobulin becomes accessible to lymphoid cells, some clones of which have normal 'sites' corresponding to one or more of the determinants which distinguish thyroglobulin from any of the normally accessible components of the body. The lymphocytes and plasma cells found in the gland substance in the fully developed disease are no doubt mainly representatives of such clones.

A point of special interest from our point of view was made at a recent discussion of this topic in England (Lancet, 1957). A considerable proportion of cases of typical Hashimoto's disease does not show circulating antibody; some produce large amounts giving easily demonstrable precipitation with thyroglobulin, others give antibody only detected satisfactorily by Boyden's tanned-cell technique. The suggestion here is strong that the essential feature is the reaction of immunologically modified mesenchymal cells with the normally inaccessible antigen in the thyroid. It is of only secondary significance whether circulating antibody is liberated.

In the same report, White is quoted as interpreting the pathogenesis of the condition in terms of an initial leak of thyroglobulin which attracts a collection of lymphocytes and plasma cells into the substance of the thyroid where they make antibody locally. Cellular destruction resulting from the antigen-antibody reaction causes the release of more thyroglobulin, thus initiating what might be called a chain reaction.

The possibility of other auto-immune conditions of basically similar pathogenesis cannot be eliminated but none has been established. Lupoid hepatitis, in which liver biopsy often shows mononuclear cell infiltration, is one which we have considered as a possible example and in fact Gajdusek's AICF test (Gajdusek, I958; Gajdusek and 
Mackay, 1958), which is positive in this condition, was originally thought to demonstrate this. Until an organspecific antigen can be obtained, however, as it has been for Hashimoto's disease, other alternatives will be more likely. In sympathetic ophthalmia conditions broadly similar to those of Hashimoto's disease may well be operative.

\section{Acquired haemolytic anaemias}

In the discussion of these conditions, Dacie's (I954) text-book will be used as the primary source of information. He divides the acquired (that is, not genetically determined) haemolytic anaemias into primary and secondary and the antibodies into warm and cold types, but stresses that detailed study will show that almost every case has individual features of its own. For the present purpose only conditions giving a positive Coombs test will be considered as falling in the auto-immune group.

In all such disease conditions there is evidence of blood destruction, anaemia, jaundice and, in acute forms, haemoglobinuria, and almost always a considerable enlargement of the spleen. The serum contains auto-antibodies in the sense that they react with the patient's own red cells. The antibody is an incomplete one which is demonstrable by the Coombs test, direct or indirect, and by various technical artifices such as the use of trypsin-treated cells. There is evidence that the warm and cold types are physically different. Fudenberg and Kunkel (I957) have found that the cold antibodies are usually associated with fast-moving gamma globulin that in the ultracentrifuge shows itself to be a macroglobulin with a sedimentation constant of $19 \mathrm{~S}$. In three patients with more acute haemolytic anaemia the abnormal antibody was carried by globulin of the commoner molecular size with a sedimentation constant of $7 \mathrm{~S}$, corresponding to a molecular weight of about 60,000 . Human beings given foreign blood by transfusion, etc., readily produce complete agglutinins, so that the failure to produce them against their own cells is 
an important point in considering the pathogenesis of haemolytic anaemia.

There are two possibilities. (i) The antigenicity of the red cells has been modified by viruses, drugs or toxins, so that they can now provoke a normal antibody-producing mechanism to produce antibody against these new determinants. In terms of the clonal selection theory, new determinants have appeared on the red cells which were not present at a time when the corresponding clones could have been eliminated.

The evidence speaks strongly against this. The antibodies present react with red cells other than those of the patient and can be shown to react with known antigens, often in the Rh group. Even the 'non-specific' antibodies which react with all but the rare $-D-/-D-$ genotype seem to correspond to a definable antigen. The suggestion often made that a virus may modify the cells to a new antigenicity has a small experimental basis (Burnet and Anderson, 1947), but it seems most unlikely that it plays any part in human disease.

(ii) The second possibility is that the antibodies represent the development of abnormal serum proteins, and this is the view to which Dacie inclines. On the clonal selection hypothesis we postulate somatic mutation giving rise to new patterns which are 'accidentally' appropriate to react with red cell determinants present in the body. Findings which can be regarded as favourable to this viewpoint are:

(a) There is frequently an abnormally high gamma globulin concentration in the blood.

(b) The antibodies present may react with known antigenic determinants on the red cells and they will react as readily with cells from other persons of the same blood type as with the patient's own cells.

(c) Thrombocytopenia is often associated with these conditions.

(d) The agglutinins present are usually incomplete and often 'cold'. 
All these suggest the production of relatively large amounts of inefficient antibody.

(e) Haemolytic crises are often seen in association with lymphatic leukaemia, Hodgkin's disease and other reticuloses where one might expect secondary mutations of mesenchymal cells already freed (? by somatic mutation) from some of the normal growth controls.

The possibility that the occurrence of somatic mutation or some equivalent process can be induced or at least made more frequently visible by virus infection must be kept in mind. The most striking example is the formation of cold agglutinins in virus pneumonia. This is almost constant in the condition due to Eaton's virus and in a small proportion of cases is accentuated to the level of a haemolytic anaemia. The complication is also reported, less commonly, in connection with infectious mononucleosis, another presumptive virus disease, which characteristically shows the appearance of non-specific circulating antibodies in high titre.

In both conditions, and perhaps in other infections not yet recognized, it seems likely that virus infection of lymph nodes or other mesenchymal centres grossly modifies the behaviour of globulin-producing cells. The possibilities to be considered would be either:

(i) an increased rate of mutation to forbidden patterns, which seems unlikely but not inconceivable when an in-built high mutability is postulated as characteristic of the cell type, or

(ii) a functional modification of infected cells rendering them insusceptible to some of the normal controls, including the homeostatic mechanism for the elimination of forbidden clones which we must continually postulate.

The strongest evidence in favour of the second is the fact that haemolytic anaemia following either virus pneumonia or infectious mononucleosis tends to show rapid and complete clinical and haematological recovery. This in itself 
seems to speak strongly in favour of the view that there is some mechanism by which a deviated immune response can be prevented from developing a vicious circle and giving rise to gross lesions and symptoms, and perhaps suggests that the change induced is dependent on the continued presence of virus in the cells of the clones concerned.

\section{(a) Sedormid purpura}

Sedormid purpura is of considerable interest in any discussion of auto-immune reactions since it is probably the most closely studied example of an auto-immune reaction due to a foreign chemical substance. Clinical findings point to an active development of the condition some time after the drug (allyl isopropyl acetyl urea) was first administered to the patient. Detailed studies such as those reviewed by Ackroyd (I955) have been made after the condition was recognized and the drug withdrawn. In a sensitive subject the clinical signs are those of a thrombocytopenic purpurasymptoms disappear on withdrawal of the drug. The significant immunological findings are: (a) a patch test of sedormid on the skin provokes a purpuric rash limited to the area of contact; $(b)$ patient's fresh serum + normal platelets + sedormid causes agglutination and lysis of platelets; $(c)$ patient's platelets in normal serum are not affected by sedormid; (d) patient's blood mixed with saturated sedormid in saline shows no clot retraction.

Ackroyd's interpretation is that platelet (or vascular endothelial cell) makes a loose union with sedormid and in this way the sedormid becomes an antigenic determinant. Circulating antibody is produced and when we have the complex, endothelial cell or platelet + sedormid + antibody + complement, a damaging reaction results. The antibody has no action on normal platelets and is clearly directed against the simple chemical determinant. In this case therefore there is no suggestion of an auto-immune response.

Where thrombocytopenic purpura is not associated with 
any drug or other causative factor, it seems likely that autoimmune processes are involved but it has proved very difficult to produce a reproducible method of demonstrating platelet agglutinins or lysins. In Ackroyd's view only a very small minority of the cases have been clearly shown to possess a circulating agglutinin or lysin although it seems likely that a relatively large proportion would be found to be of auto-immune nature were appropriately sensitive and reproducible tests available.

On the clonal selection theory these cases would be classed with the haemolytic anaemias as manifestations of casual mutation in individuals where the homeostatic mechanism was functioning inefficiently. The fact that they are not infrequently observed with the haemolytic anaemias adds weight to this contention.

An interesting condition, which presents some analogies with sedormid purpura, has recently been described as an unexpected result of incorporating zirconium salts into a proprietary deodorant. A proportion of users developed granulomatous lesions, a centimetre or two in diameter, in the axilla. Shelley and Hurley (I957) have reproduced the condition in one of ten volunteers who received small multiple subcutaneous and intradermal injections of sodium zirconium lactate. This subject showed a sudden appearance of granulomatous lesions at each of the sites of inoculation six months after the sensitizing injection. Similar granulomata were produced by test inoculations of very small amounts of zirconium salts in distant areas of skin. Biopsy of the lesions showed histologically nests of epithelioid cells with minimal round-cell infiltration, that is, an appearance probably indistinguishable from a sarcoid nodule.

One must assume that a zirconium-protein complex provides a new antigenic determinant and that when mesenchymal cells of a reactive clone reach an area containing the determinant, their reaction is to proliferate locally into an epithelioid nodule rather than give rise to the more 
characteristic accumulation of lymphocytes and plasma cells.

This, taken along with a good deal of other evidence, points to the necessity of postulating a further mode of reaction of the 'sensitized' mesenchymal cell. When it meets certain types of antigenic determinant, possibly in the form of material which is only slowly liberated from some deposit, the cell gives rise to a proliferative response in epithelioid or metalophil form.

\section{The collagen diseases}

It is generally accepted that there is at least an immunological component in the pathogenesis of the so-called collagen diseases. These are usually listed as:

(i) Rheumatic fever and acute nephritis.

(ii) Rheumatoid arthritis.

(iii) Disseminated lupus erythematosus and related conditions such as lupoid hepatitis.

(iv) Polymyositis and dermatomyositis.

(v) Scleroderma.

Local accumulations of lymphocytes and plasma cells in, or in the vicinity of, tissues responsible for symptoms are characteristic of all these conditions. Rheumatic fever and acute nephritis are in a rather special category in view of their aetiological relation to streptococcal infection and their predominant attack on the younger age groups. It is probably wise to keep them separate from what might be called (not very happily) the classical collagen diseases ((ii) to (v) above). We may take rheumatoid arthritis as the commonest example. In this the concentration of gamma globulin is usually higher than normal and two tests of what might be called pseudo-immunological character are usually positive. These are Rose's test (1948) in which sheep cells lightly treated with rabbit anti-sheep red cell serum (amboceptor) are agglutinated by rheumatoid arthritis serum to a much higher level than normal serum, and a capacity to agglutinate 
many strains of haemolytic streptococci and $R$ pneumococci. Neither of these tests is generally regarded as being more than indicative of the presence of abnormal adventitiously reactive globulin in the serum. The Cavelti's (I945) finding that tissue extracts from relevant tissues treated with streptococci reacted specifically has not been confirmed. There is, however, a considerable number of individually not very impressive experiments which suggest that the coexistence of streptococcal or staphylococcal infection or of products from these organisms confers 'antigenicity' on otherwise non-antigenic body components.

The problem of the aetiology and pathogenesis of the collagen diseases is far from solved. In all probability the causation is multiple and genetic, infective, immunological and 'stress' components may all play a part. Here we are concerned only to suggest that the clonal selection approach may have something to offer for the understanding of the immunological aspects of these diseases.

In view of the importance that has been ascribed to the lymphoid cells in immune processes, the primary approach will be to seek an explanation for the infiltration of lymphocytes and plasma cells in the tissues involved in the process. These cells are associated with areas of connective tissue that have undergone fibrinoid degeneration. Largely on the basis of Rich and Gregory's (I943a, b; 1944) experiments, in which rabbits received large doses of soluble foreign proteins intravenously, such a histological picture is widely held to be an index of the occurrence of antigen-antibody reaction in the tissues. Even in the case of rheumatic fever or acute nephritis, where there is clear association with streptococcal infection, there is no real evidence that streptococcal antigens are located in the target organs. If there is an immune reaction concerned, it is directed against tissue components.

As in the case of the haemolytic anaemias, the most promising approach is on the assumption of a dysfunction of some of the cells producing antibody globulin. Again some- 
thing of the nature of a somatic mutation must be postulated, but in regard to rheumatic fever and nephritis a definite role must be given to the streptococcus. The specially nephritogenic quality of some types of haemolytic streptococci (for example, Type 12) speaks for a rather specific role. It need not, however, be a mutagenic action. In all our discussions of clonal phenomena, we have two equally important operational factors: the appearance of the appropriate mutation and the opportunity for selective proliferation of the mutant. Streptococcal infection of the lymphoid tissues of the throat may be mutagenic, but equally it might favour the proliferation of forbidden clones by interfering with some process of control which would normally ensure their elimination. We should favour the second alternative but a decision is not vital. All we are concerned with is the appearance of mutant cells which differ from the normal in being susceptible to immunological stimulation by antigenic determinants present in some normal tissue components.

Lymphocytes are constantly 'exploring' tissues in most parts of the body and sooner or later one of our hypothetical mutant cells will meet the appropriate antigenic determinant. Depending on various circumstances, the cell's reaction to the specific stimulus might be:

(i) to release histamine and/or other pharmacologically active substances damaging both cell and tissue,

or (ii) to initiate proliferation either locally or in reticular tissue, either lymphocytes or plasma cells being produced.

A second ad hoc assumption which may be necessary is that the commonest determinant involved only becomes accessible to wandering cells under conditions of minor trauma or its equivalent.

It would be unprofitable to follow these hypotheses further until a more direct experimental approach is possible but it is easy to see that they could allow a picture to be built up corresponding reasonably well with the known pathology of 
these conditions. As has already been mentioned, a third assumption is specially necessary to give the basic hypothesis any validity - that there must exist a homeostatic mechanism which prevents most of the potentially harmful mutant clones that must be continually arising from becoming dominant enough to produce symptoms.

Possibly one of the commonest of forbidden antibody patterns is one directed against autologous gamma globulin that has been denatured by mild physical agents such as heat, surface spreading or attachment to a carrier of specific antigenic determinants. Najjar et al. (1955, I957) have studied extensively the aggregation reactions which indicate that an antigen-antibody complex has antigenic determinants not present in either component. I have been particularly interested in the potentialities of antibody against autologous denatured gamma globulin as a possible initiator of a vicious circle in persons who, for one reason or another, have a weak or malfunctioning homeostatic control. If antibody is deposited for any reason on a reactive surface within the body the new denatured configuration presents antigenic determinants which we can call $D$. This will on occasion stimulate cells of clone $d$ capable of producing antibody which will react with $D$. This in its turn will mean the deposition of more antibody globulin on the area and more production of $D$. One wonders whether we have here a mechanism which may have much to do with the accumulation of gamma globulin in the glomeruli of disseminated lupus cases and even with the deposition of amyloid which has most of the features of denatured gamma globulin in cases of chronic suppuration, etc.

Special interest attaches to those conditions in which one tissue is particularly involved, for example, polymyositis or lupoid hepatitis. The suggestion is strong here that the pathogenic mesenchymal clones react with determinants which are characteristic of, or much more frequently present on, the surface of the cells in question. In a considerable pro- 
portion of cases of lupoid hepatitis, continuing damage to hepatic cells is indicated by a high level of glutamic-oxaloacetic transaminase in the serum. O'Brien, Goble and Mackay (1958) have recently shown that this level can be strikingly reduced by treatment of the patient with adequate doses of cortisone. The obvious interpretation is that the cortisone has diminished or annulled the damaging effect of antigen-antibody reaction (or its equivalent) in the immediate proximity of the liver cells.

It appears that the antigenic determinants involved are released most freely from damaged tissue. This will hold, irrespective of whether, like the thyroglobulin in Hashimoto's disease, the liver antigen is of a type that is normally inaccessible and hence treated as foreign, or whether the mesenchymal cells represent mutant clones of forbidden specificity. In the second case, some breakdown in normal homeostasis may have to be postulated. A possible suggestion is that when a forbidden mutant appears corresponding to an antigenic determinant of an easily accessible body component, the forbidden clone is rapidly eliminated. When, however, the mutant corresponds to some rarer pattern not readily accessible except in inflamed or traumatized organs, the possibility of a vicious circle arises, presumably most readily when the organism is under stress. Cortisone can break the vicious circle.

The possibility that the establishment of one clone of such tissue-pathogenic lymphocytes may provide a basis on which other clones with different tissue specificity are more likely to arise, may have some bearing on the multiplicity of manifestations which can be observed in some cases of collagen disease.

There are many other rare conditions which have one or more of the characters that one would associate with the production of forbidden clones of mesenchymal cells. One of these is the complex of conditions in children typified by Letterer-Siwe disease. This condition is characterized by 
enlarged spleen and lymph nodes, anaemia, thrombocytopenia, skin eruption (sometimes with fever); occasionally localized defects in bone due to proliferation of mesenchymal cells are observed. In some sections from cases of this type eosinophils are abundant, in others lipoidal degeneration of reticular cells may be seen. It is a point of very considerable interest that the younger the age at which the condition appears the more malignant the course. Older children may recover.

In many ways this resembles disseminated lupus in a different age-group - a random and variable output of forbidden clones with failure of homeostatic control would provide a basis for most of the features. There is perhaps a suggestion that in infants and young people normal homeostatic control is effective and sensitive but that when the rare situation arises by which control is abrogated the effects can be acute and gross.

\section{(a) The L.E. cell test}

This is now generally considered to represent a demonstration that the serum contains an antibody-like globulin that reacts with, and facilitates the phagocytic ingestion of, nuclear material containing DNA. Recent studies with fluorescent antibody techniques make this interpretation almost certain (Godman and Deitch, I957; Holman and Kunkel, 1957).

Different methods of performing the test vary in their sensitivity and there are various appearances-for example, the so-called 'Tart' cells-which may lead to doubts in the interpretation of results. Using one of the more sensitive methods (Magath and Winkle, I952), Cowling and Thomas (1957) have recently analysed their positive results from patients studied in Melbourne. Amongst their thirty-nine positive cases were the following: D.L.E., 9, rheumatoid arthritis, 8; chronic hepatitis, Io; haemolytic anaemia, 2; thrombocytopenic purpura, 2; peripheral arterial disease, 6 ; carditis and pericarditis, 2.

The association with collagen diseases is striking and it 
should be noted that other manifestations than that given as primary diagnosis were present in this series. A positive Coombs test was observed, for instance, in five instances other than the four patients with haemolytic anaemia and/or thrombocytopenia.

\section{(b) Gajdusek's auto-immune complement fixation test}

At the experimental level, our interests in Melbourne have been largely confined to the application of this test (AICF) to the sera of patients in this group. The reaction was developed more or less by accident, Gajdusek's primary objective being to explore the possibility of recognizing a specific antigen of infectious hepatitis virus in livers of patients dying from acute yellow atrophy after hepatitis. The first reactions were obtained with convalescent sera from hepatitis cases but control antigens showed immediately that the reaction was obtainable with a variety of human organ extracts and had nothing to do with viral antigens. The titres with convalescent sera and from most sera of patients with chronic hepatitis were low, but as the range of sera tested was extended, three sources of high titre reactivity were found. A proportion of patients with (a) disseminated lupus erythematosus, (b) chronic hepatic disease, especially of the types defined by Saint et al. (I953) as chronic active hepatitis and by Mackay, Taft and Cowling (I956) as lupoid hepatitis, (c) macroglobulinaemia, gave titres measured in thousands. Each group, however, gave only a small proportion of high titre sera and all included sera which were completely negative in the test.

Over the last year there has been extensive serological study of these high titre sera and two findings may be stressed particularly.

(i) In the positive macroglobulinaemic sera the AICF reagent is present in the macroglobulin fraction but antibodies against herpes virus and staphylococcal toxin also present are not contained in that fraction. 
(ii) In five instances it has been possible to prepare autologous antigens from patients whose sera showed a high titre against standard antigens. In each case the liver antigen gave no reaction with the corresponding serum although other positive sera gave the usual high titres (Table 5).

Table 5. To show individuality of reaction to AICF test

Liver antigens from

Serum

$B E L$ (D.L.E.)

$M A G$ (Lupoid hepatitis)

JAM (Macroglobulinaemia)

$\overbrace{B E L \quad M A G \quad \mathcal{J A M} \quad \text { Other }}$

$\begin{array}{cccc}0 & - & 512 \\ 4000+ & 0 & 2000 & 4000+, 2000,2000\end{array}$

$8000+8000 \quad 0 \quad 16,000$

AICF titres are shown.

A number of other interesting features of the reaction may be mentioned.

(iii) There is no species specificity, rat tissues providing antigens of almost equivalent reactivity.

(iv) Immunization of rabbits with human tissue extracts gives a serum reacting in generally similar fashion to a positive human serum.

(v) Intensive immunization of rats with extracts of their own livers plus adjuvants gave no trace of AICF antibody (Dineen, unpublished).

(vi) There is considerable variation in titre from one sample of serum to another and a general tendency for the titre to fall under cortisone therapy.

(vii) There is no correlation between the presence or level of antibody (AICF) and the clinical manifestations of the disease state.

We have given reasons for accepting Hashimoto's disease as the result of an auto-immune reaction in the strict sense and have strongly supported Dacie's view that the acquired haemolytic anaemias are manifestations of somatic mutation or equivalent change in the antibody-producing cells. It 
remains to consider the nature of the process responsible for the appearance of AICF 'antibody'.

In any discussion of the AICF test, it seems advisable to include some consideration of the L.E. cell test. Results show a significant correlation between the two tests but it is by no means complete. A positive L.E. cell test is nowadays almost an essential before the diagnosis of D.L.E. can be accepted but this perhaps represents a rather unnatural convention. Both tests are found positive far more frequently in the 'collagen' diseases than in any other group and both are commonly associated with an increased gamma globulin level in the blood and with other serological findings such as Rose's reaction.

The evidence from Table 4 , that the AICF reagent is not active in most instances against an autologous antigen, almost eliminates any possibility that we are dealing with an auto-immune reaction of the Hashimoto type. It is much more likely that the appearance of both the AICF 'antibody' and the L.E. cell factor is related to change in the antibodyproducing cells.

This is possible, irrespective of whether the clonal selection hypothesis is acceptable or not. On any hypothesis of antibody production one can conceive of antibody-producing cells undergoing mutation and producing excessive amounts of pathological globulins with wide and rather random adventitious reactivity. The only additional feature supplied by the clonal selection hypothesis is that if the mutation produced 'sites' corresponding to body determinants, conditions which allowed those determinants to be present in the blood or lymph would, by hypothesis, favour the proliferation of the clones carrying the mutant pattern.

\section{Somatic mutation as a basis}

In order to cover what seems to be a continuous range of conditions from normal to grossly pathological, the minimal requirements for a theoretical interpretation are: 
(i) Variable extent of mutation, including the minor changes which are regarded as always occurring and providing the raw material for modification of antibody character.

(ii) Variable liberation by a variety of pathological processes of cell components not normally present in the body fluids, some of which will carry determinants not represented in normally accessible body components.

(iii) Selective proliferation or inhibition of mutant clones as determined by the nature of the mutation, the accessible concentration and duration of reactive determinants and the bearing of these on the type of response (activation, proliferation or inhibition) enforced on cells of the clones concerned.

(iv) A homeostatic mechanism must be postulated to allow, under favourable conditions, the extinction of mutant clones reacting with normal constituents of the internal environment. Presumably this consists of inhibition by excessive stimulation. It would be in accord with other pathological processes if the gross forms of these diseases only result when the homeostatic mechanism is for one reason or another rendered inoperative or grossly inefficient.

It is a legitimate objection to the hypothesis of somatic mutation wherever it is used that it makes it too easy to explain anything. Any quality required ad hoc to account for some phenomenon can be said to have resulted from somatic mutation. This should not, however, inhibit us from using the concept where it is needed. The only criteria which must be satisfied are $(a)$ that the quality appears to be distributed at random and $(b)$ that the cells responsible for the new quality can give rise to a clone of cells which can be distinguished from the parental clone when both are grown under the same conditions. The second of these cannot yet be applied in human medicine but the random character of 
the serological phenomena we are dealing with is perhaps their most obvious feature.

In many ways the situation in macroglobulinaemia is the one most suitable for consideration from this point of view. The majority of cases show no abnormal response in the AICF test and the serological features are simply those associated with a high concentration of macroglobulin. This is regarded as due to a near-malignant proliferation of mesenchymal cells, presumably those normally concerned to produce the macroglobulins of normal serum. If this results from somatic mutation, the changes have not been shown to influence the pattern of the globulin produced. In our two cases with high AICF titre an additional mutation or series of mutations must be postulated by which control over the pattern of the macroglobulin produced is wholly or partly lost. It would seem in fact that a randomization of protein pattern may have taken place basically similar to what is postulated by the clonal selection hypothesis as an essential feature of differentiation during normal development. Since other types of mutation have provided actively proliferating clones to produce the macroglobulin, there is no evidence one way or another as to whether contact of a secondarily modified cell with a corresponding determinant will stimulate it to proliferation.

\section{Congenital agammaglobulinaemia}

The normal infant is born with a relatively high proportion of maternal antibody (and gamma globulin) in his circulation. This is gradually used up and at two to three months the gamma globulin level is lower than at any other age (Fried and Henley, 1954). Subsequently active production of gamma globulin is initiated, possibly as a result of the entry of antigenic substances from the environment. There is evidence that in some children the normal response may be delayed (Spain, Bradess and Greenblatt, 1954), with a resulting period of high susceptibility to pyogenic infection. 
In a very small proportion no formation of gamma globulin ever occurs, presumably as a result of a genetic defect (Bruton, 1952). Such cases of congenital agammaglobulinaemia are of very great interest for immunological theory.

The condition, at least in typical form, is seen only in males and appears to be a sex-linked genetic anomaly. The diagnostic feature is an absence of demonstrable gamma globulin and of circulating antibody of all types. According to Martin (1954), the principal defect is in the $\gamma_{2}$ globulin. There are no natural isoagglutinins and no serological responses to any of the standard immunizing antigens.

Clinically, the usual feature is undue susceptibility to pyogenic infection, especially of the respiratory tract. Otherwise the children appear normal. It is of particular interest that they show normal responses to the common virus diseases, measles, chicken-pox and polio, influenza and Jennerian vaccination. In Bruton's first case three attacks of mumps were reported, but subsequent authors have found normal immunity to follow the primary attack and it appears highly probable that in this instance the subsequent attacks were of bacterial parotitis. In general, these virus infections are clinically normal and are followed by typical solid immunity.

Histologically the only characteristic feature is absence of plasma cells in the bone marrow and in lymph nodes draining areas that have received immunizing injections.

Other immunological features of interest are in relation to the responses which are not mediated by circulating antibody. The first report of skin transplantation (Good and Varco, $\left.1955^{b}\right)$ indicated that a graft from an unrelated individual was accepted for a long period, but subsequent experience indicates that all homografts are eventually rejected. Patients can be actively sensitized to tuberculin by BCG immunization (Porter, 1955) and to 2-4-dinitrofluorobenzene by treatment of the skin with the allergen. Sensitivity to the latter can be transferred passively to normal recipients by blood leucocytes (Good and Zak, 1956). 
The absence of natural isoagglutinins speaks strongly for the view that 'normal' antibodies are closely related to classical acquired antibodies. Good and Varco (I955a) have shown that even when patients are injected with foreign erythrocytes which in normal persons of their blood group would provoke an active rise in titre, there is no response whatever.

Rohn, Behnke and Bond (1954) describe a patient with agammaglobulinaemia who developed idiopathic haemolytic anaemia without evidence of auto-antibody production. The condition was cured by splenectomy; histologically the spleen showed excessive erythrophagocytosis.

These findings seem to be much more readily co-ordinated on a basis of the clonal selection theory than of any other theoretical concept. The basic anomaly on this view is a failure of lymphocytes (or other mesenchymal cells) carrying specific antibody-producing potentialities to develop into plasma cells, which are the only producers of circulating antibody. The functions that can be ascribed to cell-borne antibody are carried out normally or with only somewhat less efficiency than in the normal individual.

The three features of special interest are (i) the normal course of infection and immunity in virus disease, (ii) the fact that haemolytic anaemia can occur in an agammaglobulinaemic child, and (iii) the common occurrence of arthritis of rheumatoid type in children who have been maintained in reasonable health for some years by appropriate therapy. Each of these could be used as a text for an extensive discussion and as a stimulus to new experimental work on the phenomenon in question. Here we shall attempt only a very brief discussion to show the relation of these observations to the clonal selection theory.

(i) The virus diseases which have been reported on are all conditions of long incubation period in which there is reason to believe that the virus may spend the incubation period in intimate relationship with thelymphoid tissues, cf. the Warthin 
giant cells in measles. This suggests that in addition to the protection which is known to be mediated by circulating antibody, immunity is also associated with cellular changes which are sufficient to prevent multiplication in lymphoid tissue. The possibility that these viruses of long incubation period actually spend the period of incubation in potentially antibody-producing cells, may provide a fertile working hypothesis for the interpretation of what is, despite Fenner's work on ectromelia, still one of the major unsolved problems of pathology. It would be of special interest to know the response of a child with agammaglobulinaemia to a virus of the yellow fever or mosquito-borne encephalitis type in which viraemia occurs early and in which current teaching ascribes immunity wholly to serological factors.

(ii) On the interpretation of haemolytic disease presented earlier, we must consider that in Rohn's case the same basic change in one or more mesenchymal clones has occurred. The occurrence of excessive erythrophagocytosis might have several interpretations not mutually exclusive. (a) Abnormal 'stickiness' of lymphocytes in the spleen for erythrocytes might hold undue numbers to the walls of the sinusoids, and phagocytosis by macrophage cells would be expected to follow. (b) Contact of red cell determinant with specifically modified lymphocyte might detach cytoplasmic fragments which would sensitize the erythrocyte for phagocytosis. (c) Macrophages might develop from modified clones and show specific phagocytic activity for the red cells. This third alternative is a little out of line with our general conceptions and could only be considered if the other two were inadmissible.

(iii) In more than one place in our discussion of the pathology of the immune response, we have spoken of the necessity for some homeostatic mechanism to eliminate or temper the effect of the inevitable occasional mutation to a 'forbidden' pattern. It may be that the frequency with which young persons with agammaglobulinaemia develop 
arthritis provides an important clue to the nature of this process. There is evidence from studies of allergic conditions in man that classical-type antibody can protect against the symptom-producing power of hay-fever type antibody in the tissues. This suggests that if a potentially pathogenic pattern develops in a clone of cells of the type that has been suggested as responsible for one or other type of the collagen diseases, the result will be less damaging if some of the cells concerned develop into plasma cells and liberate the corresponding soluble antibody than if they do not. If this is the case, some delicately balanced equilibrium must be involved. One can conceive that under certain conditions sufficient circulating soluble antibody might be available to block all active determinants before they could stimulate cells of the clone to further proliferative and pathogenic activity. Equally possible is the suggestion that a body component with determinants reacting with cells carrying forbidden patterns might also induce overproduction of a non-specific globulin (? properdin) which prevented stimulation of specifically modified cells. Until much more is known about the pathogenesis of the collagen diseases and of the essential lesion in agammaglobulinaemia these are only speculations, but the phenomenon in question must eventually prove highly relevant to each.

\section{The nature of the homeostatic mechanism}

Since the existence of a mechanism by which forbidden clones can be prevented from developing is a vital part of the clonal selection theory, some effort to provide possible ways of implementing this requirement is needed. What is called for is a mechanism which will assure that a cell carrying a forbidden mutation will not give rise to a descendant clone under normal conditions, that this inhibition is not effective against mutations to other patterns, and that possibilities exist to account for the fact that forbidden patterns can flourish in certain pathological conditions. 
The necessary postulates can best be discussed in relation to Figure 8, p. 65, which was designed to show the response to antigen of specifically conditioned cells at different levels of maturity. If we consider a mature lymphocyte which by contact with the relevant antigenic determinant has been directed along the path of activation, settlement in an appropriate tissue niche and proliferation, we have to picture a process of what might be called rejuvenation to the 'primitive stem cell' phase followed by active proliferation with gradually increasing maturity of the descendant cells. It is reasonable therefore to suggest that the cell's reactivity to subsequent contact with the specific antigenic determinant changes progressively to a more and more immature type, that is, that at a certain stage, probably just before proliferation is well established, the cell can be destroyed by a second contact with the determinant. It might well be that there is some analogy between the radio-sensitive phase of antibody production and this postulated phase of specific susceptibility to new contact with antigenic determinant. Such a view would have a number of implications in line with the experimental findings.

Consider first a mutant cell, say a lymphocyte, which is specifically reactive with an amino-acid grouping present on the body's own plasma protein. With first contact the cell is activated and becomes progressively more sensitive to the antigenic determinant. This is ubiquitous inside the body and before the stage of proliferation is reached the inevitable secondary contacts will ensure that the cell is destroyed or rendered dormant. No proliferation and no antibody results.

Next consider a foreign antigenic determinant stimulating a cell of appropriate character. This settles down, let us assume, in the local lymph node. Here there is a very effective mechanism for the phagocytosis of foreign particles by littoral cells and unless the antigen concentration is very high most stimulated cells will cross over the vulnerable stage without 
destructive contact. If the local concentration is very high, for example by there being a substantial deposit with adjuvant in the drainage area, then one might expect the adjacent lymph node to show no antibody production while distant lymph nodes were highly active. This is precisely what Askonas and White (1956) found in their locally immunized guinea-pigs.

Finally there is the question to be considered of the way such a mechanism could break down in pathological conditions. If a lymph node, or equivalent structure such as the tonsil or some of the lymphoid accumulations in the intestinal tract, is subject to some particular type of infection, streptococcal or due to the agents of infectious mononucleosis or atypical pneumonia, possibilities arise that in that situation the infection, by enzymic action or otherwise, nearly eliminates one or more of the significant body determinants. If a mutant reacting with such a determinant should arise it may be stimulated to proliferate much in the way that a cell competent to react with a foreign antigenic determinant might. Only when cells of a clone so developed leave the centre will they have opportunity of reacting with the determinant and they will now by hypothesis have passed beyond the hypersusceptible state. In this type of anomaly the forbidden clones can only be produced in a centre modified by infection. Once the infection is eliminated they will rapidly disappear.

The nature of the longer-lasting abnormalities is obscure but in general one would expect them to be more directly dependent on the nature of the mutation itself. In another section it is pointed out that one type of somatic mutation in mesenchymal cells appears to result in a near-malignant clone of plasma cells (multiple myelomatosis) in which the physiological phase is stabilized. One can assume therefore that there could exist mutants in which the normal cycle of susceptibility on activation was modified in one way or another. In any given instance it would be necessary to know 
the nature of the antigenic determinant involved before making any more detailed suggestions.

Such a formulation of homeostatic mechanism is consistent both with the primary postulates of the clonal selection theory and with the available facts. It is by no means the only possible mechanism but the hypothesis presented seems readily susceptible to an experimental approach, notably by an elaboration of Askonas and White's findings in regard to the greater activity of distant lymph nodes than of those nearest an antigen deposit.

\section{Summary}

From the point of view taken in this chapter, Hashimoto's disease and perhaps sympathetic ophthalmia are the only true auto-immune diseases in the sense that they are produced as a result of the interaction of 'inaccessible' body components with a normal antibody-producing mechanism. The other conditions discussed, including haemolytic anaemias and the collagen diseases proper, are all regarded as being associated with abnormal functioning of clones of globulin-producing cells. These have taken on a new heritable character and are therefore said to have undergone somatic mutation. It must remain open whether such mutation is wholly random in its initiation or sometimes enforced-for example, by a chronic virus infection or some product of streptococcal growth. Until positive evidence to the contrary is available, we prefer to believe that the directive effect of infective or hormonal agents is due to selective factors acting on mutations occurring at random.

One might conclude that the evidence from (what might be called) the pathological aspects of antibody production is not inconsistent with, and in fact fits naturally into the framework of the clonal selection hypothesis. The direct template hypothesis appears to have no relevance to the phenomena. The indirect template theory, in which body components do not provoke antibody because of the presence 
of appropriate recognition units, could probably be restated so as to cover the facts but a complicated and clumsy formulation would be required. Jerne's natural selection theory in its original form rather fails to provide any point of contact with the problems of this field.

Perhaps one of the most attractive aspects of the clonal selection hypothesis is the way in which it allows immunological anomalies to be superimposed on malignant or premalignant processes. Cancer also is a clonal selection process.

\section{REFERENCES}

Ackroyd, J. F. (1955). Brit. med. Bull. 2, 28.

Askonas, B. A. \& White, R. G. (1956). Brit. 7. exp. Path. 37, 6r. Bruton, O. C. (1952). Pediatrics, 9, 722.

Burnet, F. M. \& Anderson, S. G. (1947). Aust. J. exp. Biol. med. Sci. 25, 2 I3.

Cavelti, P. A. \& Cavelti, E. S. (1945). Arch. Path. (Lab. Med.), 39, 148 .

Cowling, D. C. \& Thomas, D. (1957). Med. F. Aust. 1, 905.

DAcIE, J. V. (1954). The Haemolytic Anaemias (London).

Fried, G. J. \& Henley, W. L. (I 954). Pediatrics, r4, 59.

Fudenberg, H. H. \& Kunkel, H. G. (1957). 7. exp. Med. ro6, 689.

Gajduser, D. C. (1958). Arch. int. Med. rox, 9.

Gajdusek, D. C. \& Mackay, I. (1958). Arch. int. Med. xor, 30.

Godman, G. G. \& Deitch, A. D. (I957). J. exp. Med. 97, 575.

Good, R. A. \& VARCo, R. L. (1955 a). F. Lancet, 75, 245.

Good, R. A. \& Varco, R. L. (1955b). F. Amer. med. Ass. 157, 7 1 3.

Good, R. A. \& ZAK, S. J. (I956). Pediatrics, 18, ıо.

Holman, H. R. \& Kunkel, H. G. (1957). Science, 126, 162.

Lancet (1957). Editorial, r, 1675 .

Mackay, I. R., TAFT, L. I. \& Cowling, D. C. (1956). Lancet, 2, 1232.

Magath, T. B. \& Winkle, V. (1952). Amer. J. clin. Path. 22, 586.

Martin, N. H. (I954). Lancet, 2, I092.

NajJar, V. A. \& Fisher, J. (1955). Science, 122, 1272.

NajJar, V. A., Sidbury, J. B. \& Fisher, J. (1957). Biochim. biophys. acta, 26, I I4.

O’Brien, E. N., Goble, A. J. \& Mackay, I. R. (1958). Med. 7. Aust. (in the Press).

Porter, H. (1955). Amer. 7. Dis. Child. 9o, 6 i 7.

Rich, A. R. \& Gregory, J. E. (1943a). Johns Hopk. Hosp. Bull. 72, 65. Righ, A. R. \& Gregory, J. E. (1943 b). Johns Hopk. Hosp. Bull. 73, 239. Rich, A. R. \& Gregory, J. E. (I944). Johns Hopk. Hosp. Bull. 75, I I5. 
PATHOLOGY OF THE IMMUNE RESPONSE

Rohn, R. J., Behnke, R. H. \& Bond, W. H. (1954). F. Lab. clin. Med. 44, 918.

Roitt, I. M., Doniach, D. \& Campbell, P. N. (1956). Lancet, 2, 820.

Rose, H. M., Ragar, G., Pearce, E., Lipman, M. V. \& Olmstead, M. (1948). Proc. Soc. exp. Biol., N.Y., 68, I.

Saint, E. G., King, W. E., Joske, R. A. \& Finckh, E. S. (1953). Aust. Ann. med. 2, I13.

Shelley, W. B. \& Hurley, H. J. (1957). Nature, Lond., I8o, Io6o.

Spain, D. M., Bradess, V. A. \& Greenblatt, I. J. (i954). 7. Amer. med. Ass. 156, 246.

Witebsky, E. \& Rose, N. R. (1956). F. Immunol. 76, 408. 


\section{IX}

MODIFICATION OF THE GOURSE OF

INFECTIOUS DISEASE AS A RESULT OF

ANOMALIES OF THE IMMUNE RESPONSE

The rather unexpected finding that most children with agammaglobulinaemia can deal with most virus infections as effectively as normal individuals and show post-infection immunity has already been discussed. It is of equal interest that clinical observations suggest that there are other anomalies of the immune response which do interfere seriously with the normal course of common infections.

In this chapter an attempt is made to discuss aspects of immunological process which are or may be concerned in determining the course and some of the complications of certain infections. No attempt is made at completeness and, in general, only examples are discussed which present aspects relevant to the concepts of immunity with which we are concerned.

\section{Jennerian vaccination}

In many ways Jennerian vaccination provides the most comprehensive information. This is a standardized infection in which both the virus strain and the initial lesion are virtually identical in all subjects. The great majority of infections are uncomplicated but amongst the millions of children vaccinated annually there are always some severe illnesses and some deaths.

Kempe (1958) has classified these into several groups. There are first the eczematous children who develop severe infection of the affected skin by vaccinia virus and staphylococci (Kaposi's eruption).

The other groups comprise cases of progressive vaccinia 
in which the local lesion spreads progressively, usually with the appearance of distant foci as well. (I) Some of these are found to possess no gamma globulin and, unlike the agammaglobulinaemic children who respond normally, these fail to develop any skin sensitivity. The course appears to be uninfluenced by administration of immune globulin and in Kempe's experience always terminates fatally. In these children it seems that there is some additional functional weakness not yet clearly formulated that reduces the effectiveness of the complex cellular functions of which skin sensitivity is one index.

(2) There are some cases which have normal levels of globulin but nevertheless show progressive infection. One subgroup (2a) show a good clinical response to the administration of moderately large doses of immune gamma globulin, although they show little evidence of capacity for skin sensitization. Here it seems possible that we are dealing with individuals whose complement of available clones is inadequate to allow an effective early response, and the excess of antigen eventually paralyses immunological activity. The situation can be righted by provision of antibody produced by another individual.

( 2 b) Other cases do not respond even to very large doses of immune gamma globulin. In one patient shown me by Dr Kempe, recovery had followed heroic treatment involving surgical excision of the whole infected region and administration of leucocyte suspensions and lymph node cells from recently vaccinated donors. This is the only successful result so far obtained in this group of cases.

It may be of some interest to discuss the lines of investigation which could be suggested on the basis of the clonal selection theory of immunity for these cases of progressive vaccinia in infants. The possible functional disabilities are:

(i) Congenital agammaglobulinaemia.

(ii) Physiological delay in the normal development ofgamma globulin production around 2 to 3 months of age. 
(iii) Absence or weakness of capacity to develop skin sensitivity-this should be studied for the possibility that there is an associated failure to produce eosinophils.

(iv) Partial or complete failure to produce during differentiation clones of cells which could react with some of the significant antigenic determinants of vaccinia virus.

If the idea of differentiation of multiple clones by a random process is valid, one would expect on occasion to find curious deficiencies in ability to produce antibody due simply to random absence of the necessary prototype configuration. The strongest evidence for such an interpretation would be the knowledge that a child showing progressive vaccinia had previously responded normally to one of the common virus infections of childhood. If such a deficiency was responsible it would be more likely to be relative than absolute. In other words, if the child had been allowed time for appropriate mutant types to arise and be selected for proliferation, an effective response would have been possible. The suggestion is that with rare and 'poorly 'fitting' active sites any available were blocked rather than stimulated by the excess of antigen.

On this interpretation the logical approach to treatment would be (a) surgical excision of the source of antigen, (b) administration of immune gamma globulin, (c) immunization at a point distant from the primary lesion of dead virus plus adjuvant in the hope of facilitating the emergence of appropriately modified clones.

\section{Measles}

Measles is almost the best known of infectious diseases but its pathogenesis has never been clearly elucidated. Ever since the days of von Pirquet, observers have commented on the resemblance of the measles rash to an allergic manifestation. An individual measles lesion is hardly distinguishable from a positive pollen scratch test or a poison-ivy weal. 
In recent years two advances in knowledge seem to justify a further look at the possible significance of this resemblance. In the first place measles virus has now been grown by Enders and Peebles (1 954) in tissue culture, where it produces distinct intranuclear inclusions. The second reason is the recognition of a syndrome of giant-cell measles pneumonia as a rare fatal termination of measles presumably due to some anomaly of immunological response. The only histological evidence of measles in the incubation period is the presence of Warthin-Finkeldey giant cells in lymphoid tissue, and it is in line with all the available facts to assume that during the incubation period measles virus is present in mesenchymal cells.

With this rather slender basis of fact and deduction it may be interesting to speculate on the nature of the process that culminates in the symptomatic onset of measles 12 to 14 days after infection. We can postulate that a virus particle is taken up by mesenchymal cells to initiate infection. Multiplication is relatively slow and infection of other cells is initially confined to mesenchymal types.

It is not easy to picture the process in detail but one could suggest that a large part of the virus multiplication during the incubation period is intracellular without necrosis and that this acts as a stimulus to proliferation of at least a proportion of the mesenchymal cells concerned. In this way we can imagine the development of an extensive population of 'measles cells' which can pass like other mesenchymal cells to various parts of the body where their presence is recognizable by the proportion which have taken on the WarthinFinkeldey giant cell form (Hertzberg, 1932; Mulligan, 1944). Concomitantly an immunological response is developing-clones of appropriately patterned cells are proliferating, initially at least, as non-antibody producers for the most part. At some point an unstable situation develops which we may picture as immunological contact (of cell or globulin) with measles cells resulting in liberation 
of measles virus and antigens, of histamine and other pharmacologically active agents. This liberation of antigen will provoke a sharp secondary response of antibody production as well as of lymphoid cell proliferation. In the normal child one can assume that most of the measles cells suffer necrosis and disintegrate. Cell debris and virus, both probably 'opsonized' with antibody globulin, presumably enter the metabolic pool through phagocytosis and are rapidly disposed of. In the agammaglobulinaemic child we picture the same process minus any part played by circulating antibody-globulin. Immunity following infection will be ascribed to the continuing existence of immunologically modified clones which will provide cells capable of damaging measles cells and cutting short the process of virus multiplication in lymphoid tissue at an early stage.

Giant-cell pneumonia is not exclusively a sequel of measles but with the exception of pertussis the other aetiological agents are not clearly established. Three cases in children have been described from whom measles virus was isolated from the tissues post-mortem (Enders, I956; Cheatham, 1958). It is of interest that, of these, one suffered from fibrocystic disease of the pancreas, one was in the terminal stages of acute leukaemia and the third had been 'sick all his life' with recurrent diarrhoea. The condition may also be seen in very young infants and occasionally in children without intercurrent illness.

In most cases the measles rash is poorly developed, suggesting some inadequacy of the immunological process. The histology of the lung suggests strongly that many 'measles cells' have lodged there and have themselves developed into giant cells as well as infecting adjacent alveolar and bronchiolar epithelium without effective hindrance by immunological processes. The association with intercurrent debilitating disease would suggest that the immunological deficiency is a general one not to be allocated, for example, to an inability to produce the patterns required. It has been noted by 
Cheatham that plasma cells are very inconspicuous in the lung, which would be in line with a general inability to respond effectively to an immunological demand.

Recent work suggests strongly that canine distemper is due to a virus closely related to measles (Carlstrom, 1956), and it is of much interest that mink, which are highly susceptible to the disease, may die with a giant-cell pneumonia biologically almost identical with that of children with postmeasles giant-cell pneumonia (Pinkerton, Smiley and Anderson, 1945).

\section{Streptococcal infections}

One of the most important unsolved problems in medicine is the pathogenesis of rheumatic fever. The relation to pharyngeal infection with haemolytic streptococci is undoubted and there is a firm body of opinion that an immunological process is involved. The difficulty both here and for the related problem of acute glomerulo-nephritis is to define the nature of the hypothetical immunological process.

It has already been suggested that the answer may be found in the relationship of the streptococcus to the masses of mesenchymal cells in the tonsils and other accumulations of lymphoid tissue in the pharyngeal region. We have frequently pointed out that any clonal selection theory must accept the certainty that forbidden clones will constantly be arising and that in some way the normal body must inhibit or destroy such cells. We have constantly referred to the homeostatic mechanism needed to accomplish this. The existence of such a mechanism will have almost as a corollary the possibility of its distortion or loss under some circumstances.

It is not intrinsically unreasonable therefore to wonder whether the sub-acute infection of large regions of lymphoid tissue by streptococci might not sometimes distort the homeostatic control. As a working hypothesis to be studied for its 
relevance to the pathology and control of rheumatic fever, we may submit the following:

In children of appropriate genetic constitution suffering streptococcal infection of appropriate type and intensity, the internal environment of the lymphoid accumulations around the pharynx is modified. Amongst the thousands of clones represented, some mutation to a forbidden pattern occurs, the antigenic determinants in question being present in the inflamed region. In the absence of normal homeostasis the forbidden clones flourish along with other antibody-producing clones of normal type. It is probable that there is only a limited breakdown of control in some way dependent on the nature of the streptococcus since by no means every type of forbidden pattern is produced. The 'forbidden' cells gradually overflow into blood and body fluids and find regions where they can interact with the corresponding antigenic determinants $(X Y)$. One would postulate that the lymphocytic and inflammatory accumulations characteristic of the rheumatic process will arise where the carrier of the $X Y$ determinants is to some extent accessible and can be made more accessible or produced as a result of inflammatory action. In this way one can conceive of contact of forbidden cell with $X$ resulting in damage to the cell and to immediately adjacent tissue, resulting in greater liberation of $X$ and increased opportunity for entry of forbidden cells into the region. The result will be the rapid build-up by 'vicious circle' principles of areas of acute inflammation.

With the waning of the streptococcal infection one would postulate a gradual reorganization of the missing control, with the elimination or inactivation of the forbidden clones and a break in the local vicious circle.

Acute nephritis might be accounted for in similar fashion but it should be noted that it is exceptionally rare for one streptococcal pharyngitis to initiate both rheumatic fever and acute glomerulonephritis. The implication is obvious that the forbidden clone which can emerge depends very much 
on the character of the infecting streptococcus. The predominance of Type 12 streptococci in causing acute nephritis presumably demands that in addition to providing the conditions for weakening control the streptococcus produces locally in one way or another antigenic determinants which are common to the vulnerable glomerular component and which are different from those concerned in the pathogenesis of rheumatic fever.

From our present point of view the main problem presenting itself is to find why only a relatively small though still substantial proportion of people who suffer streptococcal pharyngitis develop rheumatic fever or nephritis. Standard epidemiological approaches indicate some genetic predisposition with a higher incidence in cold than in warm countries and amongst groups of lower economic status. None of these provides any specific clue at the immunological level, but the genetic aspect may be worth a little speculation. On a clonal selection theory of immunity one would expect that genetic factors might determine to some extent at least the composition of the range of primary patterns carried by mesenchymal clones at the time of birth. This could be reflected either in occasional failure to develop antibody against some significant group of antigenic determinants or more frequent appearance of one or other type of forbidden mutation. It is, of course, equally possible that the homeostatic mechanism varies in effectiveness for genetic reasons. Obviously no answer will be possible until the nature of the antigenic determinants with which the forbidden patterns react has been established. Does in fact the clonal selection theory offer any new leads to the experimental or clinical investigation of rheumatic fever?

If one disregards all questions of ethics, humanity and practicability, what investigations on rheumatic fever patients could establish or refute the present hypothesis? The assumption basically is that just before the onset of the acute phase lymphoid tissue (tonsils and cervical lymph nodes) contain 
large numbers of cells carrying forbidden patterns capable of reacting with mildly traumatized tissue. The experimental approach then would be to excise a swollen cervical lymph node, prepare a living cell suspension and inject this intradermally in a series of normal children, preferably over one of the sites of election for rheumatic nodules. If it could be shown that lymph-node cells taken very early in a rheumatic fever episode produced an inflamed nodule when injected into the skin of a normal child while cells from a nonrheumatic streptococcal pharyngitis patient did not, a very strong prima facie case for the present interpretation would have been established. In the case of glomerulonephritis the equivalent approach would be to give the corresponding cervical lymph-node cells intravenously to a normal child and examine the urine for evidence of transient damage to the glomeruli. Again, adequate control could theoretically allow a positive finding to be established. Whether such experiments are justifiable must be left to the judgment of paediatricians.

If such an approach gave rise to positive reproducible findings a wide field for further research would be opened up. Obviously what must be found is the nature of the antigenic determinants with which the forbidden clones react. If, to a series of patches infiltrated with lymphoid cells, solutions containing determinants $X \mathcal{Y}$ on suitable carriers were injected, one would expect the intensity of the reaction to be increased beyond that of controls. In principle this might allow the identification of $X$ and $\Upsilon$. The possibility might, of course, also have to be considered that $X$ and $Y$ in the absence of macromolecular carrier might specifically inhibit the reaction-and in so doing offer a possible lead to a chemotherapeutic approach. 


\section{Sarcoidosis}

One of the most interesting current problems in aetiology is sarcoidosis. This is a chronic and usually benign disease which is diagnosed essentially by the histological demonstration of the typical granuloma composed of epithelioid cells, occasional Langhan's-type giant cells with some infiltration with lymphocytes-which, however, is much less than is usually seen with tuberculosis nodules-and showing plasma cells in many instances. The main lesions are likely to be found in the lymph nodes at the hilum of the lungs (Smellie and Hoyle, I957; Lofgren, 1953). During the height of the disease, granulomatous lesions are widespread in the body and a useful method of histological diagnosis is by liver biopsy. In Smellie and Hoyle's series of 66 patients who showed radiological evidence of enlarged hilar lymph nodes when first seen, 2 I showed the development of radiologically visible lesions in the lung fields, followed in the majority (I2) by a return to normal appearances. The other common manifestations are erythema nodosum and skin sarcoids, and uveitis, but lesions may on occasion be found in almost any organ. Generalized lymph-node enlargement is common.

The relation of sarcoidosis to tuberculosis has been widely discussed. At the present time it is probably correct to say that a majority of writers favour the opinion that sarcoidosis represents a result of infection with the tubercle bacillus. Others would consider the association with tuberculosis nonessential and regard the disease as a special type of reactivity which might be called into play by a variety of stimuli. In the majority of patients the Mantoux test is negative, or positive only with a large dose, but a considerable minority show a positive test to a small dose of tuberculin. Tubercle bacilli are present from the lesions and a positive culture will usually be taken as rendering the diagnosis of sarcoid highly unlikely. The only laboratory type of aid to diagnosis is the Kveim test. This is an intradermal inoculation of a heated 
suspension of typical sarcoid tissue obtained at biopsy. In a positive test a slowly appearing nodule develops over two to four weeks; in the fully developed form it is reddish purple in colour, raised and firm and 7 or $8 \mathrm{~mm}$. in diameter. According to Seltzbach and Ehrlich (1954), an essential part of the test is to make a biopsy of the nodule at four weeks and establish that its histology is typical of a sarcoid nodule. If this is done they believe that the difficulty arising from nonspecific reactions is readily overcome. Control extracts from normal lymph nodes are inert.

The other relevant finding, so far unconfirmed, is due to Nethercott and Strawbridge ( 1956 ). They found in sarcoid material free of tubercle bacilli amounts of mycolic and diaminopimelic acids which provided presumptive evidence of past or present infection with acid-fast bacilli. In Smellie and Hoyle's series there was a history of contact with cases of tuberculosis, sometimes close, in $48 \%$ of cases, which seems too high to be wholly coincidental. Scadding (1956) has described several cases of proved tuberculosis with negative Mantoux reaction in which the lesions were of an indolent nature closely resembling sarcoid. He believes that no real dividing line can be drawn between these cases and those diagnosed as typical sarcoidosis.

In addition to the hypothesis of anergic tuberculosis, other aetiological suggestions have been that the condition is a virus disease analogous to lymphogranuloma inguinale (cf. the Frei and Kveim tests) or that there is a manifestation of hypersensitivity. From the point of view of the clonal approach to mesenchymal cell reactions, the Kveim reaction probably provides the major clue. This suggests that there is deposited in the dermis non-diffusible material which has determinants specifically related to some clones of cells within the body. When representatives of these clones reach the site, they settle and slowly proliferate, eventually building up the typical sarcoid nodule. The various lesions elsewhere in the body which arise during the course of the disease must be 
presumed to have a similar basic pathology: the lodgment of a source of specific antigenic determinants and the accumulation around the region of mesenchymal cells of the specifically related clones.

The real problem is the source of the antigenic determinants. If we accept the evidence that tubercle bacilli are not directly involved but are strongly suspected of having some indirect role to play, the two possibilities may be considered.

(i) The tubercle bacillus is undergoing multiplication in some form other than that of a cultivatable acid-fast bacillus. In view of modern work on protoplasts and $L$ forms, it is by no means inconceivable that a form derived from the tubercle bacillus, but lacking power to produce the characteristic cell wall, might find an opportunity to persist as an intracellular parasite of mesenchymal cells and still produce some of the antigenic determinants that make it different from any body component. The necessary assumptions are (a) that the protoplast form is a permanent mutant not cultivatable and only very rarely subject to reversion to the acid-fast bacillary form, $(b)$ that infected cells can on occasion pass to various parts of the body and there initiate foci by the combined action of the intracellular parasite and the mesenchymal response to the foreign determinants, $(c)$ that in most cases the infected cells are gradually eliminated. A corollary to such an hypothesis would be that in the usual development of the tuberculous granuloma, the epithelioid cells would probably contain the hypothetical protoplast form of the bacillus.

This suggests an interesting experimental approach which I believe has not so far been reported, namely that an extract of tuberculous tissue composed mainly of uncaseated epithelioid cells should function as a Kveim reagent.

Recent reports by Scadding (1956) offer rather strong support for this view but only if it is combined with the recognition of a host difference in reactivity to the tubercle 
bacillus. He found that when tubercle bacilli could be isolated from cases of sarcoidosis, they were of human type with normal virulence for guinea-pigs. Further, Pyke and Scadding (1952) and Citron and Scadding (1957) have shown that many sarcoid cases resemble cases of tuberculosis desensitized by tuberculin, in showing a positive Mantoux reaction to tuberculin + cortisone but not to tuberculin alone.

The immunological interpretation of the situation would perhaps be in some such terms as the following:

The basic genetic character by which the individual differs from the normal is almost the converse of agammaglobulinaemia. There is an abnormally efficient production of classical antibody and a poor development of the antibodycarrying cells (lymphocytes presumably) responsible for Mantoux reaction and the other manifestations of hypersensitivity. The result of tuberculous infection in such a person would in most instances be expected to be overcome without symptoms. On our hypothesis, the only way in which a lesion would develop is by the tubercle bacillus taking on the low-grade protoplast form and behaving virtually as a persisting virus multiplying only sufficiently to keep more or less in pace with the cells that contain it. Rarely reversion to the classical form of the tubercle bacillus may occur; more often the condition gradually eliminates itself; and very rarely a widespread fatal semi-malignant condition ensues.

(ii) The second alternative is that usually in the course of a tuberculous process, but sometimes perhaps independently, a low-grade virus, possibly resembling lymphogranuloma inguinale virus (LGV), infects the mesenchymal cells and thereafter behaves as the hypothetical protoplast of (i). There is no positive evidence of the existence of such a virus. 


\section{REFERENCES}

Carlstrom, G. (1956). Acta paediat., Stockh., 45, r8o.

Cheatham, W. J. (1958). Personal communication.

Grtron, K. M. \& Scadding, J. G. (1957). Quart. F. Med. 26, 277.

Enders, J. F. (1956). Ann. int. Med. 45, 331.

Enders, J. F. \& Peebles, T. C. (1954). Proc. Soc. exp. Biol., N.Y., 86, 277.

Herzberg, M. (1932). 7. Amer. med. Ass. 78, 139.

KeMPE, H. (1958). Personal communication.

Lofgren, S. (1953). Acta. med. scand. 145, 424, 465.

Mulligan, R. M. (1944). Arch. Path. (Lab. Med.), 37, 6r.

Nethercott, S. E. \& Strawbridge, W. G. (1956). Lancet, 2, I 132.

Pinkerton, H., Smiley, W. L. \& Anderson, W. A. D. (1945). Amer. 7. Path. 21, I.

Pyke, D. A. \& Scadding, J. G. (1952). Brit. med. F. 2, il 26.

Scadding, J. G. (1956). Tubercle, 27, 37 I.

Seltzbach, L. E. \& Ehrlich, J. C. (1954). Amer. J. Med. 16, 790.

Smellie, H. \& Hoyle, C. (I957). Lancet, 2, 66. 


\section{$\mathrm{X}$}

PROLIFERATIVE DISEASES OF THE

RETIGULAR TISSUE AND

MESENCHYMAL GELLS

In any discussion of the pathology of immunity a number of conditions of malignant or semi-malignant character must be included, and it is impossible to avoid some discussion of the nature of malignant disease in the process. For reasons which have been discussed elsewhere (Burnet, 1957) the basic approach to cancer will be along the lines of those who favour the somatic mutation theory. It will be advisable, therefore, at this point to say something more about the general concept of somatic mutation and its implications.

\section{Somatic mutation}

Geneticists agree that any genetic system, whether of man, mouse, fruit fly or influenza virus, can undergo mutation. There is every reason to believe that the chromosomes of all somatic cells are as liable to mutation as those of the germ cells. If this is the case it might be a reasonable guess that $10^{5}$ mutational events are taking place every day in the somatic cells of the human body.

Mutation by definition is an inheritable change taking place at random amongst a population of organisms or cells. It can affect the overall character of the population in which it occurs only if it results in the appearance of a large enough proportion of progeny with the new character. At the level of the cell populations which make up the mammalian body there are only three ways in which this can be accomplished.

(i) The mutation occurs at a very early stage of embryonic development in a cell which by the normal processes of development and differentiation will have many descendants. 
In Australia recently there has been much interest in what are known as fleece mosaics in sheep (Fraser and Short, 1958). Certain short-woolled sheep are found to produce areas of long loosely crimped wool over sharply delimited areas of skin. The evidence from the extent of the skin involved in the thirty or forty sheep which have been studied suggests strongly that the condition results from a mutation occurring in one of the early divisions of the fertilized ovum. One sheep in which approximately $50 \%$ of the skin area was involved presumably developed from an embryo in which the mutation occurred in one of the cells from the first segmentation division. Three others with 20 to $25 \%$ involvement might have sprung from embryos in which the mutation occurred one cell generation later.

(ii) Somatic mutation produces a change in a cell by which its descendants respond to some environmental stimulus by active proliferation which gives them a survival advantage over unmutated cells of the same stock.

The preceding chapters were concerned with the implications of this approach at the immunological level. It was assumed"that when, by differentiation or mutation, a mesenchymal cell developed patterns with a complementary relationship to an antigenic determinant, contact with that determinant under the right conditions caused selective proliferation of cells of that clone. At the present time no other physiological system is known for which a process of this type can be postulated.

(iii) Somatic mutation results in a change by which a cell and its descendants are released from one or more of the controls that maintained its type in normal spatial and numerical relation with the rest of the body.

This could equally well be expressed by saying that the mutation confers an intrinsic proliferative advantage on the mutant clone under the conditions existing in the body. Such changes are those that initiate progress of a cell line on the road to malignancy. The difference from the second (im- 
munologically determined) group is not necessarily very great. Any mutation, whether genetic or somatic, produces its effect on the phenotype only against the background of all the impacts of internal and external environments on the cells in question.

There is a genetically determined condition of one strain of merino sheep in Australia which shows itself by the appearance of multiple skin carcinomata. The cancers arise, however, only where grass seeds become embedded in the skin. The grass seed here is an essential part of the background against which the phenotypic character-multiple skin cancer development-is called into being. The development of malignant disease is, I believe, by far the most important aspect of somatic mutation, but somatic mutation can never occur in vacuo, and its results will always be determined more by the conditions which allow or inhibit selective preferential survival of the clone than by the intrinsic character of the mutation.

Those are the three conditions under which somatic mutation is significant. The converse should also be stressed. When, in a given tissue, one cell in a million mutates, the effect is completely insignificant if no survival advantage results. A well-known human genetic anomaly is oligophrenia associated with absence of phenyl-pyruvic oxidase. This produces idiocy when fully expressed. If the same mutation occurred, say, in a single liver cell, there would be no conceivable way in which it could be recognized. No matter how drastic were functional changes in a single cell, they could never be recognized if $10^{5}$ or $10^{6}$ normal cells were also present in the same tissue.

The decision to include a chapter on proliferative diseases of the lymphoid and reticular tissue was based mainly on grounds of logic and symmetry. There are no significantly new facts or ideas to be described, but the field does seem to be one from which useful suggestions may be drawn bearing on inflammatory and immune responses on the one side and malignant disease on the other.

In human pathology the conditions that can be included 
in the group are the leukaemias, multiple myelomatosis, Hodgkin's disease and a variety of rarer conditions comprehensively referred to as reticuloses.

\section{General considerations}

Experimental work on the theme of proliferative disease of mesenchymal cells has been largely confined to mice and chickens, and in both species the possibility of inducing some types of proliferative lesion with virus-like agents has added special interest to their investigation.

Perhaps the best justification for examining the pathology of human reticular tissue for evidence on a theme which provides a formally similar mechanism for antibody production and for malignancy is provided by the notorious difficulty of deciding whether Hodgkin's disease and other adenopathies are inflammatory or neoplastic in character. In addition, most of the types of cell in which we are interested are relatively mobile and have, regularly or occasionally, representatives in the circulating blood where they are easily available for investigation. Further, affected lymph nodes tend to be widely distributed and many are superficial enough to allow accurate assessment of change in size and to make biopsy of a typical gland a routine clinical procedure.

As a starting point, we may adopt Marshall's (1956) classification of hyperplastic and neoplastic conditions of the lymph nodes.

According to this there are four types of reticular tissue hyperplasia:

(i) Regenerative.

(ii) Functional, for example, of macrophage cells in reaction to foreign bodies and certain lipoid disorders, and hyperplasia of all elements in response to antigenic and infective agents-the typical lymph node of a chronic infective process.

(iii) Endocrine, as in Addison's disease.

(iv) of unknown origin, for example, sarcoidosis. 
In a hyperplasia, as opposed to a neoplastic condition, the proliferation is not unlimited in any one site, however prolonged the stimulus, and there is a considerable constancy of cytological response in relation to the stimulating agent.

Neoplastic conditions, on the other hand, rarely show local and limited cellular proliferation, and grade into conditions showing all the typical features of malignancy: invasion of adjacent normal tissues and abnormal cytological appearances, including atypical mitoses. It is, however, particularly characteristic of the group of reticuloses that there are many conditions in which, although cell proliferation is progressive and leads inevitably to death of the subject, the gross features of malignant disease are lacking or appear only as an irregular terminal event. Hodgkin's disease, follicular lymphoma and chronic lymphatic leukaemia are clearly not malignant conditions in any ordinary sense. Equally there is no evidence that they have a micro-organismal cause. There is everything to be said for the contention by Marshall (1956) that they represent conditioned neoplasms in the sense of Furth (1953, 1954), that is, they are still under partial control of hormones or other normal controlling agents.

Every cell in the body is played on by controls which ensure that the number and disposition of any type is in a reasonable relationship to the current needs of the body, whether these are physiological or represent evolutionarily significant impacts of trauma or infectious disease. The number of lymphocytes in the blood fluctuates only within narrow limits, despite the enormous numbers poured in from the thoracic duct. The lymph nodes in health remain approximately uniform in size and internal architecture. Although the controls which maintain this homeostasis are by no means fully understood, it is clear enough that they exist. There is a widespread opinion, which is rather difficult to prove or disprove, that, on the whole, control of somatic cells is essentially a matter of holding in leash tendencies of 
cells to grow and multiply, rather than of stimulating cells to abnormal activity. This is based, perhaps rather inadequately, on the behaviour of cells in tissue culture and in the process of repair, plus, perhaps, the feeling that control of any sort of mechanism tends to take the form of inhibitory devices. We assume that in the body the internal environment contains adequate nutrients to allow any cell to grow like a malignant cell, but that each cell is prevented from so doing by a variety of intrinsic and extrinsic controls.

In Addison's disease and in experimental adrenalectomy, there is a moderate enlargement of lymph nodes and a blood lymphocytosis-the obvious implication is that adrenal hormones play a part in the control of lymphocyte levels in the body. It is well-known that in acute lymphatic leukaemia in children there is a well-marked response to the administration of cortisone, indicating that, to some extent at least, the cells concerned are still responsive to that particular control. The other controls of the lymphocyte, both as regards numbers in the peripheral blood and the total number and distribution within the body, are still unspecified. There is a very interesting hint from the work of my colleague Metcalf (1956), that the thymus secretes a lymphocytosisstimulating factor which may play a part in the hormonal control of levels of lymphocytes in the circulating blood.

\section{Experimental leukaemia}

Most of the recent work on experimental leukaemia has been concerned with the spontaneous disease as seen in pure strains of mice. This work has been important in defining some of the hormonal controls which can prevent or accelerate the appearance of leukaemia, and, before continuing the discussion of human leukaemia, it seems desirable to provide a short account of the experimental studies in mice. Following largely the work of Hauschka, Furth, Kaplan and Law (as reviewed in Hauschka and Furth, I957; Law, I957; Kaplan, 1954), we may summarize the features of mouse 
leukaemia which are relevant in the present connection as follows :

(i) Different pure strains of mice differ greatly in their spontaneous incidence of leukaemia and in the ease with which leukaemogenic agents can induce the condition.

(ii) With suitable mouse strains, a wide variety of agents, notably ionizing radiation, carcinogens of methylcholanthrene type, and oestrogenic hormones, can be shown to increase the incidence of leukaemia, almost always of lymphocytic type.

(iii) If appropriate host and donor strains of mice are used, it is possible to induce the subsequent appearance of leukaemia by inoculation of new-born mice with noncellular extracts from certain types of leukaemia and malignant tumour (Gross, I95I).

(iv) A similar agent, active in transmitting leukaemia to older mice, has been described by Friend (I957).

(v) In many strains the presence of thymus is necessary for the induction of leukaemia by X-rays or carcinogens. An indirect mechanism of irradiation-leukaemogenesis is postulated by Kaplan (I954), since it can be shown that, in some experiments, tumours appearing in thymectomized irradiated mice grafted (after irradiation) with normal thymus arose in the thymus and were genetically of the donor type. Law confirms this, but only for a minority. In most experiments the tumours appeared in the graft area but were genetically of the host type.

(vi) Virus-like objects of rather characteristically variable size have been found in many mouse tumours and leukaemic cells by electron microscopy (see Dmochowski, r957).

One's first comment would be that there is an air of biological unreality about much mouse leukaemia work, simply because all transmission experiments are by parenteral 
inoculation in pure strains of mice. Neither genetically pure strains nor any close analogy to intraperitoneal inoculation exists in nature. Results must therefore be very carefully examined before any conclusions are transferred to the human field. Two topics call for some discussion: (a) whether the evidence for indirect production of leukaemia eliminates the general idea of somatic mutation, and $(b)$ the implication of transmission by non-cellular ('viral') agents.

(a) Kaplan (1954) maintains that the effect of irradiation in producing lymphomata in the thymus and leukaemia in $\mathrm{C}_{57} \mathrm{~B}$ I mice is an indirect one, and not due to the induction of somatic mutation in some of the irradiated cells. In his view the thymus atrophy following irradiation is mainly indirect, hormonal changes inducing extensive cellular destruction. During the process of regeneration, which is itself under hormonal control, opportunities are offered for cells to escape control and become malignant. Kaplan believes that somatic mutation plays no part and, by implication, that any consideration along clonal lines would be inappropriate.

This is an important current point of difference amongst those concerned with the more academic aspects of cancer research. Our approach would be that the essential feature is that finally a population of cells emerges which can be shown to be genetically different from normal lymphocytes by their capacity to produce disease in isologous hosts. We know of no way by which genetic change can occur other than by somatic mutation, and we therefore postulate that in these mice somatic mutation has occurred at some point in the ancestry of the eventual leukaemic cells.

We do not exclude the possibility that in certain strains of mice mutation to a potentially leukaemic character may be of universal occurrence, so that the thymus will always contain a few cells less susceptible to control than their congeners. Irrespective of whether these mutant forms were pre-existent or induced by X-ray, it seems likely that the process leading to the emergence of the malignant potentiality 
of these cells takes place when the irradiated or grafted tissue is regenerating under difficulties. It is quite probable that from the point of view of whether and when leukaemia develops, the indirect hormonal conditions are the dominant factors, but the difference in the behaviour of the cells from the normal lymphocytes is based on somatic mutation. The only criterion of mutation is that it occurs at random through a cell population and produces descendants that, in the same test environment, are clearly distinguishable from cells of the unmodified parental clone. There is the further point that if a cell line is, by virtue of a minor mutational change plus appropriate environmental conditions (usually hormonal), allowed a marked selective advantage, new opportunities for mutation within the line are provided. It is well accepted that in general a conditioned neoplasm is far more likely to give rise to an unconditioned malignant tumour than is normal tissue. In the case of the regenerating thymus cells in the inhospitable environment of an irradiated host, we can readily conceive that a mutant form would have an advantage over normal cells which it would lack if the environment were brought back to normal by bone-marrow injection or its equivalent. The possibility would then emerge of a secondary mutation to a form with an advantage over the normal, even in a normal environment.

A final possibility is that a mutant character provoked in a surviving irradiated cell $(A)$ of the host might be transduced to a regenerating cell $(B)$ of the grafted thymus. Under the complex local and hormonal conditions of the situation, cell $B$ and its descendants might break away from control more effectively than $A$ and emerge into dominance as the leukaemic strain.

(b) No virus could conceivably survive in nature if it were limited to genetically homozygous hosts, and the 'operational viruses' concerned in this field seem to have only two possible interpretations: (i) They are casual viruses which in most strains produce no symptoms but which in somatically un- 
stable strains can disturb some control and multiply preferentially in the uncontrolled cells; this seems the most likely interpretation of the Bittner mammary cancer factor. (ii) The agents are subcellular units genetically of host origin.

An attempt may be made to examine mouse leukaemia from this second point of view, having particularly in mind Medawar's speculations about the function of lymphocytes as carriers of nucleic acid. We have already suggested that there is immunological evidence for the possibility that in the lymph nodes transfer of genetic qualities may occur between lymphoblasts multiplying in proximity to each other. The evidence from isotope experiments that DNA can be transferred amongst lymphocytes provides a slight but significant basis for this speculation. In turn this opens up the possibility of providing a more definite picture of the second type of operational virus. If it is accepted that, under some circumstances, a lymphocyte (mesenchymal cell) can take up functional DNA, so modifying its genotype that it is now subject to growth-stimulating influence previously ineffective, the possibility of an analogy in leukaemic processes is obvious.

We might suggest that certain cells on replication release, in the fashion postulated by Medawar (I957), DNA-containing units which can be taken up by other growing cells of the mesenchymal series. In what is probably a very small proportion of such interactions, a fragment of DNA is built into the genome (transduction) and as a result some control is abrogated, just as may occur in a spontaneous mutation. It is only necessary to add the further assumption that these modified cells will, like a transformed pneumococcus, be able in their turn to liberate the agent which converted the parental cell to the new type. It is stressed that the only virtue of this formulation is that it brings the autonomous subcellular unit, plasmagene, etc., of many previous writers into relationship with phenomena observed in two other fields-the unexpectedly long persistence of labelled DNA in populations 
of lymphocytes and some features of the anamnestic responses in immunology. Experimental study of the possibility of inducing leukaemia or neoplastic change in other cells by injection of nucleic acids is actively in progress in several laboratories, and clarification of the situation can be expected in the near future.

\section{Human leukaemia}

Returning to the topic of leukaemia in man, and concentrating on clonal aspects, we will be specially concerned to look for evidence of step-like changes and of the increased frequency of a further mutation on top of one that has already induced proliferative change of a cell type.

\section{(a) Chronic myeloid leukaemia}

The best example is chronic myeloid leukaemia. It is not very infrequent for this to be recognized by the accident of a blood smear being examined routinely, before the patient shows any definitive symptoms. In such instances the myelocytic series is clearly proliferating abnormally - this is evident both from the peripheral blood and from bone marrow examination. It is never possible to be certain how a mutational change is initiated, but it is particularly in regard to myeloid leukaemia that the evidence incriminating ionizing radiation is strongest. I find it impossible to conceive any reasonably direct effect of small doses of radiation that would not be due to a mutation impressed in the first instance on an isolated cell. One could believe that even if appropriate damage were inflicted on a 'blast' cell, it might remain inert until general or local conditions allowed it to initiate a proliferative clone. It seems quite possible that this may allow a multiclonal as well as a uniclonal origin for some leukaemias. The relevant point, however, is simply that a proliferative process of mutational origin has grossly altered the number and distribution of certain clones of cells, but has left them with many normal or near-normal characteristics 
in that there is usually neither gross controlled local proliferation nor any invasion of tissues of a malignant type. Any invasion is simply of the character of normal leucocytic entry into the tissues.

Chronic myeloid leukaemia may persist in its quiescent form for several years. On the average, death takes place about three years after the first recognition of the disease, the final episode being due to a switch to a myeloblastic blood picture. On the evidence given by Scott (1957), the use of modern methods of treatment has had no beneficial effect whatever on the duration of life, although the remissions induced may be of real psychological and social value to the patient. When X-radiation therapy is used it is the normal finding that each remission is less easy to produce and lasts a shorter time until the final myeloblastic crisis closes the story. With myeleran therapy the leucocyte count can be kept under control without much change until the final phase develops, apparently with equal inevitability.

Here there is definite evidence of changes most readily interpreted as secondary somatic mutations. It is absolutely certain that acute leukaemia is enormously more likely to occur in a patient with chronic myeloid leukaemia than in a normal individual. The common-sense interpretation is that the primary mutant provides a necessary basis on which a further mutation can induce the myeloblastic behaviour. The behaviour of leukaemia under deep X-ray therapy suggests again a common-sense explanation, that in addition to its lethal effect on large numbers of leukaemic cells the radiation (a) induces mutations of various types, and (b) provides a selective survival for cells relatively resistant to the lethal effect of X-rays. With the reduction in the average number of leukaemic cells present, one would expect a delay in the appearance of the terminal mutation and its manifestation as a myeloblastic crisis.

Some other aspects of myeloid leukaemia may be relevant to the present theme. There are rare examples of neutrophil 
and eosinophil leukaemia in which the cells present in excessive numbers are much more mature than those in the classical myeloid leukaemia (Scott, I957).

This raises a number of very interesting questions which, if they could be answered, might do much to unravel the process of differentiation amongst mesenchymal clones. If, as all the evidence suggests, a single mesenchymal cell can, under appropriate stimulation, give rise to clones which contain both lymphocytic and granulocytic types, why does a case of myeloid leukaemia consistently produce granulocytic and not lymphoid cells and why in rare instances are the dormant pathological cells almost mature leucocytes?

'Somatic mutation' may well cover a wide variety of processes and, as has been suggested, both for bacteria and for Paramecium there may well be genetic mechanisms which can be switched, as it were, from one functional phase to an alternative one, the capacity to switch under appropriate stimulus being itself under genetic control. On this view, one of the common effects of somatic mutation to proliferative over-activity is loss of the ability to switch to another physiological type of activity. This is perhaps most strikingly seen in the behaviour of multiple myelomatosis where the neoplastic clones are fixed in the plasma-cell condition.

That this fixation is not invariable may perhaps be indicated by the existence of such a syndrome as chronic erythromyelosis, in which there is a blood picture with the features of both polycythaemia and chronic myeloid leukaemia with radiological evidence of medullary new-bone formation. This speaks both for a unitarian view of mesenchymal cell origin and for the mutational change in these cases having left more or less intact the capacity of cells of the resultant clone to develop in various directions.

\section{(b) Chronic lymphatic leukaemia}

Chronic lymphatic leukaemia is a very different disease from chronic myeloid leukaemia, for one thing in occurring 
later in life and showing the normal age incidence of malignant disease. Features of interest from the point of view of somatic mutation hypotheses are:

(i) The fairly common termination of lymphoid follicular reticulosis (Robb-Smith, I947) in a lymphatic leukaemia. This type of reticulosis is a relatively benign, initially focal but slowly generalizing enlargement of lymph nodes due to lymphoid hyperplasia in follicular distribution. After years it terminates by a more active process which is $(a)$ the result of involvement of increasing areas of bone marrow, or (b) lymphatic leukaemia, or (c) development of malignant invasive lymphoblastic sarcoma. Here we have a rather clear indication of the supervention of one or other of two mutations, each involving loss of one type of control.

(ii) A greatly reduced capacity to produce antibody is characteristic of chronic lymphatic leukaemia (Howell, 1920; Larson and Tomlinson, 1953) and throat infections are a common initial symptom. This may mean no more than a crowding out of all the elements concerned in normal antibody production. Equally it is compatible with the view that the pathological lymphocytes present in overwhelming majority represent only one, or a very few, clones, so that capacity to react immunologically is greatly limited. An observation in which a very high level of antibody of some single type was associated with lymphatic leukaemia would be the strongest possible evidence for a clonal hypothesis of antibody production but, even if such exists, it would need extreme good fortune to find the appropriate antigen.

Of more importance is the common occurrence in lymphatic leukaemia of haemolytic anaemia with positive Coombs test. According to Scott (1957), this is almost a standard finding at some stage. Following Dacie (1954), we regard the appearance of such auto-antibody as a result of somatic mutation, something which might well be expected to occur more frequently in the more actively replicating cells of lymphatic leukaemia than in normal lymphoblasts. It is 
implied in this that the producers of abnormal antibody are in the same line of descent as the small lymphocytes of lymphatic leukaemia. Another closely related point is the frequent association of abnormal globulins, cryoglobulin or macroglobulin, with lymphatic leukaemia. If, as has been suggested (Mackay, 1956) the presence (in abnormally high proportion) of macroglobulin in the serum is due to a mutation associated with proliferation of the clone of the cell concerned, this would indicate that the cells producing macroglobulins, and perhaps gamma globulins generally, are also on the lymphocytic line of descent.

(iii) Although the condition is essentially one of the acute leukaemias of childhood, acute sarcoma-cell leukaemia may be mentioned in which a sarcomatous process in lymph nodes, usually mediastinal, is associated with lymphoblastic cells in large number in the blood. Here we have a combination of two releases from control, one allowing tissue invasion, the other massive release into the blood stream.

The final point of interest in relation to chronic lymphatic leukaemia is why a condition which is clearly not 'fully malignant' should show the typical cancer age incidence. This implies, in our view, that the diagnosable condition is a result of two or more consecutive mutational steps, at least one of which (before the final mutation) is associated with proliferative advantage. This would suggest that there may be undemonstrable mutations going on through life which would give some clones a marked survival advantage, presumably with an associated elimination of other clones. This might be expected to result on the clonal selection hypothesis of a diminishing ability to react to any new antigen in old age. The expectation may perhaps have been realized in Sabin et al.'s (r 947 ) finding that elderly Japanese failed to respond to Japanese $B$ virus vaccine unless they had some evidence of previous contact with the virus. There are possibilities here of useful work with a better-defined series of antigens. 


\section{Hodgkin's disease}

Hodgkin's disease is the most important of the reticuloses. According to Marshall (1956) about I5 to $20 \%$ of cases of Hodgkin's disease from which early biopsies are available show, when first seen, a 'lymphoid' type of hyperplasia. Here the lymph-node structure is replaced by a proliferation of small lymphocytes with scattered, large, sometimes multinuclear, reticular cells. Sometimes a frank lymphosarcoma develops, but much more frequently the histological picture changes to that of typical Hodgkin's disease. This shows proliferating reticulum cells with pale cytoplasm, often multinuclear, and in addition lymphocytes, plasma cells and eosinophils. Marshall, in general, accepts the view that Hodgkin's disease is a benign multifocal neoplasm involving the primitive reticular cells with subsequent differentiation along some of the possible lines of their development. The additional possibility is, however, seriously considered that the primary benign neoplastic process evokes an inflammatory hyperplastic response. A proportion of Hodgkin's cases end as a 'Hodgkin's sarcoma', and in some this is the picture from the beginning. The interpretation of the histology of Hodgkin's disease, however, seems too obscure to use it in the discussion of possible clonal selection effects.

\section{Multiple myeloma}

If we are correct in applying concepts of clonal selection both to the phenomena of antibody production and malignancy, it should be of particular interest to examine the conditions in which gamma-globulin-producing cells develop malignancy. The classical example is multiple myelomatosis with Bence-Jones proteinuria. This topic has recently been reviewed by Putnam (1957) and this discussion is based essentially on his review.

The essential features of the disease arise from the localized and diffuse proliferation of plasma cells in the bone marrow, 
the presence of abnormal protein in the plasma, and in many instances the copious excretion in the urine of a small-molecular-weight protein with the unique physical quality of precipitation followed by re-solution on progressive heating. There is often an excess of plasma cells in the circulating blood.

The most conspicuous feature of the blood changes is the appearance in the electrophoresis diagram of an extremely sharp peak indicating the presence of a high concentration of a homogeneous protein species. It is of the highest importance for an interpretation that, although each individual patient shows a single spike located at a constant position in the electrophoretic pattern, the position varies widely from patient to patient and may be virtually at any point in the globulin range from $\alpha_{2}$ to $\gamma_{2}$. The positions tend, however, to concentrate about the normal beta and gamma globulin peaks. In most instances the abnormal protein is of the normal globulin molecular weight $(\mathrm{r} 60,000)$ but in a proportion of cases it is of cryoglobulin or macroglobulin character. In amino-acid composition, and in the nature of $\mathrm{N}$-terminal amino acids, we have the same sort of situation-a general resemblance to normal gamma globulin and constant individual features of difference in samples from the same patient, but specific differences in structure from one patient to another. Exactly the same expression could be used in regard to the antigenic pattern of the abnormal proteins as tested with antisera produced in rabbits.

As Putnam points out, these findings pose a fundamental problem. Is the abnormal protein one component of normal serum being produced in abnormal amount or is it a qualitatively abnormal protein? It seems to be implied in such a question that the protein is being produced by a single type of cell, a clone normally present which has been stimulated to abnormal activity by some factor extrinsic to the cells themselves, or a clone of intrinsic abnormality resulting from somatic mutation of a normal cell and malignant or semi- 
malignant proliferation of its progeny. Putnam regards the second alternative as the most likely, primarily on the basis of the chemical evidence of aberrant amino-acid composition and arrangement.

I hope it is not overstating the case to say that the multiple myeloma findings provide the best possible material for displaying the salient features of the clonal selection approach to the phenomena of antibody production and of malignancy. In most malignant conditions the cancer cells show little overt evidence of functional abnormality apart from their proliferative and destructive action. In a number of semimalignant tumours of endocrine organs hypersecretion of the characteristic hormone may produce symptoms, but this is usually no more than excessive liberation of a normal product. In multiple myeloma, however, we are concerned with a semi-malignant condition (a conditioned neoplasm) arising from a cell stock which, according to the approach we have been using, has been specifically evolved to produce a multiplicity of protein patterns, by minor mutational change. In the genesis of multiple myelomatosis, it is assumed that a mutation results in a distortion of the naturally labile globulin-synthesizing mechanism to produce an abnormal product. Concomitantly some aberration of control which, again by hypothesis, is naturally a sensitive and labile one, allows excessive proliferation in one particular environment, the bone marrow. Metastatic plasmacytomas elsewhere are apparently rare and when they do occur they are found mainly in the commonest sites of extramedullary blood formation, spleen and liver.

This characteristic of multiple myelomatosis, a free determination of proliferative lesions through the bone marrow to the virtual exclusion of other tissues, has two important implications: $(a)$ that the aberrant cells are still under partial control, that is, it represents a conditioned neoplasm, and (b) it provides a strong support for the hypothesis that a mesenchymal cell, after appropriate immunological stimula- 
tion, can settle down in an appropriate physiological environment and proliferate.

The fact that each myeloma patient produces his own characteristic and individual serum protein, with its sharp spike evidence of homogeneity, provides support for what many workers might consider a weak point of the clonal selection theory, that each clone produces a specific antibody globulin whose pattern is genetically determined. The globulins produced in multiple myelomatosis are abnormal, but they remain consistently of the one physical and chemical pattern which has been, as it were, chosen from a probably unlimited number of possibilities. This constancy of pattern can hardly be interpreted in any other fashion than as a genetically controlled quality of the clone.

On general grounds one could not expect to find a myeloma globulin functioning as a normal antibody even if it sprang from a clone which was antibody-producing. The distortion of structure is not likely to leave antibody specificity unchanged and, even if it did, the chance of finding the right antigenic determinant among the hundreds (or thousands) which might be involved would be very slight. We have already referred to the rather rare instances in which Gajdusek's AICF test is given by macroglobulinaemia sera. A considerable number of myeloma sera have been tested with completely negative results. In the macroglobulin serum most closely studied by Mackay (1956) there was indirect evidence of heterogeneity similar to that found with other high-titre sera from other clinical conditions. In the light of experience with myeloma sera we should consider that we are dealing with two distinct abnormalities of globulin production which will only very rarely affect a clone of mesenchymal cells simultaneously. The first is the production of an abnormal but genetically controlled type of globulin, the second the production of protein molecules which, in regard to one aspect not yet clearly characterized, are of randomly distributed patterns. 
The Bence-Jones (urinary) protein is of only secondary importance from our point of view, although it seems likely to provide clues of importance to the understanding of protein synthesis in the cell. From isotope studies, Putnam and Hardy (1955) conclude that the urinary protein is not a breakdown product of the abnormal circulating globulin but that its behaviour is compatible with its being a precursor or abortive product of serum globulin synthesis. It is of much smaller molecular size and is excreted by the kidney almost immediately it is formed. But it resembles the serum globulin in general amino-acid constitution and its antigenic character; each, however, showing individual differences from one patient to another.

\section{REFERENGES}

Burnet, F. M. (1957). Brit. Med. 7. r, 779, 841.

DAcie, J. V. (1954). The Haemolytic Anaemias (London).

DмосHowski, L. (1957). In Cancer, vol. I, p. 214 (Butterworth, London). Fraser, A. S. \& Short, B. F. (1958). Aust. F. biol. Sci. (in the Press). FRIEND, C. (1957). 7. exp. Med. 105, 307.

FurTh, J. (1953). Cancer Res. 13, 477.

Furth, J. (1954). Leukaemia Research, p. 38 (Ciba Foundation Symposium, London: J. and A. Churchill).

Gross, L. (195I). Proc. Soc. exp. Biol., N.Y., 76, 27.

Hauschka, T. S. \& Furth, J. (1957). Henry Ford Hospital Symposium, The Leukaemias, p. 87.

Howell, K. M. (1920). Arch. int. Med. 26, 706.

Kaplan, H. S. (1954). Cancer Res. 14, 535.

Larson, D. L. \& Tomlinson, L. J. (1953). J. clin. Invest. 32, 2 I 7.

LAW, L. W. (1957). Ann. N.Y. Acad. Sci. 68, 6 16.

Mackay, I. R. (1956). Aust. Ann. Med. 5, 244.

Marshall, A. H. E. (1956). Cytology and Pathology of the Reticular Tissue

(Edinburgh: Oliver and Boyd).

Medawar, P. B. (1957). Ann. N.Y. Acad. Sci. 68, 255.

Metcalf, D. (1956). Brit. F. Cancer, ro, 442.

Putnam, F. W. (1957). Physiol. Rev. 37, 512.

Putnam, F. W. \& Hardy, S. (1955). F. biol. Chem. 212, 361 .

Robb-Smith, A. H. T. (1947). In Recent Advances in Clinical Pathology,

p. 350 (London: J. and A. Churchill).

Sabin, A. B., Ginder, D. R., Matumoto, M. \& Schlesinger, R. W.

(1947). Proc. Soc. exp. Biol., N.Y., 65, I 35.

Scotт, R. B. (1957). Lancet, $\mathbf{x , ~ 1 0 5 3 , ~ 1 0 9 9 , ~ I ~} 162$. 


\section{XI \\ CLONAL SELEGTION AND \\ NEOPLASTIC DISEASE}

In the last chapter borderline conditions involving proliferation of mesenchymal cells were discussed, with the implicit assumption that malignancy in general was a manifestation of a clonal selection process. This approach to cancer is a standard one-somatic mutation theories of cancer have been current for many years. In this final chapter, only those aspects of the subject which appear to be reasonably relevant to our main theme of the physiological and pathological reactivity of mesenchymal cells will be discussed.

We may first state in general terms what the somatic mutation theory of cancer entails. On this view, cancer represents the development by a clone of cells (or more than one) of the capacity to multiply freely without regard to the normal controls which maintain cell relationships in the body. This state is reached by a series of mutational events, each of which either results in a selective survival advantage or brings the cell to such a state that a further mutation will endow it with an advantage.

Some immediate implications of such a view are:

(i) that the common forms of cancer will be in cell lineages which are subject to rapid turnover and in which there is scope for the exercise of selective survival advantage;

(ii) that anything which abnormally accelerates turnover, such as chronic trauma or inflammation, will increase the likelihood of cancer;

(iii) that mutagenic agents will be carcinogenic;

(iv) that the incidence of cancer will increase steeply with age if two or more consecutive and random 
mutations are needed to reach the development of clinical malignancy;

(v) in cases where, for hormonal or other reasons, a cell type increases markedly at some particular age, the slope of the age incidence of cancer of that type will increase sharply at this period-the age incidence of prostatic hypertrophy and cancer may be mentioned.

All these are, in fact, well-recognized aspects of the malignant process - and, of course, served as the stimulus for the development of hypotheses of this type.

No attempt will be made to give a comprehensive discussion of the clonal selection approach to cancer. Instead, as in the preceding chapter, I shall concentrate on a few themes which seem relevant to the general approach of these lectures. Nothing will be said of the nature of somatic mutation, and the means by which all numbers and tissue structure are maintained in a dynamic equilibrium will only be touched on very lightly. Three topics seem appropriate for somewhat more detailed consideration:

(I) The turnover of cells in various parts of the body.

(2) The age incidence of cancer in man in relation to the sequential-somatic-mutation hypothesis.

(3) The carcinogenic action of some mutagenic agents, notably ionizing radiation.

\section{The turnover of cells in various parts of the body}

Mammalian tissues may be divided into four groups in relation to the average life of their cells as individuals.

(i) Tissues which in whole or in part are composed of highly expendable cells with a relatively rapid turnover.

The blood cells are the most obvious examples. All are relatively short-lived, including erythrocytes, granulocytes, lymphocytes and platelets (see Yoffey and Courtice, I956). We should include here also the other functional types of mesenchymal cell, macrophage tissue lymphocyte and plasma cell. The other important group comprises the epi- 
thelial covering of surfaces exposed to any environment contaminated with micro-organisms. The epithelium of the skin and of the linings of respiratory and alimentary tracts is being constantly replaced, in part to repair minor lesions but much more as a means of forestalling the necessity for repair.

(ii) Tissues which are liable to functional changes in activity involving proliferation or regression of cellsbreast and uterus, and probably ovary and testis. In a less obvious sense the endocrine organs may perhaps be included here.

(iii) Tissues in which the average cell life is long but in which, when demand arises, proliferative and reparative processes take place readily and efficiently, for example, liver and kidney.

(iv) Cells of the central nervous system in which no proliferation or regeneration takes place.

In a discussion of the general problem of turnover based mainly on studies of the rat made by counting the proportion of cells in mitosis in different tissues, Leblond and Walker ( 1956 ) made a number of interesting points.

There are several tissues of the adult rat which show no sign of renewal. These include central nervous system, liver, pancreas, salivary glands, adrenal medulla. In the skin epidermis multiplication takes place in the basal layer or the immediately adjacent spinous cells. Here it is relatively easy to conceive the possibility of a mutation in a cell of the basal layer which can have a marked survival advantage until eventually its descendants control the character of a few square millimetres of surface. This is probably the nature of the small hyperkeratoses of exposed skin that are very common in elderly men. In the alimentary canal the turnover of cells can be very rapid. In the rat, and presumably also in man, intestinal cell multiplication takes place in the crypts of the mucosa with migration of chief and mucous cells toward the tip of the villus, whence they are shed into the lumen. In the stomach and large intestine, the same type of process, 
modified by the specific histological features of the different situations, takes place. Leblond and Walker make the interesting statement that if human intestinal epithelium turns over at the same rate as that of the rat, each of us sheds more than half a pound of used cells into the intestinal lumen each day.

The function of this rapid turnover in cells exposed to the environment is fairly clearly to forestall the effect of environmental injury by discarding cells before inevitable damage renders them ineffective. It is a necessary feature of any such mechanism that it can also function rapidly and effectively to repair any traumatic damage that does occur. Irritated regions subject to multiple minor traumata will always show an increased production of expendable cells.

Malignant disease can occur in any part of the body but in some regions it is much more frequent than in others. If any generalization is permissible, it is that cancer arises most frequently from cells with a high normal turnover and at those sites where the turnover is increased by the existence of chronic trauma of one sort or another.

\section{The age incidence of cancer}

Of all the objective characteristics of cancer, the relation to age is the most clearly evident. It is part of universal human knowledge that cancer is predominantly a disease of the old, that it is variable in its site and its rate of progression and that it is almost always lethal. Any attempt to understand the malignant process will always have to be primarily concerned with those three aspects. Of the three, the characteristic age incidence probably provides the best starting point for any general discussion.

A close study of the numerical relationship between age and the incidence of various forms of cancer shows an important regularity which is best demonstrated graphically. If one plots the incidence of death from cancer of the stomach at each quinquennial age interval as the number per 100,000 
of persons of those ages, the incidence rises so steeply with advancing age that a logarithmic scale is required. This gives a curve with a gentle upward convexity. If now the age scale is also plotted logarithmically the curves become a straight line (Fisher and Hollomon, I95 I Armitage and Doll, I954; Metcalf, I 955). There are a number of deviations from this regularity but all the exceptions are 'reasonable'

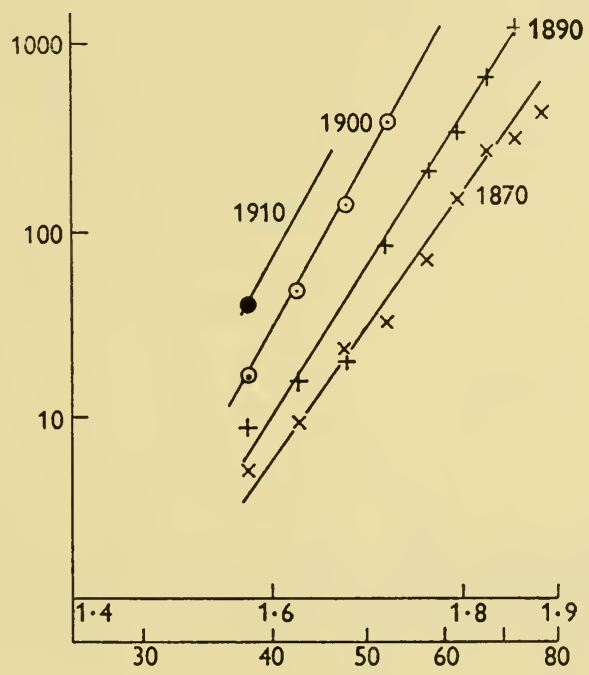

Fig. ı. To show log-log relationship between cancer mortality and age. Lung cancer mortality at ages of cohorts born around the year shown (males, Australia). Ordinates, mortality per I $^{6}$ at ages; abscissae, age in years; both expressed logarithmically.

ones. Cancer of the lung, for instance, shows approximate straight lines if we work with cohorts instead of total populations-an indication of progressive change in the last fifty years in some social factor heavily correlated with the incidence of the disease. Like most people, I believe that the factor has been the increase in cigarette smoking. Special features associated with changing functional activity at the menopause lead to a slowing down of the increase after the age of 45 of cancer of breast, uterus and ovary. 
The most striking deviation from the regularity of the relationship is with prostatic cancer. Instead of a straight line with a slope approximately 6 , this is close to a straight line with a slope between 12 and I3, lying, of course, in the old-age period only. This is undoubtedly related to hormonal factors and is discussed later.

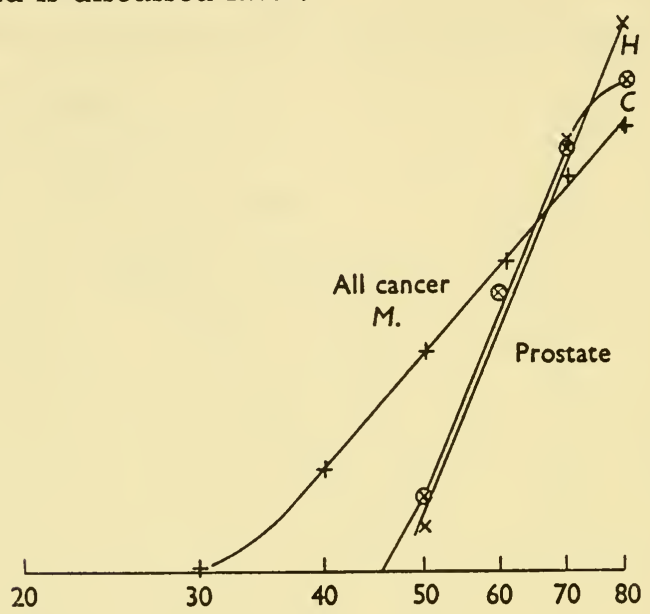

Fig. I I. Similar graph to show different slope of the log-log relationship for all cancers (male) and for prostatic carcinoma $C$ and hypertrophy $H$. To bring both on the same region the ordinates differ for the two sets.

It has been pointed out by Armitage and Doll (1954) that one way of accounting for a log-log relationship of this sort is to assume that malignancy results when a cell suffers a sequence of somatic mutations. Let us assume a uniform population of cells remaining constant in composition except for the occurrence of mutation; the cells start in state o. They are subject to mutation at a low constant rate per annum, taking on state $\mathrm{I}$. When a cell takes on state $\mathrm{I}$, it becomes subject to mutation to state 2 , and similarly from 2 to 3 and so on. If state $n$ is followed by the development of fatal cancer, then the age incidence of death from cancer should be a straight line with a slope of $n-\mathrm{I}$ when both specific age incidence and age are plotted logarithmically. 
This, however, does not seem to be likely to resemble the actual situation. All or some of the $n$ mutations are going to provide some advantage for selective survival, that is, the numbers of mutants in the population will not remain constant but will form an increasing proportion. Since it is completely unlikely that the advantage of successive mutations will be similar at each stage, it is probably impossible to provide a general mathematical expression of the situation. However, we can be certain that if there is this selective advantage, the number of mutations needed to account for a slope of $n-\mathrm{I}$ will be proportionately diminished. Instead of 6 , it may well need only 2, 3 or 4 . In a more recent paper, Armitage and Doll (1957) have considered the case where two sequential mutations are needed and shown that by the use of appropriate constants a reasonably close approximation to the observed mortality can be calculated. They do not, however, claim that this is the only hypothesis which will fit the facts. An interesting point is that relevant to this is the finding that the slope for prostatic cancer is very similar to that for the incidence of prostatic hypertrophy and has a slope of 12 to 13 instead of 5 or 6 , which is that for cancer generally. There is no faintest possibility that 13 or 14 consecutive mutations are needed to induce prostatic malignancy, but there is clear evidence that in some individuals marked proliferation of some prostatic cells is taking place about the critical age.

The characteristic age incidence of cancer fits naturally into a theory by which a sequence of inheritable changes occurring essentially at random takes place within cell populations. It is very difficult to conceive of any system of reasonable assumption by which a single cause, infection by a virus for example, could give rise to this particular type of age incidence.

If we accept the view that sequential somatic mutation is the essential basis of cancer, defining mutation as an inheritable change involving only a small, randomly distributed 
proportion of a population, it is possible to state in general terms what determines the age at which cancer appears. The two significant factors are $(a)$ the frequency with which each of the consecutive mutations needed occurs, and $(b)$ the selective advantage, in the sense of the proportionate increase in numbers of the clone concerned, that is provided by each mutation. In individual cases we can be certain that two important additional factors need to be considered, (c) the likelihood that individual genetic differences will

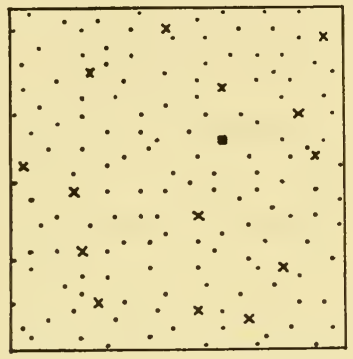

A

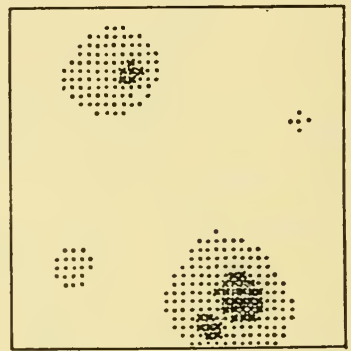

B

Fig. 1 2. Graphic comparison of two types of sequential mutation. In $A$ no proliferative advantage follows mutation. In $B$ each successive mutation confers a proliferative advantage. Successive mutation in cells uniformly present in white background indicated by dot, cross and black square.

modify the numerical values of $(a)$ and $(b)$, and $(d)$ the influence of traumatic or inflammatory stimuli in increasing the cell turnover and hence providing larger populations subject to mutation and a more rapid opportunity for selective proliferation of mutants. Any mutational step will be significant if it either $(a)$ confers a direct survival advantage on its descendants, or $(b)$ renders the cell line now unduly susceptible to undergo a further mutation which will give such a survival advantage. Mutation on this view will only involve significant change in the cellular constitution of the body if it moves along this line of increasing proliferative advantage with, as the inevitable end, malignancy. If 
somatic cells are subject, like reproductive cells, to random mutation, then cancer becomes logically as inevitable as the process of evolution and adaptive radiation that takes place when any type of organism colonizes a new major habitat.

\section{The control of cell relations}

Cancer is commonly, and probably rightly, regarded as the escape of certain cells from the controls normally exercised by the organism as a whole. In one way or another the fertilized human ovum gives rise to an intricately intercoordinated system of cells and supporting material. The maintenance of that system in healthy function obviously demands continuing controls of many sorts. At the macroscopic level experimental physiology has been mainly concerned in elucidating the nature of these homeostatic controls. At the cellular and morphological level, with which we are concerned, there is much less of substantial knowledge. Most of it concerns the hormonal control of general growth or of the growth of particular organs. In the field of cancer research proper, there has emerged the very important concept of conditioned and unconditioned neoplasms. A conditioned neoplasm is one which is capable of growth only in hosts that have been specially conditioned-for example, by thyroidectomy in the case of certain pituitary tumours, or by the induction neonatally of immunological tolerance. The neoplasm will grow on transplantation to such conditioned hosts but not in normal hosts of the same stock. In almost every such instance, however, it is found that after repeated passage in conditioned hosts the tumour becomes capable of transfer to normal animals. It is now an unconditioned transmissible neoplasm.

Such observations can tell us little more than that in some tissues the level of circulating hormone plays an important part in maintaining control of cellular relationships but that it is never the only factor.

Tissue cells are obviously influenced by the nature of the 
cell surfaces with which they are in contact. No organized tissue structure would be possible without controls of some sort maintaining cells in normal morphological and functional relations. To a large extent these proximity controls seem to be intrinsic to the cells themselves. Moscona (I956) in Weiss's laboratory has described the development of organoid structures when single-cell suspensions disaggregated from chick embryo tissues were held under tissue culture conditions on plasma clot. The cells re-aggregated into clusters, established a tissue-like association and resumed their characteristic histiotypic development. Weiss (1955) has discussed many examples from embryonic development in which special relationships are established between cell types. In such a case as the migration of the potentially pigment-producing cells of the neural crest to their allotted positions in the body, the process is presumably a result of successive 'recognition' of cell surfaces on the path of migration and of the final appropriate niche for permanent lodgment.

A more direct approach to the nature of these proximity relationships is provided by the work of Abercrombie, Heaysman and Karthauser (1957) using interference cinephotomicrography to study the movement of cells in tissue culture. With normal fibroblasts, movement is associated with undulations of the cell membrane. When contact with another cell occurs, the activity ceases at the point of contact and, if the cell is in contact with a sufficient number of surfaces, movement ceases over the entire membrane. The cell has virtually then become part of an established tissue. Malignant cells in tissue culture are not subject to contact inhibition. In mixed cultures they can be seen to move freely over the surfaces of normal cells. Obviously this quality may represent an important reason for the selective survival advantage of the cancer cell and equally provide a clue to the nature of the controls which are abrogated in somatic mutation towards malignancy. 
Green (1954, I957) has strongly supported the theory that the essential lesion in the cancer cell is a loss of specific antigens and that these, serving as identity markers, may play a major part in maintaining normal cell relations. There is much evidence to indicate that, with the development of malignant change under the action of a chemical carcinogen, the cells lose a component to which the carcinogen is specifically bound. This may be associated with loss of some antigenic specificity or even with the gain of a new antigenic determinant. There is a real possibility that such changes may be associated with loss of the proximity control we have been discussing. The only question is whether it is in the long run more profitable to look at the immunological change as a consequence of somatic mutation or to assume that immunological reactions enforce a specific type of somatic mutation. In line with our general approach in these lectures, we should prefer the first alternative.

Green's (1957) assumption that, because cancer cells have lost identity proteins they can produce antibody against normal body cells which have retained them, is quite out of accord with the clonal selection point of view. The appearance in a proportion of cancer cases of serum changes, including various types of globulin instability, increased hexosamine, etc. and a rather low-grade direct Coombs test, is best interpreted as due to the leakage of cell components from the malignant tumour into the body fluids rather than an auto-antibody reaction. Many suggestions have been made that some human tumours provoke antibodies which have an inhibitory action against their growth. Black, Opler and Speer (1954) found that the prognosis was much better if a resected gastric carcinoma showed an active lymphocytic and plasma-cell reaction around the malignant cells than if this was absent. It is reasonable to believe that in such tumours the mutations responsible had produced antigenic determinants new to the body and that a homograft-type immune response was in progress. 
Immunological considerations are paramount in the transfer of tumours to new hosts and may have importance for primary tumours, but they do not seem to merit the central position in cancer theory that Green upholds.

\section{Mutagenic and carcinogenic agents}

If the somatic mutation theory of cancer is correct, the words mutagen and carcinogen should be synonymous. Experimentally this is not quite the case, but there is a sufficient number of agents with both types of action to allow us to retain the general hypothesis, with the reasonable qualification that access to the nuclear mechanisms concerned will vary according to many circumstances and that the manifestation of malignancy may require conditions beyond simple mutation. If the point of view that we have adopted from consideration of the age incidence of different forms of cancer is correct, then a single exposure to a carcinogenic (mutagenic) agent in a population of young individuals may be expected to produce a large crop of what we called mutation $\mathrm{I}$ and an occasional mutation 2. The overall result could well be no more than a lower average age of cancer than in an untreated population.

In human experience, the only mutagen-carcinogen which is available for discussion is ionizing radiation which, for all practical purposes, means X-rays as applied in the course of diagnosis and therapy. In the early days of X-rays, it was a commonplace to find that radiologists suffered from multiple skin carcinomata of the hands. A hundred radiologists were said to have died of malignant disease induced by radiation by the year 1922. For obvious reasons, there is little possibility of obtaining significant information in regard to dose, latent period, etc., from such data. In recent years much more attention has been paid to the rising incidence of leukaemia and the impressive evidence that some portion of this increase is attributable to ionizing radiation from the medical uses of X-rays. This may be summarized as follows: 
(i) Patients heavily irradiated for treatment of ankylosing spondylitis showed a significant incidence of myeloid leukaemia. Analysis of the data by Court-Brown and Doll (1957) indicated that there was an approximately linear relation between dose and the likelihood of leukaemia and a latent period with a mode about three to four years after a single heavy dose of radiation.

(ii) Retrospective study of leukaemia in childhood shows that children under Io with leukaemia include a higher proportion ( $15 \%$ ) who were irradiated in utero than is found in normal control children (8\%) (Stewart et al. 1956). The implications of this finding are $(a)$ that $85 \%$ of leukaemia in childhood is certainly, and another $8 \%$ probably, not due to irradiation in utero. (b) The normal chance of death from leukaemia in childhood (about $I$ in 2000) is doubled (to $I$ in I000) by the fact of foetal X-radiation.

(iii) Persons exposed to atomic-bomb radiation at Hiroshima and Nagasaki in 1945 have shown an increased incidence of leukaemia, again with an approximate linear relationship of incidence to dose.

It can be calculated (Lewis, 1957) from what has been published that the effect of I roentgen of whole-body radiation is to give a probability of dying of leukaemia of about I to $2 \times 10^{-6}$ per person per annum.

This does not, however, indicate that the whole of the increase in leukaemia since 1920 has been due to the increasing use of X-rays. Unless there is some quite unsuspected flaw in data or logic, the very striking increase in leukaemia in this century involving all ages is due to some aetiological factor other than ionizing radiation, which is unlikely to be responsible for more than 5 to $10 \%$ of the increase. The nature of the other factor or factors provides one of the important challenges to present-day preventive medicine and it may be of interest, although not perhaps very closely relevant to my main theme, to enumerate the epidemiological indications which may be relevant to the nature of these factors: 
(i) In all advanced countries with adequate statistics there has been a steep and continuing rise in leukaemia. (As in all other statistical statements leukaemia covers all types.)

(ii) The incidence of leukaemia is higher

(a) in advanced as against backward countries: Denmark $>$ U.S.A. $>$ Canada $>$ Australia $>$ England and Wales $>$ Eire.

(b) in higher social classes: White > coloured in U.S.A. In England and Wales Social Classes I and II: I 76, I 25; III, IV, V: 9o, 93, 84 (in terms of average Ioo for all classes).

(c) in males rather than females, especially for chronic lymphatic leukaemia.

(d) in urban as against rural populations.

(iii) Increasing incidence over the last 30 years has involved all ages and, by implication, all three types of the disease.

(iv) The age incidence of leukaemia in childhood has shown important changes in the emergence of a wellmarked peak of incidence between 3 and 4 years. This peak has more than doubled the incidence o to 5 since 1920. It is not seen in the curve for coloured populations in the United States. The increase is far greater than would be produced as a result of pelvic X-rays in pregnancy and offers a very important problem for aetiological diagnosis.

The age incidence of chronic lymphatic leukaemia is that of a normal cancer but acute and myeloid leukaemias, which are those for which radiation has been incriminated, differ sharply. There is much to suggest that a single somatic mutational event or its equivalent-rather than a sequence of such events-is the rate-determining factor here. As a corollary, the effect of specifically mutagenic agents might well be more strikingly displayed in the production of leukaemia than in carcinogenesis. This seems to hold for ionizing radiation, in so far as this is an effective stimulus 
with an effect which, according to Lewis, can be expressed in the form of a linear relation to the cumulative dose. In itself this points towards the significance of a single mutational event.

If it is true, as all the data suggest, that some other mutagenic agents are concerned in the continuing rise in leukaemia mortality, their detection and characterization becomes one of the important tasks for research in preventive medicine. So far we have only a few clues to their nature. Like the medical use of X-rays, the unknown factors are increasingly operative in the more advanced countries, in the more economically secure classes and in more recent years. They must be operative at all ages but one or more seem to be particularly potent at the very beginning of life, just before or just after birth.

There are many things that might be thought of. If we judge from bacteria, mutagens are commoner than we thought. Caffeine, for instance, is a potent bacterial mutagen and I suspect that, like the medical use of X-rays, the amount of caffeine absorbed per head per annum increases with the level of prosperity. It would be ridiculous to start looking askance at coffee and I mention it only to stress the potentialities of changing ways of life for introducing new medical problems. All sorts of things have been happening in the last thirty or fifty years to modify the things we eat and the air we breathe and the way we act. Three diseases are sharply demarcated from the rest-lung cancer, coronary disease and leukaemia — as steadily increasing causes of death. All are increasing because of changing ways of life. We have a fair understanding of the first two. Leukaemia presents an equal challenge. Some first-rate detection work is needed and, as with lung cancer, it must be work done directly with the human problem. Mouse experiments can do no more than offer clues to profitable approaches. In Australia we have felt that an initial step is to see that leukaemia is made a notifiable disease and that an accurate 
haematological diagnosis will be attached to each death certificate. Without such a background, investigations are not likely to be fruitful.

\section{Conclusion}

These lectures were designed primarily to present what seemed to be a novel and perhaps productive way of approaching the problems of immunity and especially the medical problems which arise when immunological responses are distorted.

The approach can, I think, be legitimately called an evolutionary one and it was essentially to clarify the resemblance between cellular reactions within the body on the one hand and the population dynamics of micro-organisms reproducing asexually on the other, that the chapter on bacterial and viral population changes was included. Irrespective of what field we are considering, as the environment changes the nature of the population changes, and in the present state of our knowledge the changes are best understood in terms of mutation and selective survival.

It is universally accepted that the phenomena of immunity are based on the functional activity of populations of mesenchymal cells within the body. The chief novelty of the clonal selection theory is its concentration, not on what happens in an individual cell, but on the way cell populations are modified by the presence of antigenic determinants in their environment of the body fluids. It is a Darwinian approach which, pressed to its logical conclusion, demands that immunological specificity is based on a special type of differentiation occurring in embryonic life plus a high subsequent potential for somatic mutation in that region of the genome (using this term in its broadest sense to cover all genetic determinants, nuclear or cytoplasmic) concerned with immunologically significant pattern.

If this interpretation of the primary formation of immune pattern is in error, it should be relatively easy to devise experi- 
ments to disprove it, and replace it with something better. Nevertheless (whatever the results of further research) I believe that the general concept of the importance of the population dynamics of mesenchymal cells must be accepted. I hope, too, that I have been able to show how the type of somatic mutation that must be postulated to account for the physiological aspects of immunity grades smoothly into those concerned with the appearance of auto-immune disease and some of the proliferative diseases of the mesenchymal cell system.

It is only a minor step then to bring the picture into relation with the somatic mutations that are basic to our understanding of neoplastic disease. I know that in stressing somatic mutation and clonal selection in cancer I am going counter to the general trend of thought amongst experimentalists in the field. But I have a basic scepticism of the laboratory model when it fails to conform to clinical experience. As physicians, surgeons, and radiologists, all our practical thinking about cancer is based implicitly on an acceptance of somatic mutation as the origin of the process.

It is probably fair to say that in many respects, these lectures are superficial in their approach, making no attempt to face the real problems of immunity and cancer which lie in the nature of mutation and the way genetic changes are translated into their phenotypic expression. The approach that I have used has led to a rather simple picture in terms which are not those of chemistry and physics, but of biology. And it is an article of my scientific faith that there is intrinsic virtue in simplicity, if it aids understanding without doing violence to the facts of observation and experiment.

\section{REFERENCES}

Abercrombie, M., Heaysman, J. E. M. \& Karthauser, H. M. (1957). Exp. Cell Res. 13, 276.

Armitage, P. \& Doll, R. (1954). Brit. F. Cancer, 8, I.

Armitage, P. \& Doll, R. (1957). Brit. F. Cancer, r1, 16r. 
Black, M. M., Opler, S. R. \& Speer, F. D. (1954). Surg. Gynec. Obstet. 98, 725 .

Court-Brown, W. M. \& Doll, R. (1957). M.R.C. Special Report Series, No. 295 (H.M.S.O., London).

Fisher, J. C. \& Hollomon, J. H. (195 I). Cancer, 4, 96 I.

Green, H. N. (1954). Brit. med. F. 2, I374.

Green, H. N. (1957). Ann. N.Y. Acad. Sci. 68, 268.

Leblond, C. P. \& Walker, B. E. (1956). Physiol. Rev. 36, 2.

Lewis, E. B. (1957). Science, 125, 965.

Metcalf, D. (1955). Med. F. Aust. r, 874.

Moscona, A. (1956). Proc. Soc. exp. Biol., N.Y., 92, 4 Io.

Stewart, A., Webb, J., Giles, D. \& Hewitt, D. (I956). Lancet, 2, 447. Weiss, P. (i 955). In Willier, B. H., Weiss, P. \& Hamburger, V., Analysis and Development (Philadelphia, Saunders).

Yoffey, J. M. \& Courtice, F. C. (I 956). Lymphatics, Lymph and Lymphoid Tissue (London, Arnold). 


\section{INDEX}

Adaptive changes, 5, 14

and analogy with mesenchymalcell change, 27

and $O-D$ change, 17

in virus populations, $4^{-23}$

Adaptive enzyme, 4 and 'indirect template' theory of antibody production, 55

Addison's disease, I 70

Adjuvants

as antigen depot, 80

proliferative effect on clones, 82

Agammaglobulinaemia, 42, 47, 95, 141

congenital, 42

and hypersensitivity, 42

and immune response, 143

virus diseases in, 142

Agglutinin

cold, 97

iso-, 39, 43, 57, 95

$T, 39,95-9$

see also natural antibody

Allergic diseases, 12 I

Amino acids, of abnormal globulins, I8I

Amniotic cavity, 16

limit dilution passage, 18

Amyloid disease, I 34

Anaemia, haemolytic, 43 acquired, 126

Anamnestic response, 72, 74, 77

cellular basis of, I 19

Anaphylaxis, and stimulation of clone by antigen, 64

Anopheles (annulipes), in myxomatosis, 25

Antibody, 5, 13, 30, 35, 38-40, 44, 45, $47,50-4,57-9,61-7,69,70$, 72-109, 1 22-9, I 32-43, I 46-8, I $78,180,183$

acute production of, 103

against tumours, 193

auto-, 35, 1 23, 126

cell-borne, 107, 125

classical circulating, 30, 36, 38-9

cold, 126 effect of irradiation on production of, 89

fluorescent, staining detection of, 44 , I 09

hay-fever type, 37,39

natural, 53, 95, 99

nature of, 30

production and X-rays, Ioo

production in old age, I 79

see also Agglutinins, Mesenchymal cells

Antigens, 30-2, 34-40, 49-52, 54, 59, $6 \mathrm{I}-9,72-9,80-2,86,88,90-6$, 101-7, I13, I1 7, 123-7, 1 $31-8$, $146-8,152-8,162,179$

auto-, thyroglobulin, 124

bacterial, I I I

and clonal selection theory, 49-67

diminishing response to, 179

as identity marker, 195

nucleoprotein, 79, 88

primary response, $3^{1}$

secondary response, 3 I

tolerance to, 92 , I 1 I

see also Antibody, Immunity, Mesenchymal cells

Antigenic determinants, $30,36,49,5^{\text {I }}$, $6 \mathrm{r}, 7 \mathrm{r}, 73,78,146$

reacting with forbidden clones, I 59

Antigenicity, 36

transfer of, 132

Appendix

and antibody production, 100

lymphoid tissue in, 83 , IOI

ARBOR viruses, 77

Arthritis, in agammaglobulinaemia, I $44^{-5}$

Arthus reaction, 103

Autoantibody, 35, 126

Autoantigen, thyroglobulin, 124

Auto-immune complement fixation test, 137

Auxotrophs, 8

$\beta$-galactosidase, $4,13,7$ I

Bacterial antigens, I OI

Bacterial papillae, 7 
Bacteriophage, as antigen, 32

Bence-Jones protein, 184

Blood group

Bombay anomaly, $5^{8}$

chimera, 58

Bone marrow, 89

Caffeine, as bacterial mutagen, 199

Cancer

age-incidence of, 188

log-log relationship in, I9o

somatic mutation theory of, 165

Carcinogenesis, chemical, 195

Carcinoma, in merino sheep, 167

Chick embryo

amniotic inoculation of, 16

viral infection of, 22

Chimeras, 58, 87

$\mathrm{X}$-ray, 1 i 8

Clonal selection theory, 53

and absence of normal homeostasis, 157

and cancer, 149, I 86

cellular basis of, 1 I 8

development of abnormal serum proteins, 127

diminishing response to antigens, 179

dominance of best adapted clone, 25

effect of adjuvants on cell proliferation, 80

elimination of antibody-producing clones by irradiation, 89

eosinophils, 1 I 8

evolution of forbidden clones, I 24

fixation of reactant lymphocyte, 84

homeostatic mechanism, 130

homograft immunity, 89

immunology, 69

importance of lymphocytes in immune response, I00

inhibition of forbidden mutation, 1 45 , I 48

interpretation of agammaglobulinaemia, 143

justification of, 69

mechanism of clonal selection, 75

multiplication of lymphoid tissue,

144

and natural antibodies, 95

number and rate of proliferation of cells, 104 pathology of the immune response, 122

predication of active (antigenstimulable) sites of cells, 80

proliferation of stimulated mother cells, I 26

somatic mutation of clones, 122

special function of lymphocyte in, I 19

at subcellular level, I05

and tolerance to antigens, 92

and tolerance to bacterial antigens, IOI

see also Immune responses, Mesen-

Clones chymal cells

clonal phenomena in bacteria and viruses, 4

forbidden, 136

forbidden patterns, 1 22, I 45, I 57

forbidden, reacting with antigenic determinants, 159

of globulin-producing cells, 54

mutant, reaction of, 140

Collagen diseases, I 31 , I32

Complementary configurations of cell and antigen, 31

Complementary relationship, 67

Conditioned neoplasm, 169, I 73, I93

Contact dermatitis, 4 I

Contact inhibition in tissue culture, 194

Control

morphogenetic, I93

proximity, 194

see also homeostatic mechanism

Corneal transplantation, 35

Cortisone, in acute lymphatic leukaemia, 170

Critical point of Medawar, 60

Davenport's phenomenon, 74

Denaturation of antibody, 54

Diaminopimelic acid, I6I

Differentiation

embryonic, 56

phase of, 60

Diphtheria toxoid, 37

Direct template theory, 50

Disseminated lupus erythematosus (DLE), I $36-9$

Distemper, canine, 156

DNA nucleoprotein, 79, I 12 
Ecology, bacterial, I 5

Ehrlich's side-chain theory, 49

Electron microscopy, particle counts and infectivity, 22

Endotoxins, 102, 109

Enzyme formation, adaptive, 4, 55

Eosinophils, I 17

in disease, 136

in proliferation, 93

significancein immunereactions, I 17 see also Mesenchymal cells

Erythromyelosis, I 77

Erythrophagocytosis, 144

Escherichia coli (E. coli), 7 I

histidine-requiring, I I

and 'permease', I 3

see also Adaptive changes, Mutations

Evolutionary approach to immunity, 200

Fibroblasts, I 16

Fleece mosaic in sheep, 166

Fluorescent staining of antibody, 44, 70, 109

Follicular lymphoma, 169 , 178

Forbidden clones, see Clones

Forbidden patterns, see Clones

Galactosidase, $\beta-, 4,13,71$

and 'permease', 13

Gamma globulin, 30, 52

denatured, 134

level in blood, $14 \mathrm{I}$

Genetic pool, 9

Genocopy, 5I

Giant-cell measles pneumonia, 154

Globulins

$\alpha 2,40$

abnormal in lymphatic leukaemia, I 79

and amino acids, $18 \mathrm{I}$

gamma, see Gamma globulin

individuality in myelomatosis, 183

macro-, 126

in myelomatosis, 181

properdin, 39, 99

Goodness of fit of antigen and reaction site, 93

Graft intolerance, 89

Granuloma, tuberculous, 162

Granulomatous lesions, effect of zirconium salts, I 30
Haemagglutination

as evidence of infection, 18

for virus isolation, 16

Haemolysis, immune, 64

Haemolytic anaemia, 43

acquired, 126

in agammaglobulinaemia, 143

in lymphatic leukaemia, 178

Haemolytic streptococci, I 56

Hashimoto's disease, I 23-6

Hepatitis, lupoid, 125, 134

Histamine release, 133

Histidine-requiring $E$. coli, I I

Hodgkin's disease, 128, I68, 180

Homeostatic mechanism, 122, 128, 134, 140, 145, 193

and elimination of forbidden clones, 122

and haemolytic anaemias, 130

malfunction of, 156

Homograft immunity, 40, 41, 79, 88

Hypersensitivity

and agammaglobulinaemia, 42

to antigens, 37

passive transfer of, $37,4^{1}$

tuberculin, 40, 79

to vaccine, 43

Immune responses, 29

classical antibody production, 38

and eosinophils, I 8

hay-fever type, 38

tuberculin type, 38

Immunity

local, 83

to virus diseases, 43

Immunization, primary, 69

Immunological 'memory', 63, 79

Immunological reactivity, types of, 65

Incubation period of virus disease, 143

Indirect template theory, 5 I, $14^{8}$

Infectious mononucleosis, 123,128

Influenza virus, $16,20,75$

filamentous form, I9-20

neurobiopic, 19

Information, cellular storage of, 120

Information problem, in differentiation of 'self' from 'not-self', 36,47

Inhibition, contact in tissue culture, 194

Intestinal cell multiplication, 187

Intestinal viruses, 84 
Ionizing radiation, 196 in production of leukaemia, 175

Isoagglutinins, 39, 43, 57, 95

Japanese $B$ virus vaccine, $\mathbf{I} 79$

Kaposi's eruption, I 5 I

L.E. cell test, 136, I 39

Letterer-Siwe disease, 135

Leukaemia

acute sarcoma-cell, I 79

age incidence of, 179 ; in childhood, 198

from atomic-bomb radiation, 197

experimental, I 70

granulocytic, I 76-7

induction by virus of, $17 \mathrm{I}$

induction by X-rays of, 197

ionizing radiation in, 175

lymphatic, 128; abnormal globu-

lins in, I 79; antibody production

in, 178 ; chronic, 169 ; haemolytic

anaemia in, I 78 ; use of cortisone, I 70

mouse, I 70-4

myeloblastic crisis, I 75

myeloid, 1 75-7, 197

production by ionizing radiation, $\mathrm{I} 75$

recent increase in, 197

relation of thymus, I 7 I

and response to antigens, I 79

statistics of, 198

$\mathrm{X}$-radiation in pregnancy, $\mathrm{I} 97$

in X-rayed mice, 172

Limit dilution passage, 21

in amniotic cavity, 18

Lupus erythematosus, disseminated (DLE), I 36-9

Lymphatic leukaemia, see Leukaemia

Lymph node cells, in cellular transfer

of immunological reactivity, 45

Lymphocyte, 54

as antibody producer, 44

as carrier of nucleic acids, I 12

destruction by X-rays, IOI

fixation of reactant, 84

functions of, 118

in immune response, 44

liberation of antibody by, 109

life history of, 55

mobility and transformation of, I 19 role in immunity, 107

survival time of, $174-5$

tissue infiltration of, 132

transfer of DNA amongst, I 74

transformation, I I I, I I 4

Lymphocytosis, stimulating factor, 170

Lymphoid tissue, 83

relation to virus disease, 143

Lymphoma, follicular, 169 , 178

Macroglobulin, 126

Macroglobulinaemia, I37, I4I

Macrophages, 82, II 5

and secondary antigen, 33

Mammary gland, plasma cells in, 84

Mast cells, 64

Maturation of cells, 94

Measles, I 53-6

giant cells in, 144

pathogenesis of, 154

pneumonia, giant-cell, I 54

Medawar, critical point of, 60

Mesenchymal cells

acquired haemolytic anaemias, I 26 adjuvants, 82

anamnestic response of, 79

antibody-producing, 56

clonal selection theory, $49,5^{8}, 64$, $67,118,200$

collagen diseases, 1 31, 134-6

differentiation during embryonic life, $56,60,200$

eosinophils, I I0, I I 7

forbidden patterns of, 128,135 , see clones

function in immunity, 29, 107-20

genetic characteristics, ${ }^{1} 5^{8}$

granulocyte, I IO

haematoblast, 110

Hashimoto's disease, 124

Hodgkin's disease, I68, 180

and immunological tolerance, ıоo, 103

immunologically reactive sites of, 54

interrelation of forms of, 1 10-16

and leukaemia, I 75

liberation of pharmacologically active agents, 64

and lupoid hepatitis, 125

lymphoid-macrophage system, I 5 
Mesenchymal cells (cont.)

modification by virus infection, 123

multiple change to stem cell macrophage, lymphocyte and plasma cell when stimulated, I 18

mutation, and selective survival, 27 , 127,128 ; to malignant form, 124 and neoplastic disease, 185

non-antibody-producing stage of, 96

and pathology of immune response, 123-8

population genetics of, 200

physiological and mutational change, $5^{6}$

proliferation when stimulated, 69 , I 8

and proliferative diseases, $165-8$, I 74-7

and protein synthesis, 184

reticules, I I I

and sarcoidosis, $16 \mathrm{I}$

self-replicating phenomena of, 79

sensitivity to tuberculin, $4^{1}$

and spleen, I03

stimulation of, by antigenic determinant, 67

and transduction of DNA, 174

see also Homeostatic mechanism,

Lymphocyte, Proliferation of cells

Mesenchymal cell system, characteristics of, 15

Mesenchymal reserves, 46

Metalophil cells, I I 5

Migration of neural crest cells, 194

Mosquitoes, transmission of myxomatosis by, 25

Multiple myeloma, I80

Mutagen, caffeine, 199

Mutagenic action, 196

Mutagenic agents, 8

caffeine, 199

streptococcal, 133

Mutant clones, reactions of, 140

Mutations, 6, 21, 27

antibiotic-resistant strains, 7

bacteriophage-resistant, 7

and cancer, 195

definition of, 165

during segmentation, I 66

and haemolytic anaemia, 132 histidine-independent, 7

malignant, 139

nutritionally deficient, 7

$O-D$ change, I 7

phenotypic expression of, 167

prerequisite for clonal selection

theory, 200

pseudo-, 12

rarity of, I I

regulation of, 145; see homeostatic mechanism

rough $E$. coli, 9

sequential, I9I

in skin epidermis, 187

somatic, $55,63,67,80,127$

somatic theory of cancer, 165

and tumours, 195

Mycolic acid, $16 \mathrm{r}$

Myelomatosis

a conditioned neoplasm, 182

multiple, 147, 177, 180

Myxomatosis

in Australia, 23

Australian field strain, 24

in Europe, 26

French strain, 27

natural infection, I I

transmission by mosquitoes, 25

Myxomatosis virus, 22

virulence of (in Australia), 22-7

Natural selection theory (Jerne's), 52

Neoplasms, conditioned, I69, I 73, 193

Nephritis, acute, 157

Neural crest cells, migration of, 194

Neuraminidase, $9^{8}$

Non-reactivity of young animals, 93

Nucleoprotein antigens, 79, 88

DNA, I 12

$O-D$ change, $15^{-1} 9$

definition of, 17

Ophthalmia, sympathetic, 126

Ovalbumin as antigen, 40

Paralysis, immune, 94

Passive transfer, 37

Penicillin

effect on $B$. cereus, 4 effect on sensitive bacteria, 8

Periodic selection, I0, 12 
Permease, 13, 71

Peyer's patches, 83

Phase change in Salmonellas, 10

Phenotypic lag, I5

Plasma cells

in agammaglobulinaemia, 42 antibody in, 109

as antibody producers, 44

in experimental influenza, 84

function of, 70

mature, I 15

origin of, 115

proliferation of, I 13

Plasma-cell tumours, 180

Platelet and antigenic determinant, 129

Pneumonia

atypical, 99, 123, 128

giant-cell measles, 154

Poissonian distribution, 21

Polio viruses, 83

Population dynamics of mesenchymal cells, 8r, $20 \mathrm{r}$

Population genetics, 9, 10, 12, 16

Prausnitz-Kuster phenomenon, 39

Primary immunization, 69

Primary response, 3I

Proliferation of cells, 6I-2, 77-8, 1045, I 20, I 30-1, I $33^{-6}, 140,145^{-7}$, I 53, I $66-8$, I 75, I 80, I 85-7, 201 ; see Mesenchymal cells

Properdin, 39, 99

Protoplasts, I 62-3

Prototrophs, 7

Purpura sedormid, 129 thrombocytopenic, 129

Pyrogenic response, 103

Randomization, 60 of pattern, 66

Reactive site, 30, 65, 67

Reactivity of clone with antigen, $3^{2}-7,41,53,91-3,163$

Recognition mechanism, 62

Replica method, Lederberg's, 8

Response

primary, 3I

pyrogenic, 103

secondary, 31,70

varieties of immune, 92

Reticular cell, primitive, I I I, I I9
Reticuloses, 169

Rheumatic fever, 156 investigations on, $15^{8}$ predisposing causes, $15^{8}$

Rheumatoid arthritis, 43, I 31

Rose's test, I 3 I

Runt disease, 88

Salmonellas, phase change in, 10

Sarcoid, relation to tuberculosis, 160

Sarcoid nodule, I 30

Sarcoidosis, $160-3$

Kveim test, 160

Secondary response, 31, 70

Sedormid purpura, 129

Selection, periodic, 10, 12

Selective survival, 27

of virus particles, 22

'Self' and 'not-self'

components, $34,46,59$

information problem, 36,47

recognition, 59

self-markers, $5^{\mathrm{I}}$

self substance, 34

Self-antigens, lack of response to, ${ }_{13} 8$

Sheep, fleece mosaics in, 166

Shwartzman phenomenon, ro3

Skin epidermis, mutation in, 187

Somatic mutations, see Mutations

Staphylococcal toxoid, 32

Stem cell, 46

Streptococcal infections, 147, I 56-9

Streptococci

haemolytic, 156

nephritogenic, 133

Subcellular units, selection amongst, I05

Sympathetic ophthalmia, 126

$T$ agglutinin, 39, 95-9

Template theory

direct, 50

indirect, 51, 55, 62

Thoracic duct lymph, 45, Io9, I I 4

Thrombocytopenia, 136

Thymus, relation to leukaemia, I 7 I

Thyroglobulin, 34

as autoantigen, 124

Tissue culture, 69

Tolerance, 34-5, 50-I , 58, 6 I, 65, 87-8, 90-I02

development of, 60 


\section{INDEX}

Tolerance (cont.)

immunological, 34, 52

mutual, 87

to non-cellular antigens, 35

persistence of, $9 \mathrm{I}$

to red cells, 90

to 'self' components, 34

to soluble antigens, 9 I

Tonsils, 83

streptococcal infections of, 156

Transaminase in serum, 135

Transduction, 63, 78, I 73-4 by temperate bacteriophage, 9

Transplantation to the anterior chamber, 35 corneal, 35

Traumata and proliferation, 188

Tuberculin sensitivity, 40, 79 and $\mathrm{X}$-radiation, $\mathrm{IOO}$

Tuberculosis, relation of sarcoid to, I6o

Tuberculous granuloma, 162

Tumours, I95

Turnover of cells, 186

Vaccination, Jennerian, I5 I

Vaccine, Japanese $B$ virus, 179
Vaccinia, progressive, I $5 \mathrm{I}$

Virus

adaptation of, 16

ARBOR, 77

influenza, see Influenza virus

influenza $A, 16,75$

intestinal, 84

myxomatosis, 22-7

polio, 83

Virus diseases

immunity to, 73

incubation period, 143

Virus infection, asynchrony of, $2 \mathrm{I}-2$

X-radiation, 88-9, го0-1, I 7 I-6, rg6-9

and bone marrow, 89

destruction of lymphocytes by, ror induction of leukaemia by, 197

in pregnancy, 197

$\mathrm{X}$-ray

chimeras, I 18

influence on immunological responses, 100

Zirconium, I30 








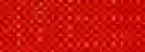

\%

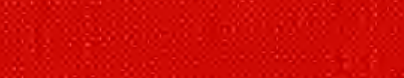

x.x.

$\% 8$

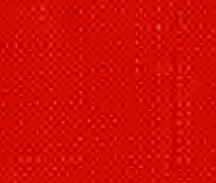

$8 \%$ \%x:

xx

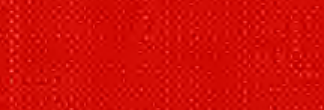

ses

xas

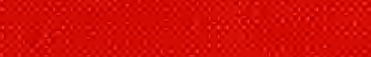

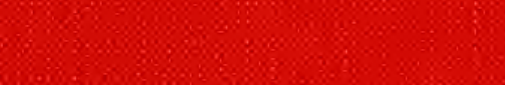

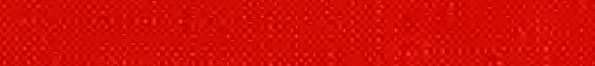

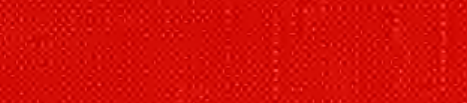

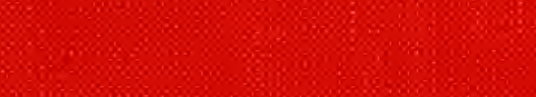

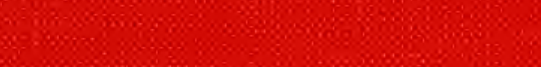

\%on.

\%

\%x.

xix

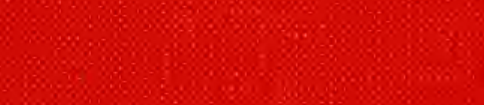

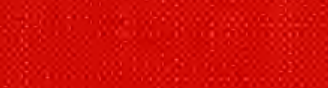
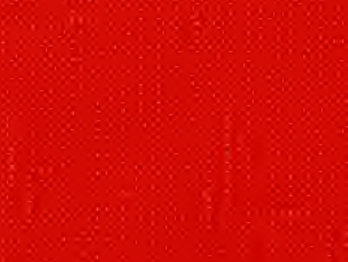

s.

$8 \times x \times$

.

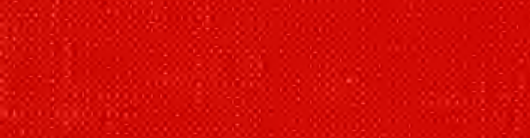

Q⿻isis. 